\title{
COE Reductions through Active Aerodynamic Control of Rotor Aerodynamics and Geometry
}

Subcontract Report NREL/SR-500-43391

December 2008

\section{August 10, 2004 - May 31, 2007}

D.A. Griffin and T.J. McCoy

Global Energy Concepts

Kirkland, Washington
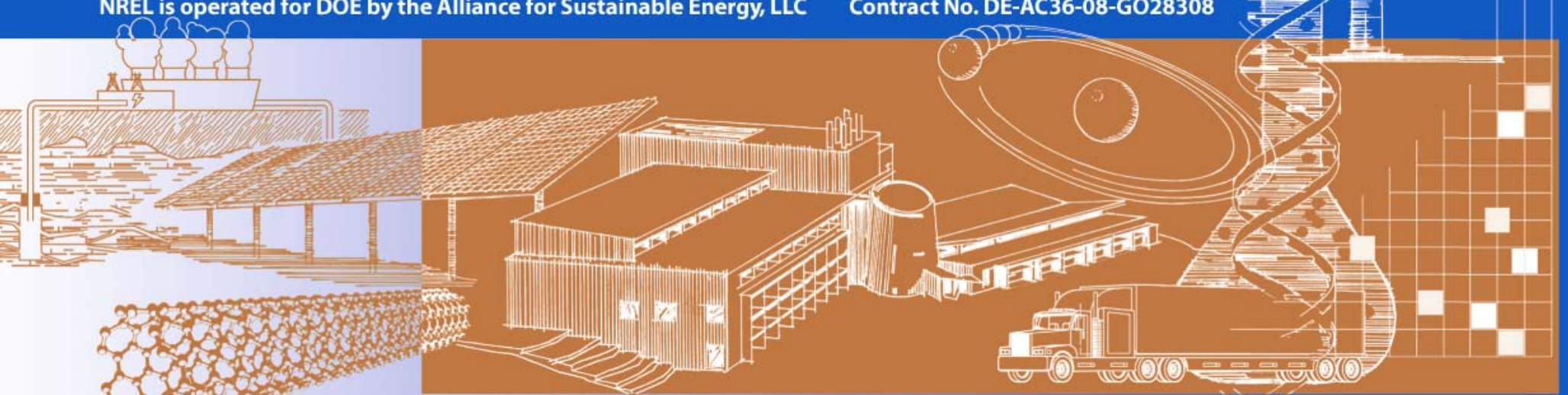


\section{COE Reductions through Active Aerodynamic Control of Rotor Aerodynamics and Geometry}

\section{August 10, 2004 - May 31, 2007}

D.A. Griffin and T.J. McCoy

Global Energy Concepts

Kirkland, Washington

NREL Technical Monitor: Scott Schreck

Prepared under Subcontract No. YAM-4-33200-08

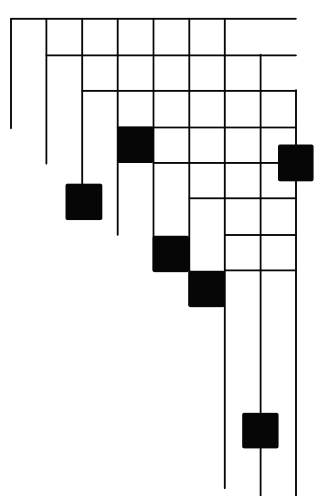




\section{NOTICE}

This report was prepared as an account of work sponsored by an agency of the United States government. Neither the United States government nor any agency thereof, nor any of their employees, makes any warranty, express or implied, or assumes any legal liability or responsibility for the accuracy, completeness, or usefulness of any information, apparatus, product, or process disclosed, or represents that its use would not infringe privately owned rights. Reference herein to any specific commercial product, process, or service by trade name, trademark, manufacturer, or otherwise does not necessarily constitute or imply its endorsement, recommendation, or favoring by the United States government or any agency thereof. The views and opinions of authors expressed herein do not necessarily state or reflect those of the United States government or any agency thereof.

Available electronically at http://www.osti.gov/bridge

Available for a processing fee to U.S. Department of Energy and its contractors, in paper, from:

U.S. Department of Energy

Office of Scientific and Technical Information

P.O. Box 62

Oak Ridge, TN 37831-0062

phone: 865.576 .8401

fax: 865.576 .5728

email: mailto:reports@adonis.osti.gov

Available for sale to the public, in paper, from:

U.S. Department of Commerce

National Technical Information Service

5285 Port Royal Road

Springfield, VA 22161

phone: 800.553 .6847

fax: 703.605.6900

email: orders@ntis.fedworld.gov

online ordering: http://www.ntis.gov/ordering.htm

This publication received minimal editorial review at NREL 


\section{Table of Contents}

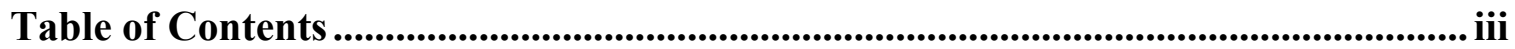

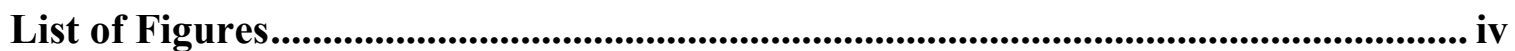

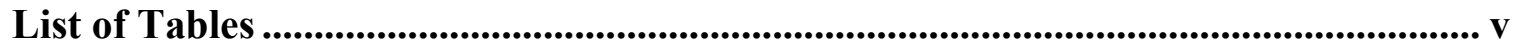

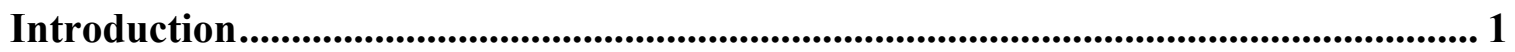

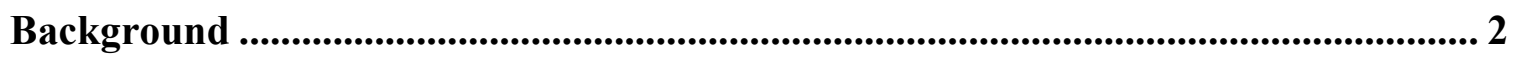

Scope and Approach .................................................................................................................... 3

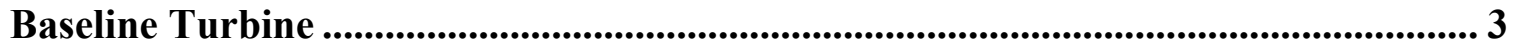

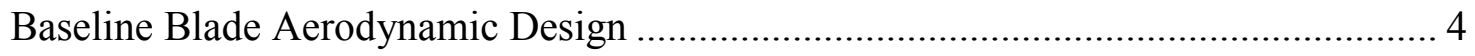

Baseline Blade Structural Design ........................................................................ 9

Power Performance .......................................................................................... 11

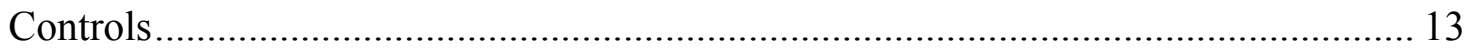

Load Calculations and COE............................................................................... 13

Retractable Blade Rotor ................................................................................................ 15

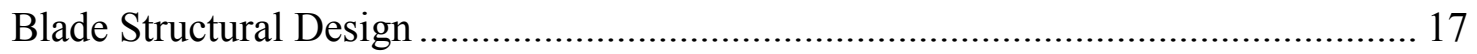

Tip Retraction Mechanism Modeling .................................................................... 22

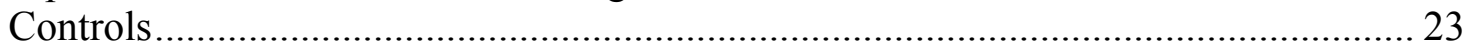

Loads and COE Results ................................................................................... 24

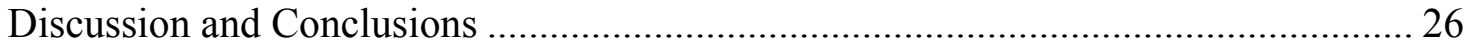

Active Aero Devices ................................................................................................. 30

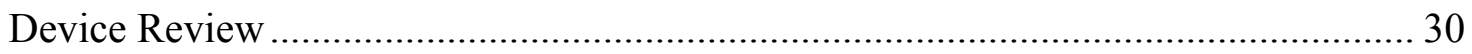

Generic Aerodynamic Properties (Camber Modification)........................................ 35

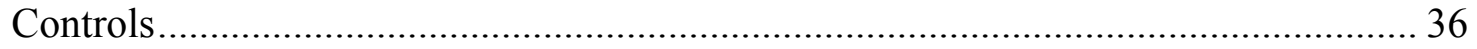

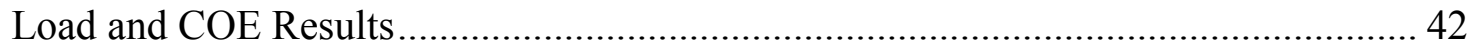

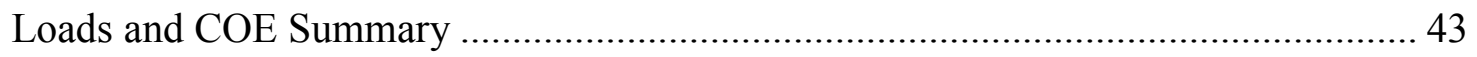

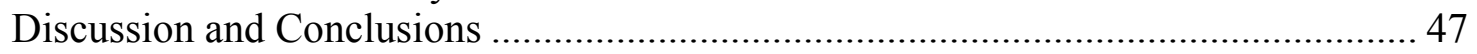

Recommendations ......................................................................................................... 48

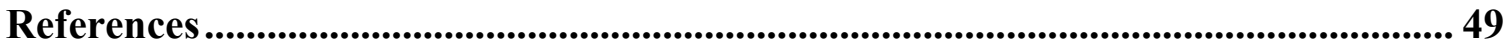

Appendix A: AEP Calculations ................................................................................. A-1

Appendix B: COE Calculations ................................................................................. B-1

COE Calculation for RBR Configuration 12 .................................................. B-2

COE Calculation for IBP Plus Full Active Aero ….............................................. B-3

Appendix C: MATLAB Script Example................................................................. C-1

Appendix D: Abbreviations and Coordinates for Load Cases and Loads .............. D-1

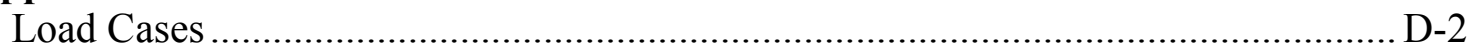

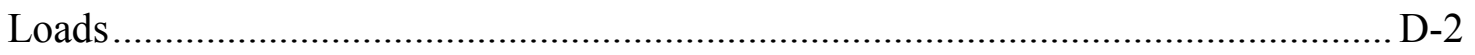




\section{List of Figures}

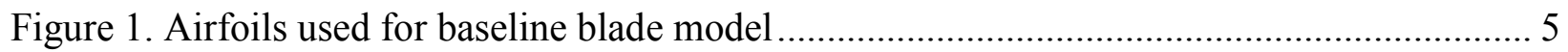

Figure 2. Aerodynamic data for scaled S818 airfoil (near-stall AOA) ........................................... 6

Figure 3. Aerodynamic data for scaled S818 airfoil (extended AOA) ………............................... 7

Figure 4. Aerodynamic data for scaled S825 airfoil (extended AOA) ……………........................ 7

Figure 5. Aerodynamic data for scaled S826 airfoil (extended AOA) ………............................... 8

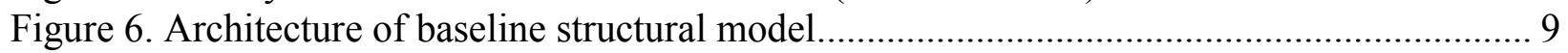

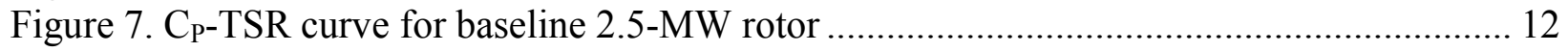

Figure 8. Baseline turbine power curve at sea level ................................................................... 12

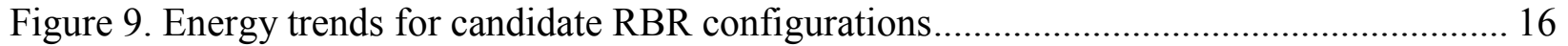

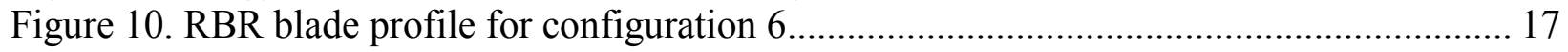

Figure 11. RBR blade profile for configuration 12......................................................... 17

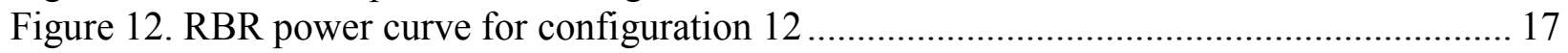

Figure 13. Clearance between RBR tip and inner-blade profile for configuration 12 .................. 22

Figure 14. Comparison of RBR tip profile with inner-blade spar for configuration 12 ............... 22

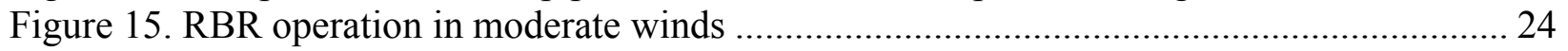

Figure 16. Change in peak loads relative to baseline for RBR ………………………................ 25

Figure 17. Change in fatigue loads relative to baseline for RBR ................................................. 25

Figure 18. CAD modeling of tip aerodynamic profile................................................................ 27

Figure 19. Aerodynamic effect of S826 shape modification (constant inset).............................. 28

Figure 20. Effect of S826 shape on rotor efficiency for RBR configuration 12.......................... 28

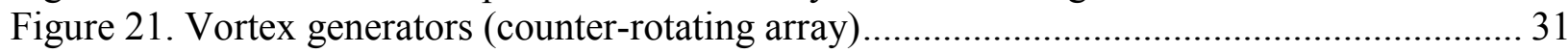

Figure 22. Lift curve changes resulting from boundary layer modification .................................. 31

Figure 23. Nominal operating points on the lift curves for selected spanwise locations............... 32

Figure 24. Lift curve changes resulting from increased effective camber..................................... 34

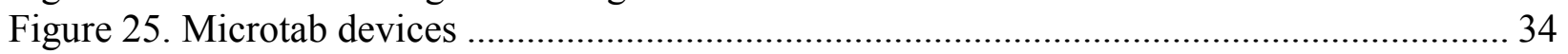

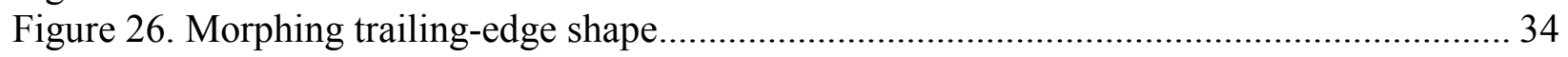

Figure 27. Lift and drag for the S825 airfoil with generic camber modification.......................... 35

Figure 28. Aerodynamic derivatives versus wind speed for turbine operating variables .............. 38

Figure 29. Aerodynamic derivatives versus wind speed for camber modification devices........... 39

Figure 30. Plant and closed loop eigenvalues at $14 \mathrm{~m} / \mathrm{s}$........................................................... 40

Figure 31. Comparison of load reduction at $14 \mathrm{~m} / \mathrm{s}$ using (from top to bottom) the PI, IBP, and aero controls for a step change in wind shear occurring at $100 \mathrm{~s}$......................................... 41

Figure 32. Active aero device groupings .............................................................................. 42

Figure 34. Change in fatigue loads relative to baseline for IBP and active aero control............... 44

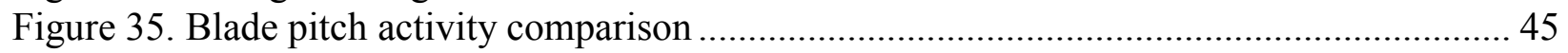

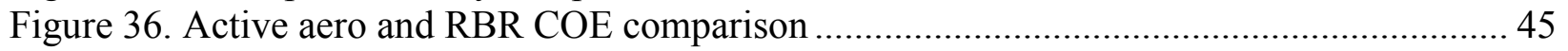




\section{List of Tables}

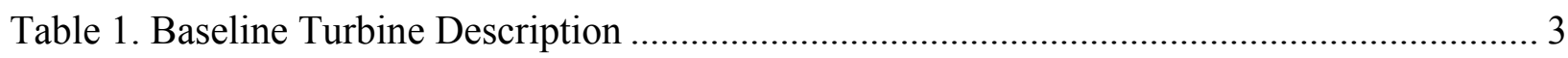

Table 2. Airfoil Shape Modifications (Baseline Blade).............................................................. 5

Table 3. Planform Description for Baseline Blade .................................................................. 8

Table 4. Baseline Structural-Shell Definition .......................................................................... 9

Table 5. Summary of Baseline Blade Material Properties........................................................... 10

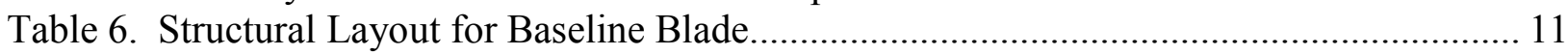

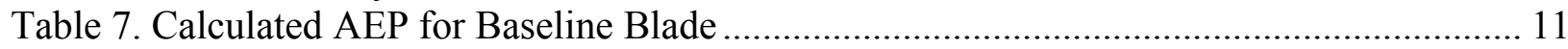

Table 8. Baseline Control Parameter Settings ……………......................................................... 13

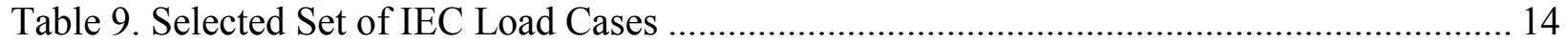

Table 10. Candidate RBR Configurations (highlighted in yellow) .............................................. 16

Table 11. Assumed Carbon Spar Material Properties................................................................. 18

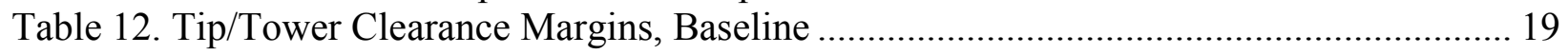

Table 13. Tip/Tower Clearance Margins, RBR 12 ……........................................................ 20

Table 14. Summary Structural Layout for RBR Configuration 12 ............................................... 21

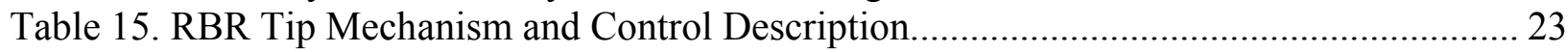

Table 16. Load Cases for Maximum Loads: RBR versus Baseline............................................. 25

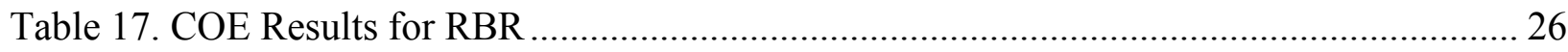

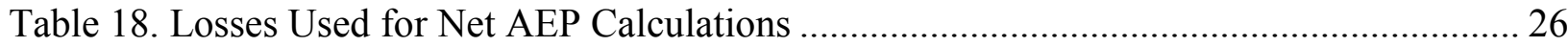

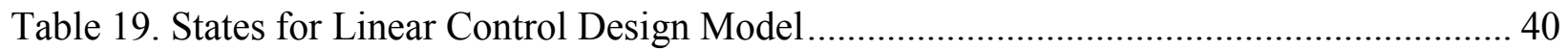

Table 20. COE results for Active Aero Control …………............................................................ 46

Table 21. Load Cases for Maximum Load: Active Aero versus Baseline........................................ 46 


\section{Introduction}

Under contract with the National Renewable Energy Laboratory (NREL), Global Energy

Concepts, LLC (GEC) conducted research on using active aerodynamic ("active aero") control to reduce loads on commercial wind turbines. The overall objective of this study was to support the Low Wind Speed Turbine (LWST) project goal of identifying means for reducing the cost of energy (COE) for wind energy projects in areas with low wind speeds.

The concepts evaluated in this study fall into two distinct categories. First are devices or methods that can be used to actively alter the local aerodynamic properties of the rotor blade. These devices would typically have response times on the order of, or faster than, a full-span, variablepitch system. Here, COE reductions are realized through reduced system loads. An actively controlled retractable blade rotor (RBR) is the second concept, for which increased energy capture is the primary advantage. In this case, mitigating cost increases associated with increased loading and added mechanical systems is the engineering challenge. In contrast to the active aero control, the response and actuation time for varying diameter is expected to be slow relative to pitch control.

Substantial research has been done on active aero modifications, and to a lesser extent, on RBRs. No systematic study of the performance gains and loads is available, though, in the public domain. GEC's study is intended to yield detailed performance and load data for a range of parameters for active aero and geometry controls. This study, which incorporated the most current control, material, and mechanism technologies, was conducted at a rating consistent with the current market for utility-scale turbines. The performance and load results are used with COE models to determine how much such systems could add to the cost of a wind turbine without increasing the COE. These results will permit researchers and turbine designers to efficiently determine the degree to which using these devices is likely to reduce the COE. 


\section{Background}

In the Wind Partnership for Advanced Component Technologies (WindPACT) Rotor Study (Marshall and Hansen 2003), researchers evaluated a wide range of turbine rotor configurations for potential COE reductions. A major result from that study was an illustration of the difficulty of achieving substantial COE improvements through component cost reductions alone. The same study predicted an $8.2 \%$ reduction in COE for a rotor that had the combined features of a slender planform with flap-twist coupling. About $2 \%$ of the COE benefits were attributed to the twist coupling and the remaining $6.2 \%$ of improvements were thought to result from other design features. A key aspect of this rotor configuration is that the design combined blade cost reductions with aeroelastic behavior that reduced governing loads throughout the turbine system and allowed corresponding cost savings on the tower and other major system components.

RBRs have been proposed in the past to solve the problem of obtaining high production in low winds while minimizing the loads penalties associated with a large rotor in high wind conditions. Clipper Windpower and Energy Unlimited are both interested in developing such technology to achieve COE reductions. To date, however, no publicly available information has presented the performance gains achievable with this approach.

Prototype turbine designs have been developed using classic aerodynamic control surfaces (e.g., flaps and ailerons), and passive boundary-layer controls (e.g., stationary vortex generators) have been widely used for many years (Rueger and Gregorek 1991; Griffin 1996; Stuart, Wright, and Butterfield 1996; Perivoralis and Voutsinas 2001; Timmer and van Rooij 2003; and Janiszewska, Gregorek, and Lee 2003). Recent developments in control, sensor, and microelectromechanical (MEM) technologies have motivated new research into the benefits possible from active control (Yen Nakafuji et al. 2001; Yen Nakafuji et al. 2002; vanDam et al. 2004). No comprehensive study has been available, however, to quantify the extent to which these devices could reduce the COE through load mitigation.

The fact that blades represent a relatively modest fraction $(10 \%-20 \%)$ of the turbine system's initial capital cost (ICC) cuts both ways. A 10\% reduction in blade cost, which could be achieved by implementing more efficient materials or structures or by mitigating blade self-loading, will reduce ICC by only $1 \%-2 \%$. COE reductions will be even smaller. On the other hand, a substantial increase in the cost of blades or other systems could be justified if the energy capture improvements are sufficiently high. In this study, GEC has built on all the model development and results of the WindPACT study (Malcolm and Hansen 2003), and has investigated the range of potential COE reductions available via active systems designed to mitigate loads throughout the turbine system. 


\section{Scope and Approach}

For this study, GEC conducted analytical studies of the COE benefits of active aerodynamic control of wind turbine rotors. This type of analysis typically includes the following:

- Blade structural and aerodynamic properties

- Performance and load predictions

- COE predictions based on loads and material costs.

Because this is a concept study, many assumptions were made, including the following:

Detailed engineering of the devices was not considered

Sensors and actuators required for control are assumed to exist

To calculate turbine loads, the investigators used MSC-ADAMS, a general purpose, commercially available simulation code, combined with the aerodynamic force calculation subroutines found in Aerodyn (Windward Engineering 2002). The Aerodyn inputs were modified for this project to reflect the RBR and active aero control effects. These loads were then used to size the major turbine structural components, material costs were applied, and a turbine capital cost was supplied to the COE calculation. The WindPACT rotor study gives a detailed description of the methodologies used for costing based on loads results (Malcolm and Hansen 2003).

\section{Baseline Turbine}

To enable comparisons, the researchers chose a baseline turbine design. The design was initially based on the work done in the WindPACT rotor study (Malcolm and Hansen 2003)., in which the primary baseline turbine was rated at $1.5 \mathrm{MW}$. Because the technologies being examined are more likely to show benefits at a larger size, though, a larger turbine was chosen for this study. The primary architectural details of the virtual design used for the baseline follow:

- Three-blade, upwind, $90 \mathrm{~m}$ in diameter, 2.5-MW, variable-speed, pitch-to-feather configuration

- $\quad$ Eighty-meter hub-height tube tower, fiberglass reinforced polyester (FRP) blades, and a 3-stage gearbox with doubly fed generator

- Torque speed curve controls to follow optimum tip speed ratio (TSR) in low wind and a proportional-integral (PI) controller from rotor speed to collective pitch in high wind.

Table 1 gives a detailed description of the baseline turbine.

Table 1. Baseline Turbine Description

\begin{tabular}{|l|l|}
\hline \multicolumn{1}{|c|}{ Feature } & \multicolumn{1}{c|}{ Description } \\
\hline \multicolumn{1}{|c|}{ General Turbine Configuration } & \\
\hline Manufacturer and model & Virtual WindPACT design \\
\hline Orientation & Upwind \\
\hline Rotor diameter $(\mathrm{m})$ & 90.0 \\
\hline
\end{tabular}




\begin{tabular}{|c|c|}
\hline Feature & Description \\
\hline Hub height $(\mathrm{m})$ & 80.0 \\
\hline \multicolumn{2}{|l|}{ Performance } \\
\hline Rated electrical power $(\mathrm{kW})$ & 2,500 \\
\hline Rated wind speed $(\mathrm{m} / \mathrm{s})$ & 12.0 \\
\hline Cut-in wind speed (m/s) & 4.0 \\
\hline Cut-out wind speed $(\mathrm{m} / \mathrm{s})$ & 25.0 \\
\hline Extreme 50 -year wind speed $(\mathrm{m} / \mathrm{s})$ & 59.5 \\
\hline \multicolumn{2}{|l|}{ 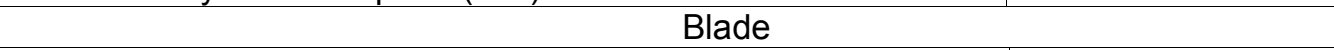 } \\
\hline Manufacturer, model of blades & WindPACT design \\
\hline Length $(\mathrm{m})$ & 43.5 \\
\hline Material & Fiberglass \\
\hline Mass $(\mathrm{kg})$ & 9,391 \\
\hline Radial distance of center of mass from root face $(\mathrm{m})$ & 16.19 \\
\hline Upwind distance of center of mass from plane of rotation $(\mathrm{m})$ & 0.00 \\
\hline Coning/prebend & None \\
\hline \multicolumn{2}{|l|}{ Rotor } \\
\hline Number of blades & 3 \\
\hline Swept area $\left(\mathrm{m}^{2}\right)$ & 6,362 \\
\hline Rated rotational speed (rpm) & 15.90 \\
\hline Rotor hub type & Rigid \\
\hline Effective hub diameter (m) & 3.0 \\
\hline Coning angle $\left({ }^{\circ}\right)$ & 0.0 \\
\hline Tilt angle $\left({ }^{\circ}\right)$ & 5.0 \\
\hline Direction of rotation (looking downwind) & Clockwise \\
\hline Rotor mass including blades $(\mathrm{kg})$ & 53,174 \\
\hline Hub centerline to yaw axis distance $(\mathrm{m})$ & 4.20 \\
\hline Rotor mass imbalance, fraction of radius & 0.001 \\
\hline Blade pitch imbalance ascribed to Blades 2 and $3\left(^{\circ}\right)$ & \pm 0.3 \\
\hline \multicolumn{2}{|l|}{ Drivetrain } \\
\hline Gearbox ratio & NA \\
\hline Effective low-speed shaft (LSS) diameter (m) & 0.600 \\
\hline Effective LSS length (m) & 2.400 \\
\hline Drivetrain torsional stiffness (in LSS frame) & $0.38 \mathrm{E} 6 \mathrm{kNm} / \mathrm{rad}$ \\
\hline Generator inertia (in LSS frame; $\mathrm{kg} \cdot \mathrm{m}^{2}$ ) & 100,000 \\
\hline Nacelle (not including rotor) cg distance from yaw $(\mathrm{m})$ & 1.22 upwind \\
\hline Nacelle mass $(\mathrm{kg})$ & 80,000 \\
\hline \multicolumn{2}{|l|}{ Control/Electrical System } \\
\hline Overspeed control & Full-span pitch \\
\hline \multicolumn{2}{|l|}{ Tower } \\
\hline Tower type & Tubular steel \\
\hline Height (m) & 78.0 \\
\hline Top outer diameter $(\mathrm{m})$ & 3.000 \\
\hline Top wall thickness (mm) & 9.0 \\
\hline Bottom outer diameter $(\mathrm{m})$ & 5.000 \\
\hline Bottom wall thickness (mm) & 21.5 \\
\hline Tower head mass $(\mathrm{kg})$ & 133,174 \\
\hline Tower mass $(\mathrm{kg})$ & 131,022 \\
\hline
\end{tabular}

\section{Baseline Blade Aerodynamic Design}

The airfoils used in this study are based on the National Renewable Energy Laboratory's (NREL) S-series (Tangler and Somers 1995). In the work of Griffin (2001), the S818/S825/S826 family was identified as having desirable aerodynamic properties, but the airfoils were deemed 
too thin for efficient application to large blades. In that work, a more structurally suitable set of airfoil shapes was derived by scaling the S818/S825/S826 foils and by adding a finite-thickness trailing edge. The modified shapes and locations of airfoils along the blade are summarized in Table 2; the resulting shapes are shown in Figure 1. Two-dimensional aerodynamic properties (lift-and-drag curves) for the modified shapes were calculated using the Eppler Design and Analysis code (Eppler and Somers 1980).

Table 2. Airfoil Shape Modifications (Baseline Blade)

\begin{tabular}{|l|l|l|l|l|l|}
\hline Airfoil & \multicolumn{2}{|c|}{$\begin{array}{l}\text { Radial Station } \\
\text { (\% radius) }\end{array}$} & $\begin{array}{c}\text { Original } \\
\text { Thickness } \\
\text { (\% chord) }\end{array}$ & $\begin{array}{c}\text { Scaled } \\
\text { Thickness } \\
\text { (\% chord) }\end{array}$ & $\begin{array}{c}\text { Trailing-Edge } \\
\text { Thickness } \\
\text { (\% chord) }\end{array}$ \\
\hline S818 & 25 & 24 & & 30 & 1.3 \\
\hline S825 & 75 & 17 & 21 & 1.0 \\
\hline S826 & 95 & 14 & 16 & 0.75 \\
\hline
\end{tabular}

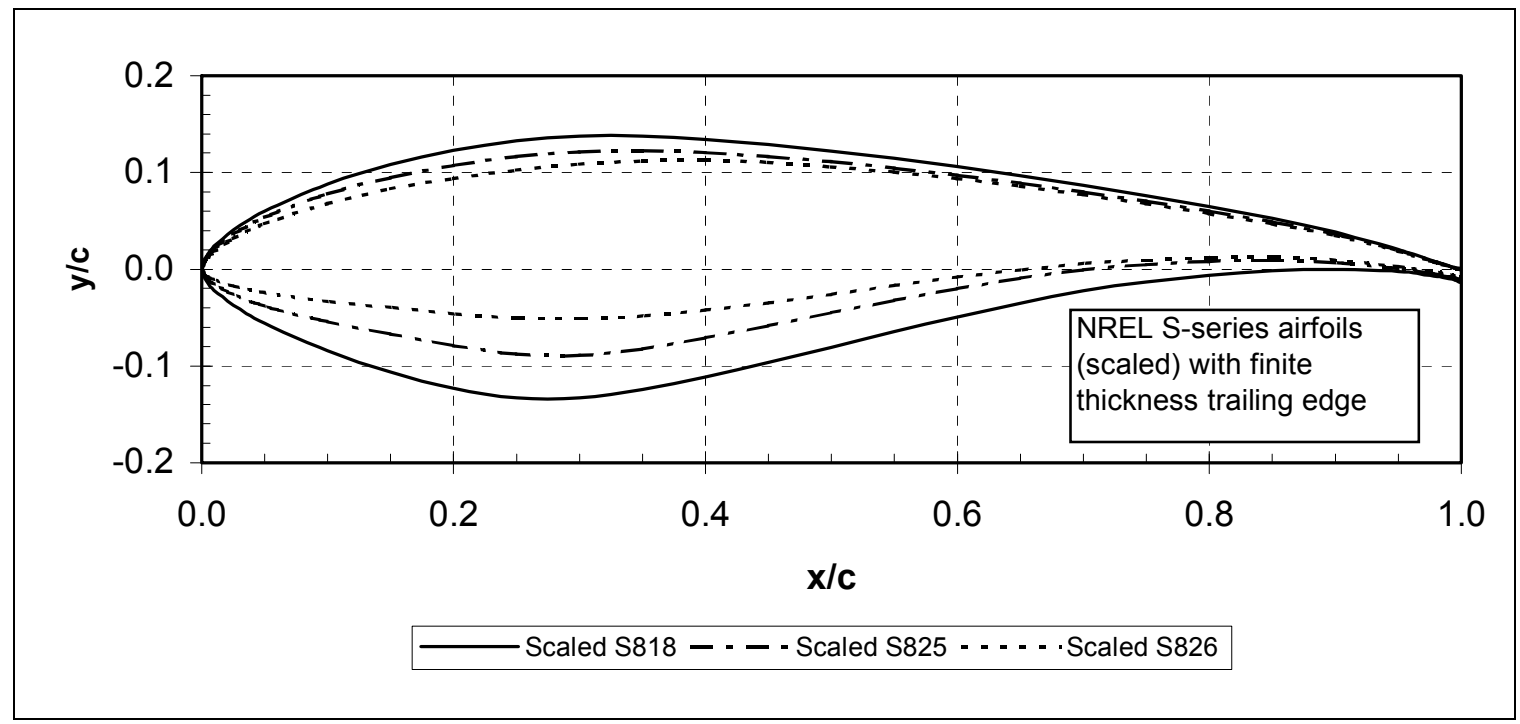

Figure 1. Airfoils used for baseline blade model

Stall-delay effects were added using the AirfoilPrep code (Hansen 2007), which uses the DuSelig model for corrections to lift (Du and Selig 1998), and the drag adjustment per the model of Eggars, Chaney, and Digumarthi (2003). Input data to the stall delay model include the spanwise location and chord length for each airfoil, as well as the inflow wind speed and rotational speed of the rotor. For example, for the S 818 (located at $25 \%$ span), a chord dimension of $3.9 \mathrm{~m}$ was assumed along with a wind speed of $7 \mathrm{~m} / \mathrm{s}$ and a rotational speed of $15.9 \mathrm{rpm}$. Three-dimensional (3-D) stall delay is a strong function of rotor spanwise position, with the largest effects seen in the inboard region and diminishing effects seen in the outboard region. Based on previous modeling experience, GEC assumed that the 3-D effects could be neglected outboard of the $75 \%$ radial station.

Figure 2 shows the aerodynamic data for the scaled S818 at near-stall angles of attack (AOA). The figure shows that the stall-delay effects result in a large increase in both lift and drag relative to the two-dimensional (2-D) values. Figures 3 through 5 show the aerodynamic data for the S818, S825, and S826 airfoils, respectively, over an extended AOA range. Data for intermediate 
locations along the blade span were generated by linearly blending the lift-and-drag data from the three primary airfoils.

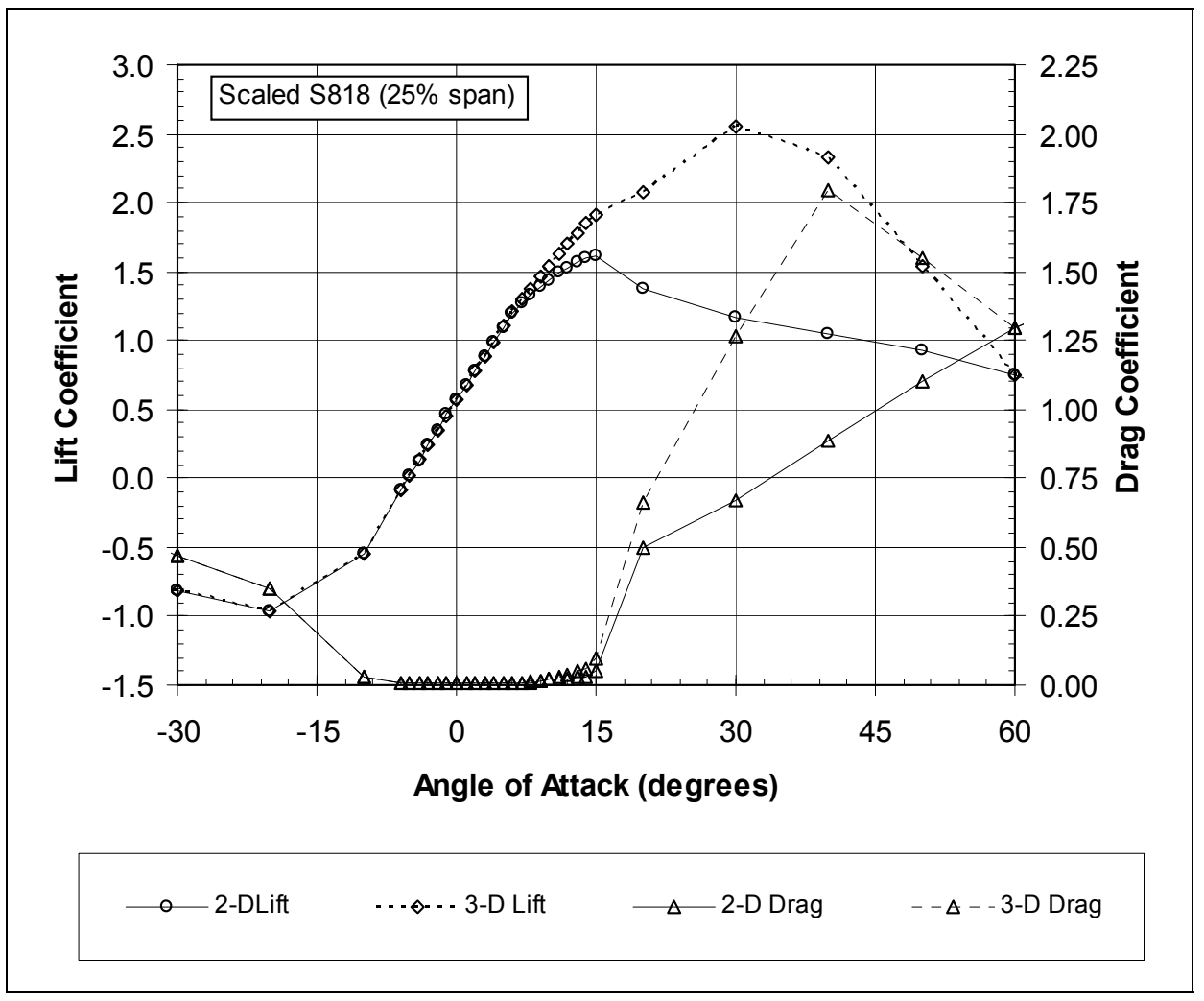

Figure 2. Aerodynamic data for scaled S818 airfoil (near-stall AOA) 


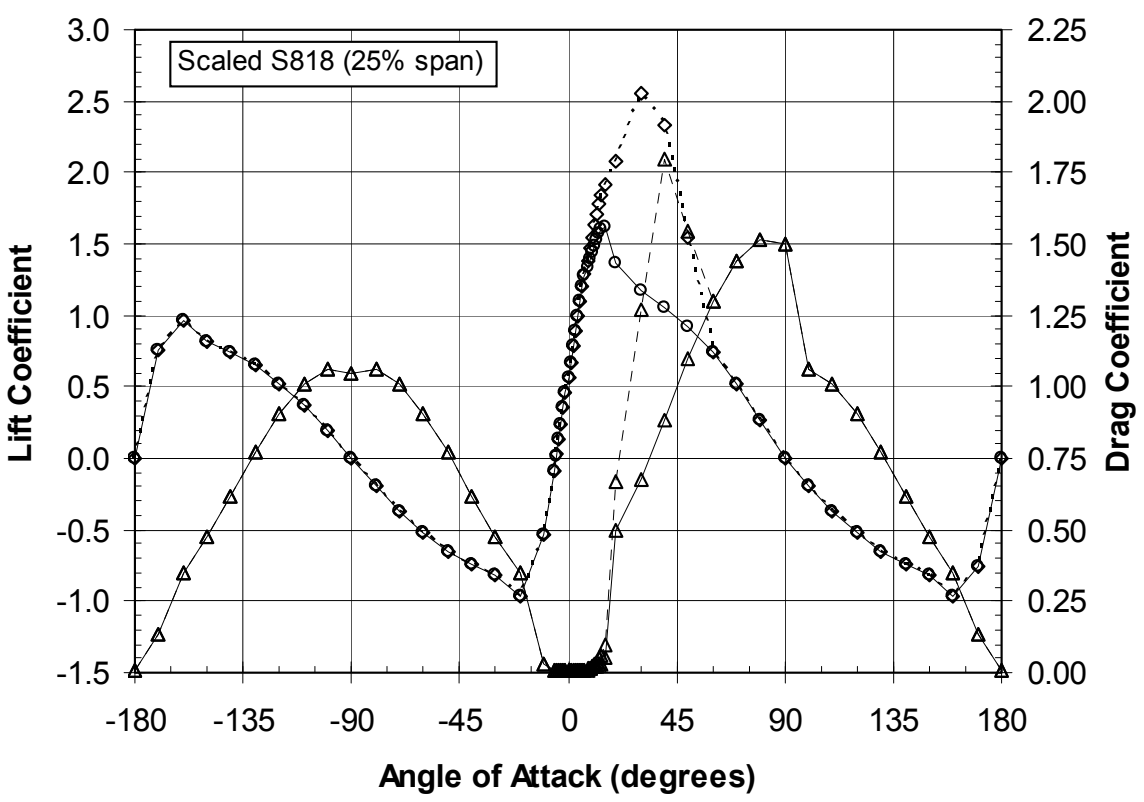

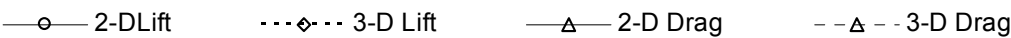

Figure 3. Aerodynamic data for scaled S818 airfoil (extended AOA)

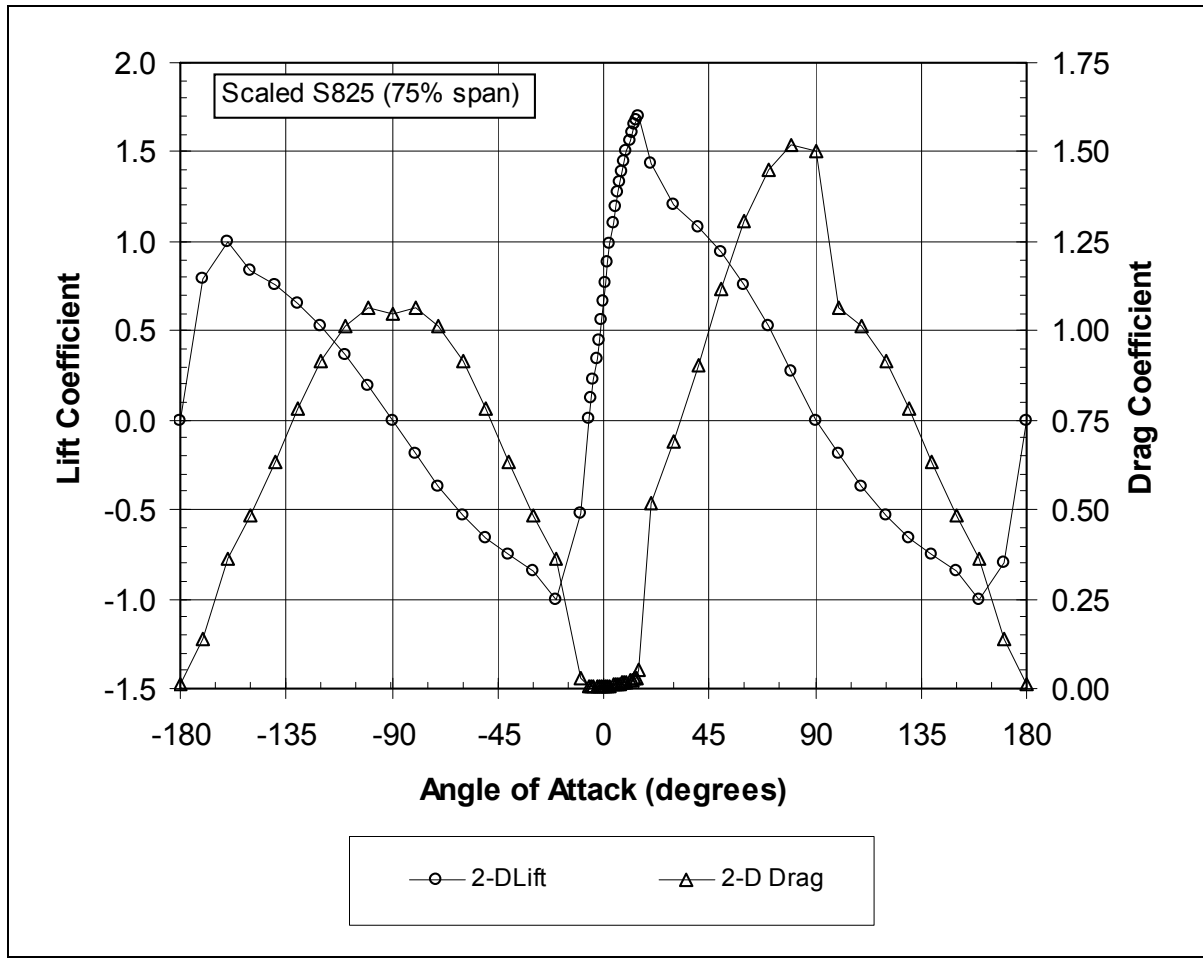

Figure 4. Aerodynamic data for scaled S825 airfoil (extended AOA) 


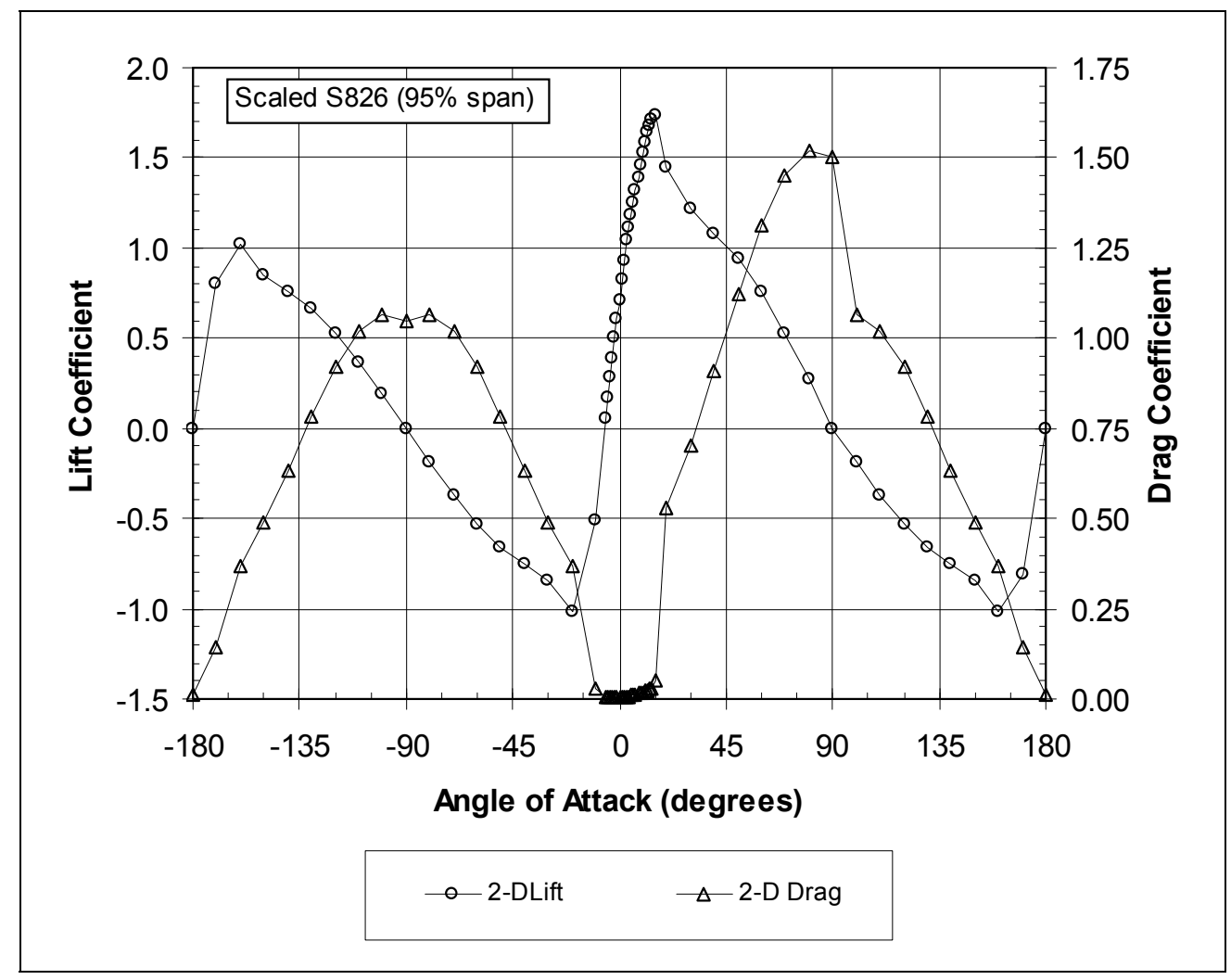

Figure 5. Aerodynamic data for scaled S826 airfoil (extended AOA)

The baseline blade aerodynamic design was developed using the PROPID inverse-design code (Selig and Tangler 1994). Following the methodology described by Griffin (2000), the nearoptimal chord distribution from PROPID was linearized over the outer portion of the span. Table 3 describes the baseline blade planform. The TSR at maximum rotor power coefficient (the design TSR) is 7.5 at a blade pitch angle of $1.5^{\circ}$.

Table 3. Planform Description for Baseline Blade

\begin{tabular}{|l|l|l|l|l|l|l|}
\hline \multicolumn{1}{|c|}{$\mathbf{r / R}$} & \multicolumn{1}{c|}{$\mathbf{c} / \mathbf{R}$} & \multicolumn{1}{|c|}{ Twist } & $\mathbf{R} \mathbf{( m )}$ & Chord $\mathbf{( m )}$ & \multicolumn{1}{|c|}{ Airfoil } & \multicolumn{1}{c|}{ /c } \\
\hline 0.05 & 0.0500 & 9.93 & 2.25 & 2.250 & Cylinder & 1.000 \\
\hline 0.15 & 0.0650 & 9.93 & 6.75 & 2.925 & Hybrid & 0.650 \\
\hline 0.25 & 0.0800 & 9.93 & 11.25 & 3.600 & S818 & 0.300 \\
\hline 0.35 & 0.0675 & 5.59 & 15.75 & 3.038 & Hybrid & 0.282 \\
\hline 0.45 & 0.0552 & 3.11 & 20.25 & 2.485 & Hybrid & 0.264 \\
\hline 0.55 & 0.0455 & 1.60 & 24.75 & 2.049 & Hybrid & 0.246 \\
\hline 0.65 & 0.0407 & 0.63 & 29.25 & 1.832 & Hybrid & 0.228 \\
\hline 0.75 & 0.0359 & 0.00 & 33.75 & 1.615 & S825 & 0.210 \\
\hline 0.85 & 0.0311 & -0.29 & 38.25 & 1.398 & Hybrid & 0.185 \\
\hline 0.95 & 0.0263 & -0.42 & 42.75 & 1.181 & S826 & 0.160 \\
\hline
\end{tabular}




\section{Baseline Blade Structural Design}

Following the methodology in Griffin (2004), the blade structural design was developed using the ANSYS finite element analysis (FEA) code with a NuMAD preprocessor (Laird 2001). The EBEAM code (Malcolm and Laird 2003) was used to determine blade local mass and stiffness properties.

A baseline structural architecture was selected as representative of current commercial blade designs. The primary structural member is a box-spar, with webs at $15 \%$ and $50 \%$ chord and a substantial buildup of spar cap material between the webs. The exterior skins and internal shear webs are both of sandwich construction with triaxial fiberglass laminate separated by balsa core. Figure 6 depicts this arrangement.

Table 4 lists the layers in the baseline structural shell and describes the material contained in each. Cores for the leading and trailing edge panels were approximately $0.5 \%$ and $1.0 \%$ of chord, respectively, with triaxial facings of $1.4 \mathrm{~mm}$ thickness.

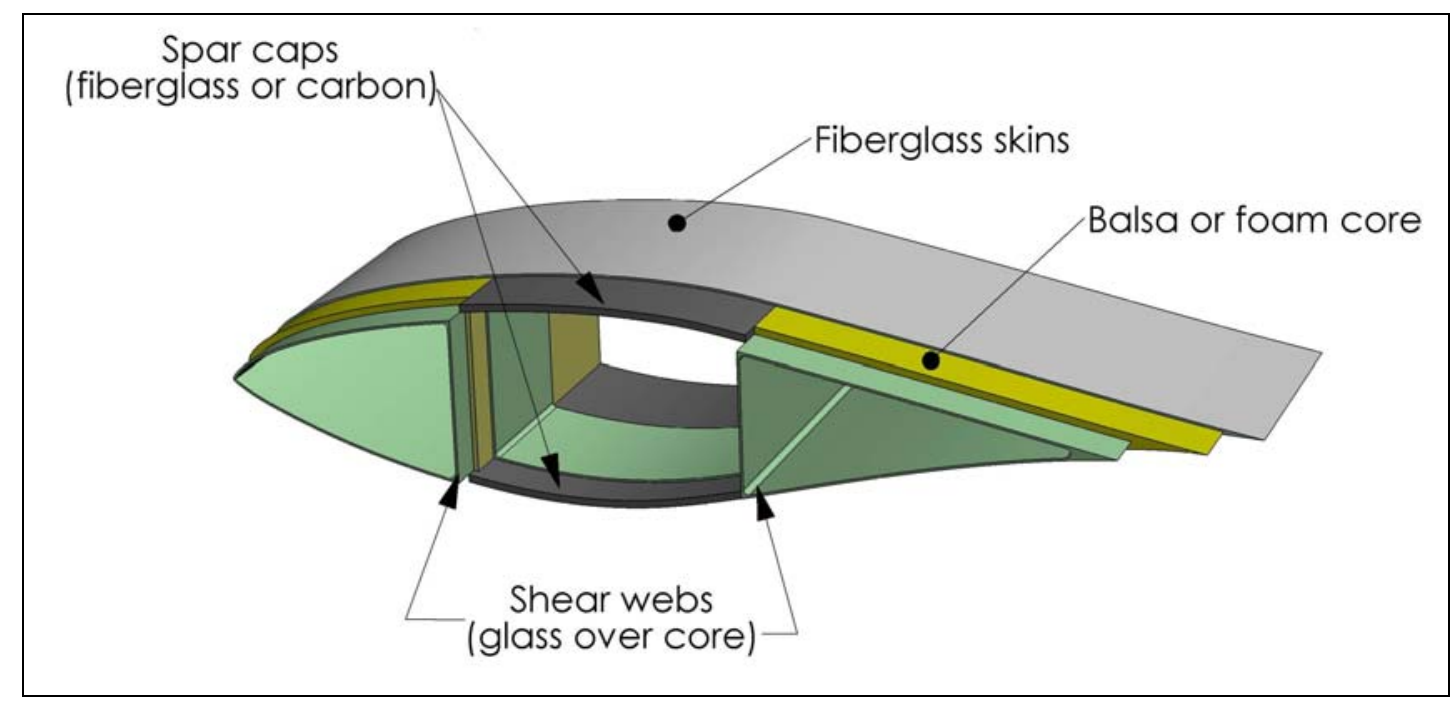

Figure 6. Architecture of baseline structural model

Table 4. Baseline Structural-Shell Definition

\begin{tabular}{|l|l|l|}
\hline \multicolumn{1}{|c|}{$\begin{array}{c}\text { Layer } \\
\text { Number }\end{array}$} & \multicolumn{1}{c|}{ Material } & \multicolumn{1}{c|}{ Thickness } \\
\hline 1 & Gel coat & $0.51 \mathrm{~mm}$ \\
\hline 2 & Random mat & $0.38 \mathrm{~mm}$ \\
\hline 3 & Triaxial fabric & $1.40 \mathrm{~mm}$ \\
\hline 4 & Spar cap mixture & As needed \\
$0.15 \mathrm{c}-0.50 \mathrm{c}$ & Triaxial fabric & $1.40 \mathrm{~mm}$ \\
\hline 5 & \multicolumn{2}{|l}{} \\
\hline
\end{tabular}

The skins and spar cap are E-glass/epoxy laminate. The triaxial fabric is designated as CDB340, and has a $25 \%, 25 \%$, and $50 \%$ distribution of $+45^{\circ},-45^{\circ}$, and $0^{\circ}$ fibers, respectively. The spar cap is composed of alternating layers of triaxial and uniaxial (A260) fabric. This stacking 
sequence results in spar cap laminate with $70 \%$ uniaxial fibers and $30 \%$ off-axis fibers by weight.

Investigators at Montana State University (MSU) determined the characteristic material properties for the baseline blade lamina using a combination of test data and laminate theory calculations.

Table 5 summarizes the mass and stiffness properties for each material. Characteristic values for static strain were $2.2 \%$ and $1.05 \%$, respectively, in tension and compression. The combined material partial safety factors were 2.90 for peak loading, and 1.93 for fatigue.

Table 5. Summary of Baseline Blade Material Properties

\begin{tabular}{|l|l|l|l|l|l|l|l|}
\hline \multicolumn{1}{|c|}{ Property } & \multicolumn{1}{|c|}{ A260 } & CDB340 & $\begin{array}{c}\text { Spar Cap } \\
\text { Mixture }\end{array}$ & $\begin{array}{c}\text { Random } \\
\text { Mat }\end{array}$ & Balsa & $\begin{array}{c}\text { Gel } \\
\text { Coat }\end{array}$ & $\begin{array}{c}\text { Fill } \\
\text { Epoxy }\end{array}$ \\
\hline$E_{x}(\mathrm{GPa})$ & 31.0 & 24.2 & 25.0 & 9.65 & 2.07 & 3.44 & 2.76 \\
\hline $\mathrm{E}_{\mathrm{y}}(\mathrm{GPa})$ & 7.59 & 8.97 & 9.23 & 9.65 & 2.07 & 3.44 & 2.76 \\
\hline $\mathrm{G}_{\mathrm{xy}}(\mathrm{GPa})$ & 3.52 & 4.97 & 5.00 & 3.86 & 0.14 & 1.38 & 1.10 \\
\hline$v_{x y}$ & 0.31 & 0.39 & 0.35 & 0.30 & 0.22 & 0.3 & 0.3 \\
\hline$v_{f}$ & 0.40 & 0.40 & 0.40 & - & N/A & N/A & N/A \\
\hline$w_{f}$ & 0.61 & 0.61 & 0.61 & - & N/A & N/A & N/A \\
\hline$\rho\left(\mathrm{g} / \mathrm{cm}^{3}\right)$ & 1.75 & 1.75 & 1.75 & 1.67 & 0.144 & 1.23 & 1.15 \\
\hline
\end{tabular}

GEC selected the composite material data used for the baseline blade laminate to be consistent with the data used in the earlier WindPACT blade (Griffin 2001) and rotor (Malcom and Hansen 2003 ) studies. The laminate properties are characteristic of woven fiberglass fabrics with epoxy resin in a hand-layup (open-mold) process. When the earlier WindPACT studies were conducted, this process represented a significant percentage of blades in commercial production.

In recent years, the manufacturing of megawatt-scale blades has shifted almost entirely to processes using either vacuum-assisted resin transfer molding (VARTM) or preimpregnated fibers (prepreg). As a result, the modeled baseline blade mass is toward the upper end of commercial designs of similar length. GEC expects, though, that this study will still realistically characterize the incremental change in loads, structural cost, and COE for the active aero control technologies evaluated.

The blade spar was dimensioned at several spanwise locations, based on simulations of International Electrotechnical Committee (IEC) load cases, and design properties for the FRP material assumed for the baseline blade structure. Considerations for the blade structural design included static and fatigue strength, as well as tip-tower clearance.

In performing the blade structural calculations, the spar cap dimensions were not required to be integer multiples of the selected material lamina thickness. GEC chose this approach to avoid the need for step-jumps in the model definition and results. The investigators assumed that a suitable fabric (or combination of fabrics) could be identified that would be a near match to the dimensions and fiber content modeled for each blade. 
Table 6 presents the structural layout and distribution of mass and bending stiffness for the baseline 2.5-MW blade. Note that the mass distribution includes a factor of 1.09 to account for non-structural mass contributions that are not included in the FEA models.

Table 6. Structural Layout for Baseline Blade

\begin{tabular}{|c|c|c|c|c|c|c|}
\hline \multicolumn{2}{|c|}{ Blade Station } & \multicolumn{2}{|c|}{ Spar Cap Thickness } & \multicolumn{2}{|c|}{ Section El $\left(\mathrm{N}-\mathrm{m}^{2}\right)$} & \multirow{2}{*}{$\begin{array}{c}\text { Mass } \\
(\mathrm{kg} / \mathrm{m})\end{array}$} \\
\hline r/R (\%) & $(\mathrm{m})$ & $(\% t)$ & $(\mathrm{mm})$ & Flap & Edge & \\
\hline 5 & 2.25 & N/A & N/A & $1.40 \mathrm{E}+10$ & $1.40 \mathrm{E}+10$ & 1731 \\
\hline 7 & 3.15 & N/A & N/A & $2.66 \mathrm{E}+09$ & $2.66 \mathrm{E}+09$ & 305 \\
\hline 25 & 11.25 & 4.0 & 43.2 & $7.52 \mathrm{E}+08$ & $1.96 \mathrm{E}+09$ & 296 \\
\hline 50 & 22.5 & 13.4 & 72.1 & $1.44 \mathrm{E}+08$ & $4.80 E+08$ & 256 \\
\hline 75 & 33.75 & 7.4 & 25.1 & $2.62 \mathrm{E}+07$ & $1.53 \mathrm{E}+08$ & 126 \\
\hline \multirow[t]{4}{*}{95} & 42.75 & 4.7 & 8.1 & $1.41 \mathrm{E}+06$ & $2.42 \mathrm{E}+07$ & 27 \\
\hline & & & & \multicolumn{2}{|c|}{ Blade structure $=$} & $10,361 \mathrm{~kg}$ \\
\hline & & & & \multicolumn{2}{|c|}{ Root connection = } & $253 \mathrm{~kg}$ \\
\hline & & & & Total blad & & $10,614 \mathrm{~kg}$ \\
\hline
\end{tabular}

\section{Power Performance}

The WT_PERF code was used to calculate rotor power coefficient $\left(\mathrm{C}_{\mathrm{P}}\right)$ versus TSR for the baseline blade. Researchers used a spreadsheet calculation to convert from $\mathrm{C}_{\mathrm{P}}$-TSR to a power curve, accounting for variable-speed operation and drivetrain efficiency. Power losses resulting from wind turbulence and controller effects were not included in the power curve calculation. The baseline turbine $\mathrm{C}_{\mathrm{P}}$-TSR curve is shown in Figure 7 and the power curve is shown in Figure 8 for sea-level air density.

Annual energy production (AEP) calculations were made using the steady power curve as predicted by WT_PERF. AEP was calculated for two wind speed distributions. Table 7 lists the reference and hub-height wind regimes, as well as the calculated baseline turbine AEP for each. Appendix A gives details of AEP calculations in tabular form.

Table 7. Calculated AEP for Baseline Blade

\begin{tabular}{|l|l|l|l|l|l|}
\hline & \multicolumn{2}{|c|}{ Reference } & \multicolumn{3}{c|}{ Turbine Hub } \\
\cline { 2 - 7 } & $\begin{array}{c}\text { Height } \\
(\mathrm{m})\end{array}$ & $\begin{array}{r}\text { Average Wind Speed } \\
(\mathrm{m} / \mathrm{s})\end{array}$ & $\begin{array}{c}\text { Height } \\
(\mathrm{m})\end{array}$ & $\begin{array}{c}\text { Average Wind Speed } \\
(\mathrm{m} / \mathrm{s})\end{array}$ & $\begin{array}{c}\text { Gross AEP } \\
(\mathrm{MWh})\end{array}$ \\
\hline 4 & 10 & 5.8 & 80 & 7.8 & 8,724 \\
\hline 6 & 10 & 6.7 & 80 & 9.0 & 10,708 \\
\hline
\end{tabular}




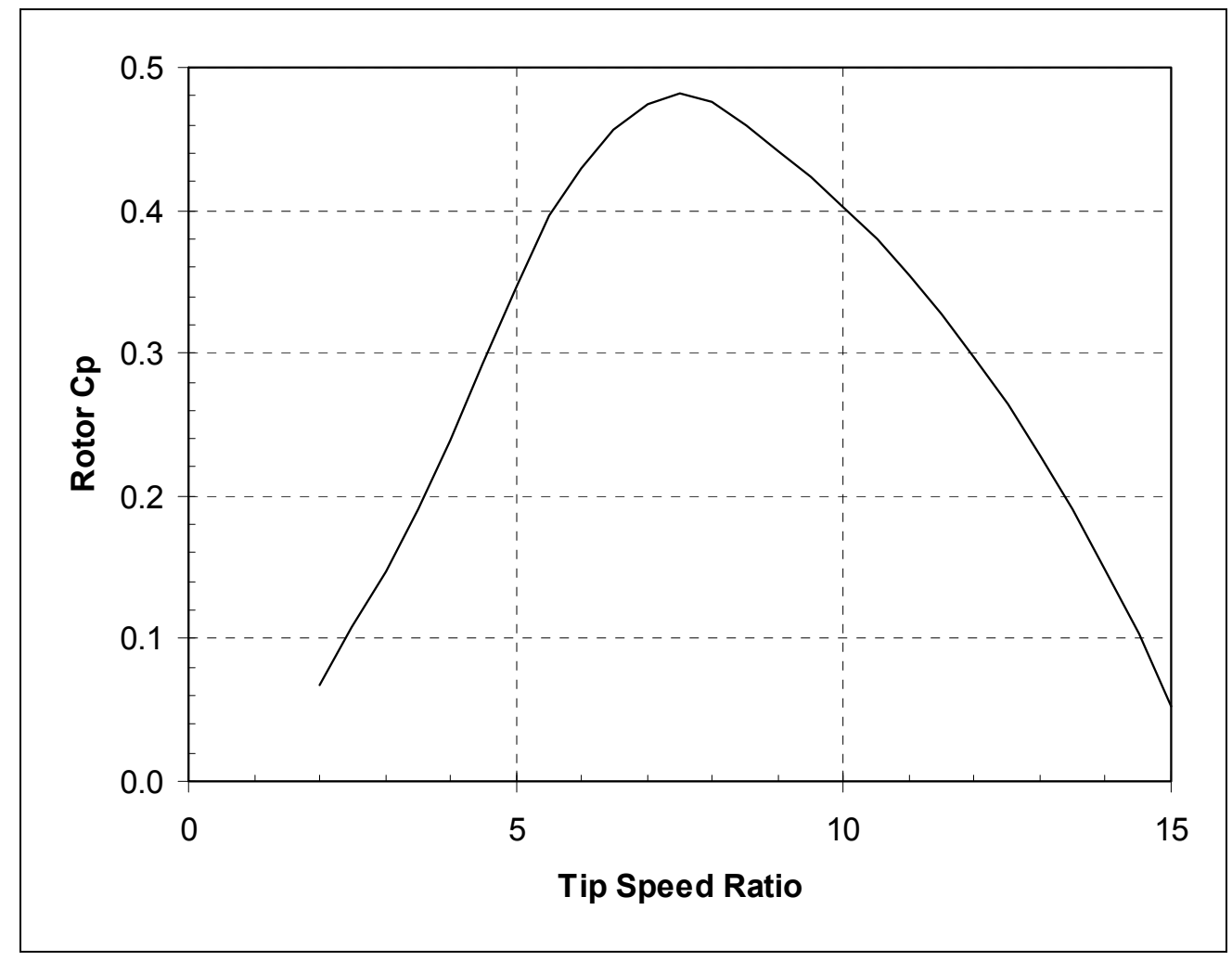

Figure 7. $\mathrm{C}_{\mathrm{P}}-\mathrm{TSR}$ curve for baseline 2.5-MW rotor

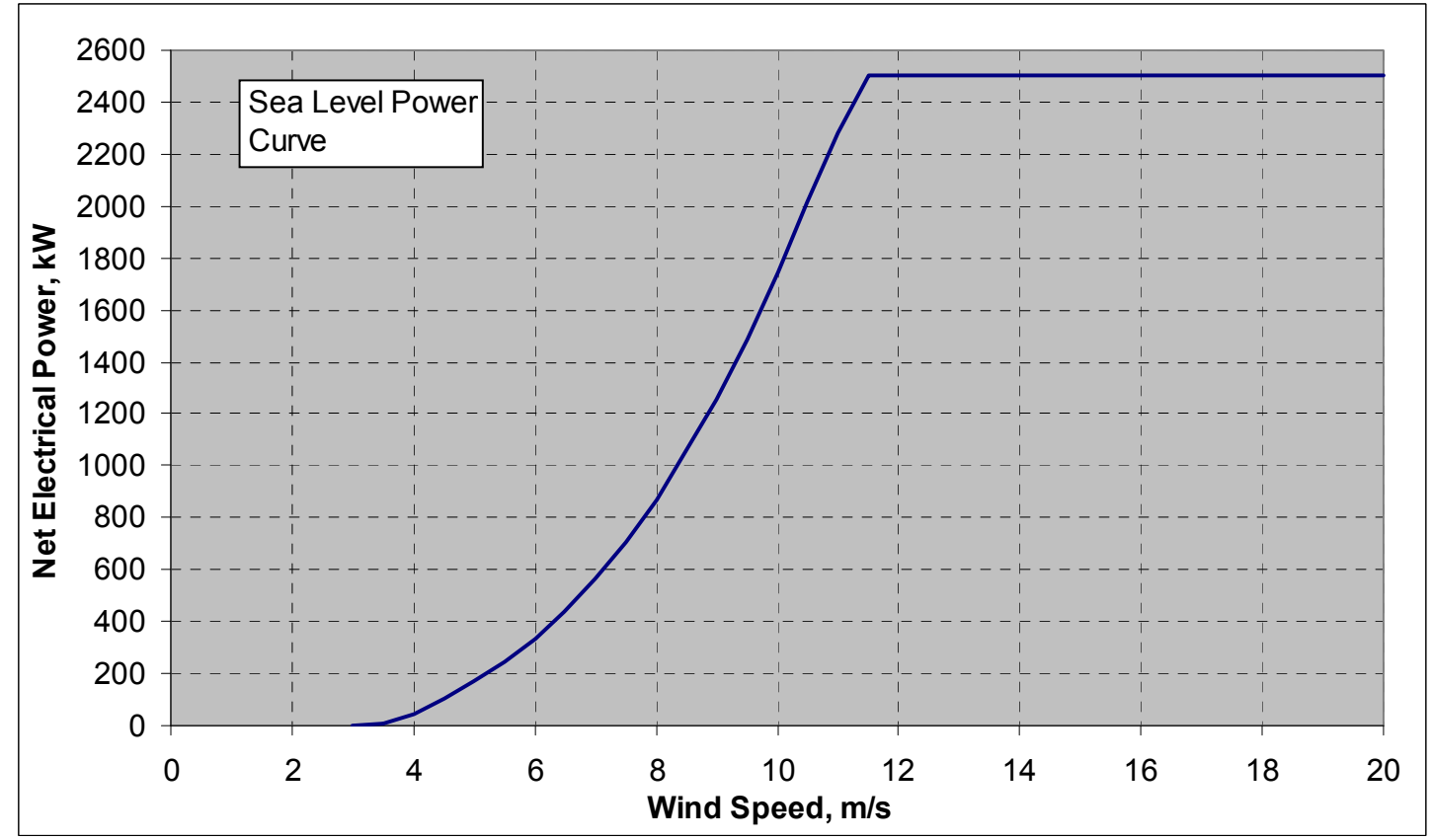

Figure 8. Baseline turbine power curve at sea level 


\section{Controls}

The controls for the baseline turbine include a PI loop from rotor speed to blade pitch for revolutions-per-minute regulation in high winds and a torque speed curve for tracking optimal TSR in low winds. In addition, feedback of tower fore-aft acceleration was used to dampen tower vibrations via a low pass filter. The blades were pitched collectively.

Although the pitch actuator is modeled as a fast servo (16- Hz bandwidth), the pitch demand is filtered with a first-order filter with a $1-\mathrm{Hz}$ cutoff frequency. No rate or acceleration limits are applied to the pitch motion; however, the filter typically limits the pitch rate to about $10 \% \mathrm{~s}$ and the acceleration to about $50^{\circ} / \mathrm{s}^{2}$. Table 8 gives the control parameters.

Table 8. Baseline Control Parameter Settings

\begin{tabular}{|l|l|l|}
\hline \multicolumn{1}{|c|}{ Parameter } & \multicolumn{1}{c|}{ Value } & \multicolumn{1}{c|}{ Units } \\
\hline Controller update rate & 0.050 & seconds \\
\hline rpm normal operating set point & $15.9(1.67)$ & $\mathrm{rpm}(\mathrm{rps})$ \\
\hline rpm PI proportional gain & 3.35 & degrees/rpm \\
\hline rpm PI integral gain & 0.422 & degrees/rpm-s \\
\hline rpm PI minimum pitch & 1.50 & degrees \\
\hline rpm PI maximum pitch & 90.0 & degrees \\
\hline rpm PI low pass filter time constant & 0.15 & seconds \\
\hline Tower damping filter gain & 4.3 & degrees $/\left(\mathrm{m} / \mathrm{s}^{2}\right)$ \\
\hline Torque-speed gain (LSS) & 410.7 & $\mathrm{kNm} /(\mathrm{rad} / \mathrm{s})^{2}$ \\
\hline Maximum generator torque (LSS) & 1619.0 & $\mathrm{kNm}$ \\
\hline Power max for torque reduction & 3000 & $\mathrm{~kW}$ \\
\hline
\end{tabular}

\section{Load Calculations and COE}

Turbine structural loads were calculated using ADAMS for a selected set of IEC load cases. Table 9 lists these load cases.

The formula used to calculate the COE was prescribed in the NREL request for proposals (RFP) and is given here:

$$
\mathrm{COE}=\left\{(\underline{\mathrm{FCR} \times \mathrm{ICC})+\mathrm{LRC}}+\mathrm{O} \& \mathrm{M}\} / \mathrm{AEP}_{\text {net }}\right.
$$

where

$\mathrm{COE}=\quad$ Levelized cost of energy (dollars per kilowatt-hour)

$\mathrm{FCR}=\quad$ Fixed charge rate $(11.85 \%$ per year was used $)$

ICC $=\quad$ Initial capital cost, including turbine and balance of station (dollars)

LRC $=\quad$ Levelized replacement cost (dollars per year)

AEPnet $=\quad$ Net annual energy production (kilowatt-hours per year)

AEPgross $=$ Adjusted for availability, array losses, and soiling, among others

$\mathrm{O} \& \mathrm{M}=\quad$ Operations and maintenance cost (dollars per year) based on dollars per kilowatt of rating. 
Table 9. Selected Set of IEC Load Cases

\begin{tabular}{|c|c|c|c|c|c|c|}
\hline $\begin{array}{l}\text { IEC } \\
\text { Load } \\
\text { Case } \\
\text { Number }\end{array}$ & Load Case Name & $\begin{array}{l}\text { Description, } \\
\text { Wind Speed }\end{array}$ & Conditions & $\begin{array}{l}\text { Load } \\
\text { Type }\end{array}$ & $\begin{array}{l}\text { Load } \\
\text { Factor }\end{array}$ & Comments \\
\hline 1.1 & $06 \ldots 24 \mathrm{~ms} 1 . .6$ & $\begin{array}{l}\text { NTM } \\
\text { Vin }<\text { V }<\text { Vout }\end{array}$ & $\begin{array}{l}\text { Normal } \\
\text { operation }\end{array}$ & Extreme & 1.35 & $\begin{array}{l}6 \times 10 \text { min of } \\
\text { turbulent flow at } \\
\text { each wind speed }\end{array}$ \\
\hline 1.2 & $06 \ldots 24 \mathrm{~ms} 1 . .6$ & $\begin{array}{l}\text { NTM } \\
\text { Vin }<\text { V }<\text { Vout }\end{array}$ & $\begin{array}{l}\text { Normal } \\
\text { operation }\end{array}$ & Fatigue & 1.0 & Same as above \\
\hline 1.3 & $\begin{array}{l}\text { ECD }(P \mid N) R \text { ECD }(P \mid N) R-2^{*} \\
\text { ECD }(P \mid N) R-4^{*}\end{array}$ & $\begin{array}{l}\text { ECD V=Vr } \\
\text { NWP }\end{array}$ & $\begin{array}{l}\text { As defined in } \\
\text { IEC code }\end{array}$ & Extreme & 1.35 & $\begin{array}{l}\text { 120-s simulation } \\
\text { for each case }\end{array}$ \\
\hline 1.6 & $\begin{array}{l}\text { EOG50(R|O) EOG50R-2* } \\
\text { EOG50R-4* }\end{array}$ & $\begin{array}{l}\text { EOG50 } \\
V=V r \text { or } \\
V=V o u t\end{array}$ & 50 -year gust & Extreme & 1.35 & $\begin{array}{l}\text { 120-s simulation } \\
\text { for each case }\end{array}$ \\
\hline 1.7 & 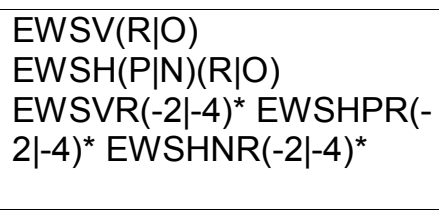 & $\begin{array}{l}E W S V=V r \\
\text { or } V=V o u t\end{array}$ & $\begin{array}{l}\text { Extreme wind } \\
\text { shear, vertical, } \\
\text { and horizontal } \\
\text { (in both } \\
\text { directions) }\end{array}$ & Extreme & 1.35 & $\begin{array}{l}\text { 120-s simulation } \\
\text { for each case }\end{array}$ \\
\hline 1.8 & $\begin{array}{l}\text { EDC50(P|N)(R|O) } \\
\text { EDC50(P|N)R-2* } \\
\text { EDC50(P|N)R-4* }\end{array}$ & $\begin{array}{l}\mathrm{EDC} 50 \mathrm{~V}=\mathrm{Vr} \\
\text { or } \mathrm{V}=\mathrm{V} \text { out }\end{array}$ & $\begin{array}{l}\text { Extreme } \\
\text { direction } \\
\text { change in both } \\
\text { directions }\end{array}$ & Extreme & 1.35 & $\begin{array}{l}\text { 120-s simulation } \\
\text { for each case }\end{array}$ \\
\hline 1.9 & ECGR ECG(R-2|R-4)* & $E C G V=V r$ & $\begin{array}{l}\text { Extreme } \\
\text { coherent gust }\end{array}$ & Extreme & 1.35 & $\begin{array}{l}120-s \\
\text { simulations }\end{array}$ \\
\hline 6.1 .1 & EWM011..3 & $\begin{array}{l}\text { EWM }(1 \\
\text { year) } \\
\text { Vmax }(3 \mathrm{~s}) \\
=44.6 \mathrm{~m} / \mathrm{s}\end{array}$ & $\begin{array}{l}\text { Stationary } \\
\text { rotor, pitch to } \\
\text { operate, } \\
\text { (minimum } \\
\text { radius RBR) }\end{array}$ & Extreme & 1.35 & $\begin{array}{l}\text { Brake on } \\
3 \times 10 \mathrm{~min} \\
\text { Vmean }=33 \mathrm{~m} / \mathrm{s}\end{array}$ \\
\hline 6.1 .1 & EWM013..6 & $\begin{array}{l}\text { EWM }(1 \\
\text { year) } \\
\text { Vmax }(3 \mathrm{~s}) \\
=44.6 \mathrm{~m} / \mathrm{s}\end{array}$ & $\begin{array}{l}\text { Stationary } \\
\text { rotor, pitch to } \\
\text { feather } \\
\text { (maximum } \\
\text { radius RBR) }\end{array}$ & Extreme & 1.35 & $\begin{array}{l}\text { Brake on } \\
3 \times 10 \mathrm{~min} ; \\
\text { Vmean = } 33 \mathrm{~m} / \mathrm{s}\end{array}$ \\
\hline 6.1 .2 & EWM501..6 & $\begin{array}{l}\text { EWM }(50 \\
\text { year) } \\
\text { Vmax }(3 \mathrm{~s}) \\
=59.5 \mathrm{~m} / \mathrm{s}\end{array}$ & $\begin{array}{l}\text { Stationary } \\
\text { rotor, fully } \\
\text { feathered } \\
\text { (minimum } \\
\text { radius RBR) }\end{array}$ & Extreme & 1.35 & $\begin{array}{l}\text { Brake off } \\
6 \times 10 \mathrm{~min} ; \\
\text { Vmean = } 44 \mathrm{~m} / \mathrm{s}\end{array}$ \\
\hline
\end{tabular}

*These runs made for the RBR only.

Notes: $(\mathrm{P} \mid \mathrm{N})=$ positive|negative for directions and shear; $(\mathrm{R} \mid \mathrm{O})=$ rated wind speed $\mid$ cut-out wind speed; $(\mathrm{R}-2 \mid \mathrm{R}-4)=$ rated wind $-2 \mathrm{~m} / \mathrm{s} \mid$ rated wind $-4 \mathrm{~m} / \mathrm{s}$. 


\section{Retractable Blade Rotor}

\section{Blade Aerodynamic Design}

An aerodynamic trade study was conducted to determine an appropriate diameter range for the RBR. The study assumed that the fixed inboard portion of the blade would have the same profile as the baseline blade. The extendable outboard section of the blade would be a constant-chord, constant-twist section sized to fit within the inboard section at the cut-off radius.

The performance calculations assumed that the maximum generator torque would be maintained at the same level as the baseline but that the rotor rpm could increase as the diameter decreases below nominal in high winds. This approach maintains the same maximum tip speed but allows the rated power to increase. Performance and annual energy results were calculated for several cut-off radii and several maximum lengths as indicated in Table 10 and Figure 9. Tip-chord fraction refers to the chord of the tip relative to the chord at the cut-off radius. The minimum and maximum radii refer to the corresponding radii of the rotor that can be achieved by fully retracting or extending the blade tip section.

Based on the amount of predicted energy capture, and on assumptions about the feasibility of accommodating different blade tip lengths within the blade, GEC chose configuration 6 as the first candidate for simulation in ADAMS. This configuration is depicted graphically in Figure 10. The solid black outline shows the baseline blade chord dimensions. The blue line indicates the cutline at $90 \%$ of the original radius, and the dashed lines indicate two possible locations for the extended RBR tip. Figure 11 depicts the chord schedule for configuration 12. The steady power curve for configuration 12 is shown in Figure 12. The steps in the power curve result from the discrete steps in rotor radius used for the WT_PERF analysis. 
Table 10. Candidate RBR Configurations (highlighted in yellow)

\begin{tabular}{|l|l|l|l|l|l|l|l|l|l|}
\hline $\begin{array}{c}\text { Configuration } \\
\text { Number }\end{array}$ & $\begin{array}{c}\text { Tip } \\
\text { Cut-off } \\
\text { Radius } \\
(\%)^{*}\end{array}$ & $\begin{array}{l}\text { Tip Chord } \\
\text { Fraction } \\
(\%)\end{array}$ & $\begin{array}{c}\text { Minimum } \\
\text { Radius } \\
(\mathrm{m})\end{array}$ & $\begin{array}{c}\text { Maximum } \\
\text { Radius } \\
(\mathrm{m})\end{array}$ & $\begin{array}{c}\text { Maximum } \\
\text { Power } \\
(\mathrm{kW})\end{array}$ & $\begin{array}{c}\text { Wind } \\
\text { Class 4 } \\
\text { AEP } \\
(\mathrm{MWh})\end{array}$ & $\begin{array}{c}\Delta \\
\text { AEP } \\
(\%)\end{array}$ & $\begin{array}{c}\text { Wind } \\
\text { Class6 } \\
\text { AEP } \\
(\mathrm{MWh})\end{array}$ & $\begin{array}{c}\Delta \\
\text { AEP } \\
(\%)\end{array}$ \\
\hline 0 & N/A & N/A & 45 & 45 & 2,500 & 8,724 & 0.0 & 10,708 & 0.0 \\
\hline 1 & 95 & 85 & 45 & 50 & 2,500 & 9,660 & 10.7 & 11,592 & 8.3 \\
\hline 2 & 95 & 85 & 45 & 55 & 2,500 & 10,402 & 19.2 & 12,267 & 14.6 \\
\hline 3 & 90 & 85 & 45 & 50 & 2,500 & 9,657 & 10.7 & 11,590 & 8.2 \\
\hline 4 & 90 & 85 & 45 & 55 & 2,500 & 10,412 & 19.4 & 12,280 & 14.7 \\
\hline 5 & 90 & 85 & 42.75 & 50 & 2,632 & 9,836 & 12.7 & 11,871 & 10.9 \\
\hline 6 & 90 & 85 & 42.72 & 55 & 2,632 & 10,591 & 21.4 & 12,560 & 17.3 \\
\hline 7 & 85 & 85 & 45 & 50 & 2,500 & 9,644 & 10.5 & 11,579 & 8.1 \\
\hline 8 & 85 & 85 & 45 & 55 & 2,500 & 10,395 & 19.2 & 12,265 & 14.5 \\
\hline 9 & 85 & 85 & 40.5 & 50 & 2,778 & 9,965 & 14.2 & 12,102 & 13.0 \\
\hline 10 & 85 & 85 & 40.5 & 55 & 2,778 & 10,716 & 22.8 & 12,788 & 19.4 \\
\hline 11 & 90 & 80 & 42.75 & 55 & 2,632 & 10,577 & 21.2 & 12,546 & 17.2 \\
\hline 12 & 90 & 75 & 42.75 & 55 & 2,632 & 10,547 & 20.9 & 12,519 & 16.9 \\
\hline 13 & 90 & 70 & 42.75 & 55 & 2,632 & 10,505 & 20.4 & 12,477 & 16.5 \\
\hline
\end{tabular}

*Percentage of baseline rotor radius

$\dagger$ Percentage of local blade chord at cutline

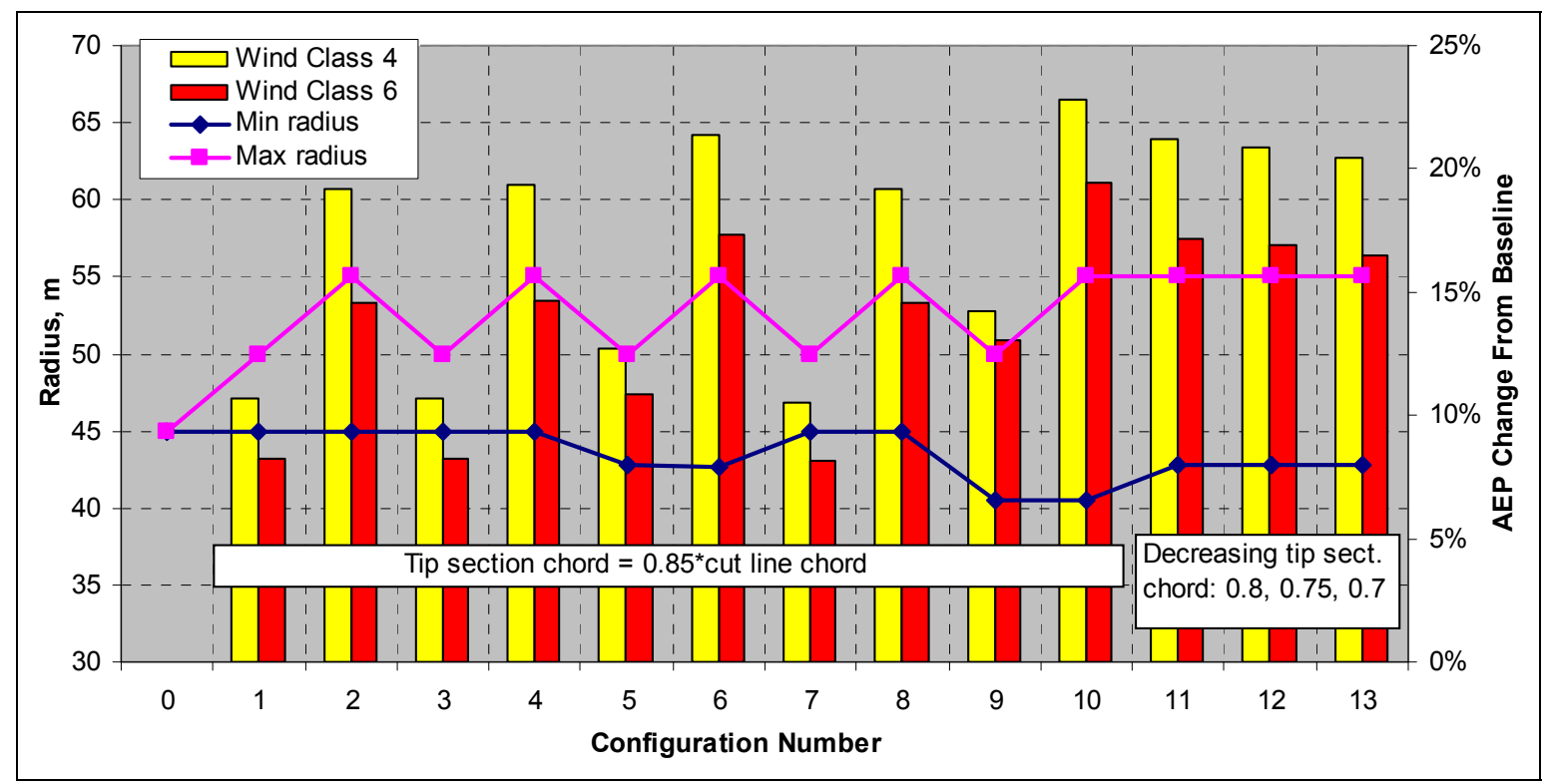

Figure 9. Energy trends for candidate RBR configurations 


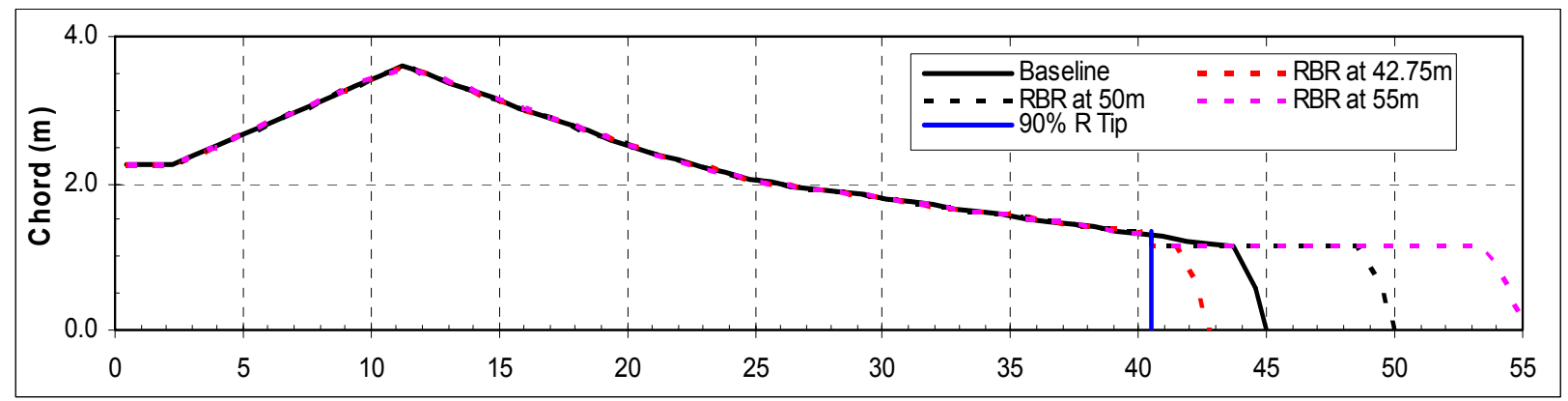

Figure 10. RBR blade profile for configuration 6

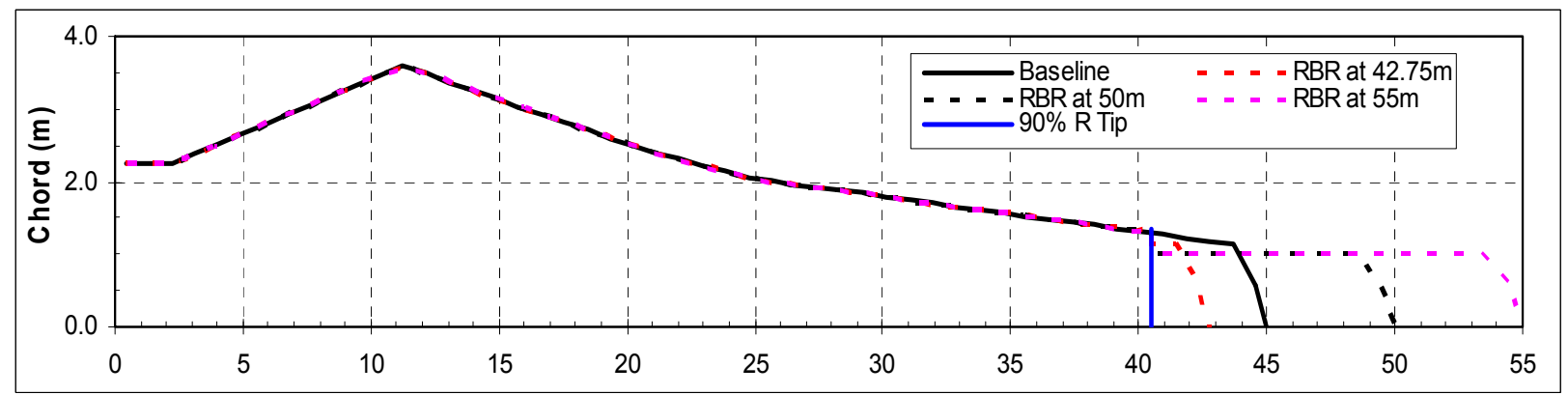

Figure 11. RBR blade profile for configuration 12

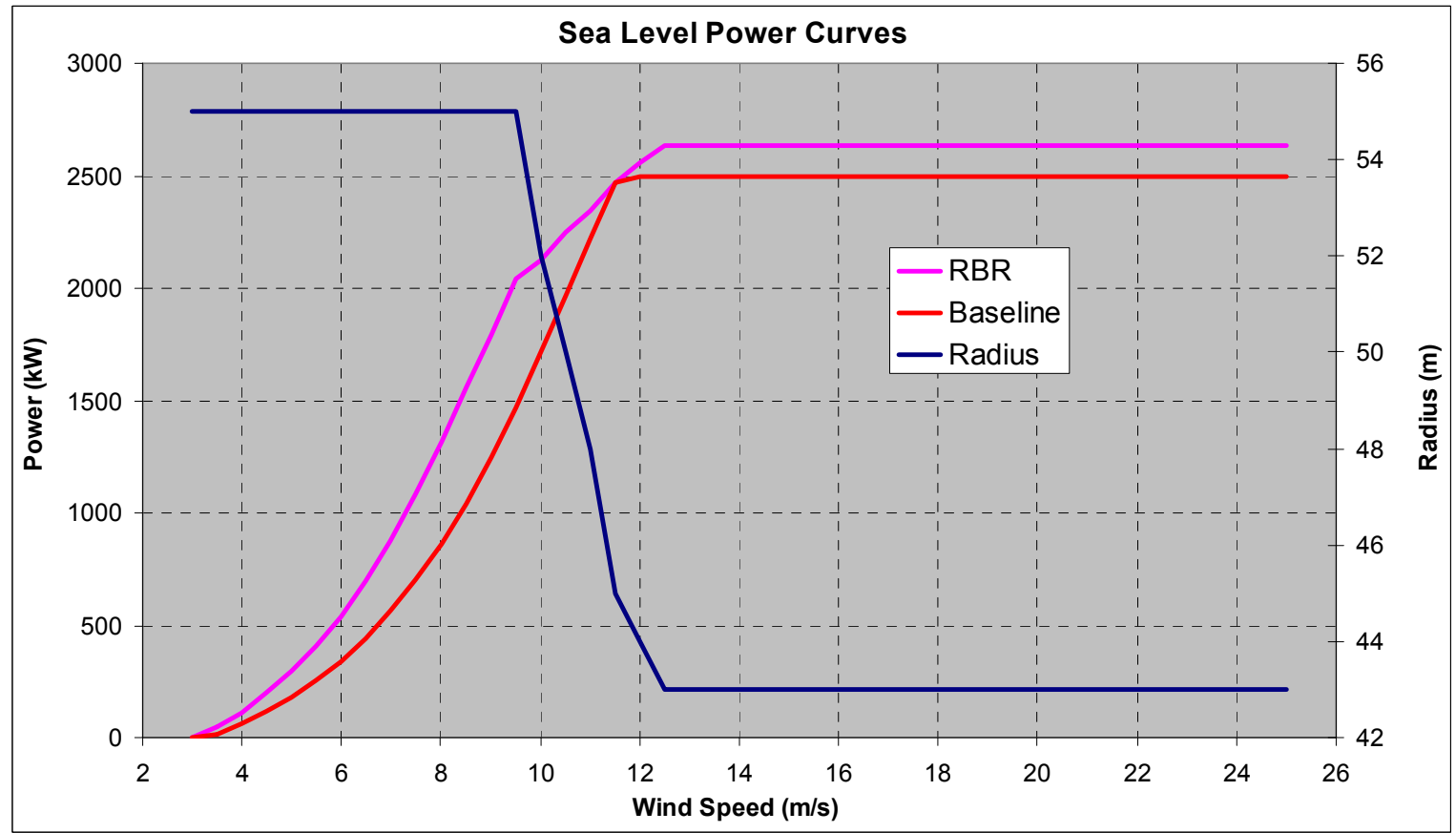

Figure 12. RBR power curve for configuration 12

\section{Blade Structural Design}

The approach to the blade structural design is necessarily linked to that of the aerodynamic design. In a fully optimized RBR system, design objectives for aerodynamics and structure could be considered in an integral fashion. For the purposes of this conceptual study, though, 
simplified assumptions were made. GEC developed the RBR designs described here according to the following guidelines:

- $\quad$ The RBR outer mold line (OML) shape is the same as the baseline blade, up to a specified spanwise location at which a cutline is introduced to accommodate the retractable tip.

- The retractable tip is the same airfoil as that at the cutline, but scaled in a self-similar fashion so that it fits into the main blade at the cutline.

- The OML shape of the retractable tip is constant over its span.

- Structural laminate for the main blade must be sized so that sufficient space exists to accommodate the OML of the retractable tip.

- Changes to the baseline laminate materials and processes are acceptable to achieve the necessary blade stiffness.

As with the baseline blade, the RBR structural designs were developed using the ANSYS FEA code with the NuMAD preprocessor and the EBEAM postprocessor. Mass and stiffness contributions from the bearings and reaction points were not rigorously modeled in this study because they depend greatly on the details of the mechanism design. Some added mass elements and features of the load transfer at the interface between the tip and main blade were approximated in the ADAMS models.

For the baseline blade model, the primary load-carrying spar is assumed to be a box-beam (refer to Figure 6). The internal structure of the blade, however, would need to be modified to accommodate the RBR tip in the retracted position. As a result, blade stations that require clearance for accepting the RBR tip were modeled as monocoque without shear webs. This approach is suitable only for preliminary estimation of the RBR laminate weight. These models did not include details of the nesting design such as hard points for bearings and actuators and buckling support for the blade in both the retracted and extended positions.

\section{Material Properties}

During the RBR modeling, it was immediately apparent that achieving adequate stiffness would require the baseline fiberglass spar cap to be replaced with carbon fiber laminate. For the initial set of configurations, investigators assumed that the carbon fiber spar would be produced using the same process as the baseline blade (i.e., wet layup). Although that might be convenient from a manufacturing standpoint, the process would typically result in low fiber volume fractions and stiffness properties that fall significantly below the capability of carbon fibers.

As the project progressed, the need for stiffer carbon materials became evident. As a result, later versions of the RBR assumed the use of prepreg carbon for the spar material. Table 11 lists the laminate properties used for RBR configurations 6 and 12.

Table 11. Assumed Carbon Spar Material Properties

\begin{tabular}{|c|c|c|c|c|c|c|}
\hline \multirow{2}{*}{$\begin{array}{c}\text { RBR } \\
\text { Config. }\end{array}$} & \multirow{2}{*}{$\begin{array}{c}\text { Fiber Volume } \\
\text { Fraction }\left(u_{f}\right)\end{array}$} & \multicolumn{3}{|c|}{ Laminate Stiffness (Gpa) } & \multirow{2}{*}{$\begin{array}{l}\text { Density } \\
\left(\mathrm{kg} / \mathrm{m}^{3}\right)\end{array}$} & \multirow{2}{*}{$\begin{array}{c}\text { Laminate } \\
\text { Cost }(\$ / \mathrm{kg})\end{array}$} \\
\hline & & $E_{X}$ & $E_{Y}$ & $\mathbf{G}_{X Y}$ & & \\
\hline 6 & 0.45 & 105.4 & 6.82 & 3.32 & 1430 & $\$ 20.00$ \\
\hline 12 & 0.60 & 139.4 & 8.69 & 4.35 & 1520 & $\$ 22.50$ \\
\hline
\end{tabular}


As Table 11 shows, increasing the fiber volume from $45 \%$ to $60 \%$ resulted in a stiffness increase of about $33 \%$ for a density increase of only $6.3 \%$. Characteristic values for static strain were $0.75 \%$ for both tension and compression. These numbers are conservative for prepreg carbon fibers, but this became a moot point because the structural design was strongly dominated by stiffness requirements to avoid tower strikes. Additional information on the design and manufacturing aspects of these materials is given in the following section.

Note that the laminate cost assumptions are for the completed blade structure (including materials and labor). The underlying cost models were selected to be consistent with the earlier WindPACT studies to facilitate comparisons with technologies evaluated in those studies (Griffin 2001; Malcolm and Hansen 2003). At the time of the earlier WindPACT studies, though, carbon fiber was at an all-time-low price of about $\$ 16.50 / \mathrm{kg}$.

The price of carbon fibers has risen sharply and availability has been limited in recent years. A trend toward end users entering into multiyear purchase agreements with carbon fiber suppliers has also been seen. In the past year such agreements have been announced by the Boeing Company (Toray fibers for the 787 commercial airplane) and Vestas (Zoltek fibers for the V90 and V92). Although such agreements are expected to help stabilize the price and availability of carbon fibers, the details of these agreements are not public. As a result, it is difficult to establish with certainty an accurate price for the carbon fibers needed to develop and commercialize RBR technology. At the time this report was written, a better estimate might be closer to $\$ 20 / \mathrm{kg}$, but pricing is subject to either upward or downward fluctuation.

\section{Structural Modeling of RBR Configurations}

The most significant results from the RBR modeling are the importance of blade stiffness and the challenges associated with achieving the required stiffness within the available structural envelope.

Table 12 lists the tip/tower clearance margins for the baseline blade and Table 13 shows the RBR 12 configurations. Note that for deterministic load cases such as an extreme coherent gust with direction change (ECD), an azimuth window of $\pm 15^{\circ}$ was used to filter tip displacements. This window was not applied to results from stochastic load cases. Note also that a margin of $0 \%$ indicates a passing design but with no reserve margin.

Table 12. Tip/Tower Clearance Margins, Baseline

\begin{tabular}{|c|c|c|c|}
\hline $\begin{array}{l}\text { Clearance } \\
\text { Contribution }\end{array}$ & $\begin{array}{c}\text { Clearance } \\
\text { Available } \\
(\mathrm{m})\end{array}$ & $\begin{array}{l}\text { Displacement } \\
\text { Term }\end{array}$ & $\begin{array}{l}\text { Displacement } \\
(\mathrm{m})\end{array}$ \\
\hline & & Load case & $\begin{array}{l}\text { ECD at rated (with } \\
\text { azimuth window) }\end{array}$ \\
\hline $\begin{array}{l}\text { Hub-yaw axis } \\
\text { overhang }\end{array}$ & 4.20 & Maximum elastic displacement* & 4.333 \\
\hline $5.0^{\circ}$ tilt & 3.92 & Load factor & 1.35 \\
\hline Blade coning & 2.00 & Material factor & 1.10 \\
\hline Tower radius & -2.00 & Design displacement & 6.435 \\
\hline Total clearance & 8.12 & Margin $=(\text { clearance } / \text { design displ }-1)^{\star} 100 \%$ & $26.2 \%$ \\
\hline
\end{tabular}

*Tip displacement is measured from the unloaded tip position in the downwind direction. 
Table 13. Tip/Tower Clearance Margins, RBR 12

\begin{tabular}{|c|c|c|c|}
\hline $\begin{array}{c}\text { Clearance } \\
\text { Contribution }\end{array}$ & $\begin{array}{c}\text { Clearance } \\
\text { Available }(\mathrm{m})\end{array}$ & $\begin{array}{l}\text { Displacement } \\
\text { Term }\end{array}$ & $\begin{array}{l}\text { Displacement } \\
(\mathrm{m})\end{array}$ \\
\hline & & Load case & $\begin{array}{c}\text { Normal operation at } 8 \mathrm{~m} / \mathrm{s} \text { (no } \\
\text { azimuth window) }\end{array}$ \\
\hline $\begin{array}{l}\text { Hub-yaw axis } \\
\text { overhang }\end{array}$ & 4.20 & $\begin{array}{l}\text { Maximum elastic } \\
\text { displacement*}\end{array}$ & 5.430 \\
\hline $5.0^{\circ}$ tilt & 5.27 & Load factor & 1.35 \\
\hline Blade coning & 2.50 & Material factor & 1.10 \\
\hline Tower radius & -2.33 & Design displacement & 8.064 \\
\hline Total clearance & 9.15 & $\begin{array}{l}\text { Margin }=(\text { clearance/design } \\
\text { displ }-1)^{*} 100 \%\end{array}$ & $13.4 \%$ \\
\hline
\end{tabular}

*Tip displacement is measured from the unloaded tip position in the downwind direction.

The more important observation is the change in governing load case for the maximum tip deflection. For the baseline rotor the tower clearance is governed by an ECD. For the RBR, though, the maximum out-of-plane deflection occurs under normal operation at a wind speed of $8 \mathrm{~m} / \mathrm{s}$. Figure 12 shows that this falls in the middle of the range of wind speeds for power production at full blade extension. A speed of $8 \mathrm{~m} / \mathrm{s}$ is also close to the mean wind speed for the sites used for AEP calculations. Therefore, mitigating the tip deflections by reducing the rotor diameter would significantly reduce the AEP benefits from this technology. The alternative, which the investigators pursued in this study, is to determine the structural layout necessary to achieve the required stiffness. GEC encountered significant challenges with this approach.

Using the blade geometry and laminate properties assumed for RBR configuration 6, GEC was able to hypothetically achieve an adequately stiff blade. On further review, however, researchers determined that the structural design was not feasible because the laminate thickness required for the inner blade did not leave sufficient room for the RBR tip to be retracted. As a result, configuration 12 was developed using a reduced chord dimension for the retractable tip and increased laminate stiffness as shown in Table 11.

Table 14 shows the mass and stiffness distribution for RBR configuration 12 and offers a comparison with the baseline blade. The table indicates a substantial stiffening of the inner blade relative to the baseline. As noted earlier, the blade sections were dimensioned in such a way as to achieve the necessary blade stiffness, and also to attempt to leave a feasible clearance between the inner blade structure and the retractable tip. Even with the revised assumptions, this proved difficult, and some aspects of this preliminary structural design are far from optimal.

Review of the calculated blade deflection curves indicated that the largest bending occurred over the outer half of the extended RBR. Consequently, GEC found that the greatest improvement in clearance margin (per unit carbon fiber) could be achieved by stiffening the outer blade stations. The result of this is evident in Table 14, which shows that the increase in $\mathrm{EI}_{\text {Flap }}$ becomes much greater with increased radial location. 
Table 14. Summary Structural Layout for RBR Configuration 12

\begin{tabular}{|c|c|c|c|c|c|c|c|c|}
\hline \multirow{3}{*}{ Station } & \multirow{3}{*}{$\mathbf{R}(\mathrm{m})$} & \multicolumn{3}{|c|}{ RBR Configuration 12} & \multicolumn{2}{|c|}{ Baseline Blade } & \multirow{2}{*}{\multicolumn{2}{|c|}{ Difference }} \\
\hline & & Blade Ma & $s(\mathrm{~kg} / \mathrm{m})$ & $\mathrm{EI}_{\text {Flap }}$ & Mass & $\mathrm{EI}_{\text {Flap }}$ & & \\
\hline & & Total & Carbon & $(\mathrm{kN}-\mathrm{m})$ & $(\mathrm{kg} / \mathrm{m})$ & $(\mathrm{kN}-\mathrm{m})$ & Mass & $\mathrm{EI}_{\text {Flap }}$ \\
\hline $5 \%$ of baseline $\mathrm{R}$ & 2.25 & 1731 & 0 & $1.40 \mathrm{E}+10$ & 1731 & $1.40 \mathrm{E}+10$ & $0.0 \%$ & $0.0 \%$ \\
\hline $7 \%$ of baseline $\mathrm{R}$ & 3.15 & 305 & 0 & $2.66 \mathrm{E}+09$ & 305 & $2.66 \mathrm{E}+09$ & $0.0 \%$ & $0.0 \%$ \\
\hline $25 \%$ of baseline $\mathrm{R}$ & 11.25 & 136 & 29 & $9.20 \mathrm{E}+08$ & 296 & $7.52 \mathrm{E}+08$ & $-54.1 \%$ & $22.3 \%$ \\
\hline $50 \%$ of baseline $\mathrm{R}$ & 22.50 & 131 & 74 & $3.50 \mathrm{E}+08$ & 256 & $1.44 \mathrm{E}+08$ & $-48.9 \%$ & $143.1 \%$ \\
\hline $75 \%$ of baseline $R$ & 33.75 & 97 & 66 & $9.61 \mathrm{E}+07$ & 126 & $2.62 \mathrm{E}+07$ & $-22.8 \%$ & $266.8 \%$ \\
\hline $90 \%$ of baseline $\mathrm{R}$ & 40.50 & 95 & 73 & $3.87 \mathrm{E}+07$ & & & & \\
\hline Inboard end of tip & 40.50 & 75 & 56 & $1.30 \mathrm{E}+07$ & & & & \\
\hline Outboard end of tip & 55.00 & 47 & 28 & $8.40 \mathrm{E}+06$ & & & & \\
\hline
\end{tabular}

Even though this structural layout achieves acceptable stiffness, the spanwise distribution of spar thickness is problematic. As currently dimensioned, the carbon spar caps at $25 \%$ span are relatively thin. At 50\% span, they are quite thick. Although adding spar cap plies between $25 \%$ and $50 \%$ can be done, this is uncommon in commercial blades. This "double-taper" of the spar cap could be eliminated by dimensioning the $25 \%$ station to match the thickness of the $50 \%$ station. This would result, though, in a relatively small contribution to the clearance margin relative to the weight and cost of carbon fibers used in doing so. Also, the $75 \%$ span station spar cap thickness is lower than the adjacent stations. While this feature would not be desirable in a final spar design, the dimensional difference in this region is not large and so should not present significant problems.

Achieving acceptable clearance for the RBR tip and associated mechanisms remained challenging for configuration 12. Figure 13 depicts the OML profiles for the retractable tip and inner blade at the cutline. The gap between the two profiles represents the maximum theoretical clearance to accommodate structural laminate and whatever bearings or hardware would be required at the interface. Figure 14 shows the same profiles, along with a representation of the spar cap dimensions assumed in the structural model of configuration 12. As the figure indicates, achieving acceptable clearance is feasible, but would still present practical challenges.

Review of these figures also reveals that the assumption of self-scaling the airfoil at the cutline complicates the challenges associated with clearance and bearing mechanisms. Specifically, the wall thickness between the inner and outer profiles varies significantly. The gap, which represents the available envelope for structural laminate, is largest in the aft portion of the highpressure surface and smallest at the trialing edge of the RBR tip. This trend is not conducive to a structurally efficient spar for the inner blade.

Having identified some of these practical challenges, GEC decided that configuration 12 was close enough to feasibility to proceed with detailed modeling and COE calculations. Practical issues and challenges will be addressed further in Section 0. 


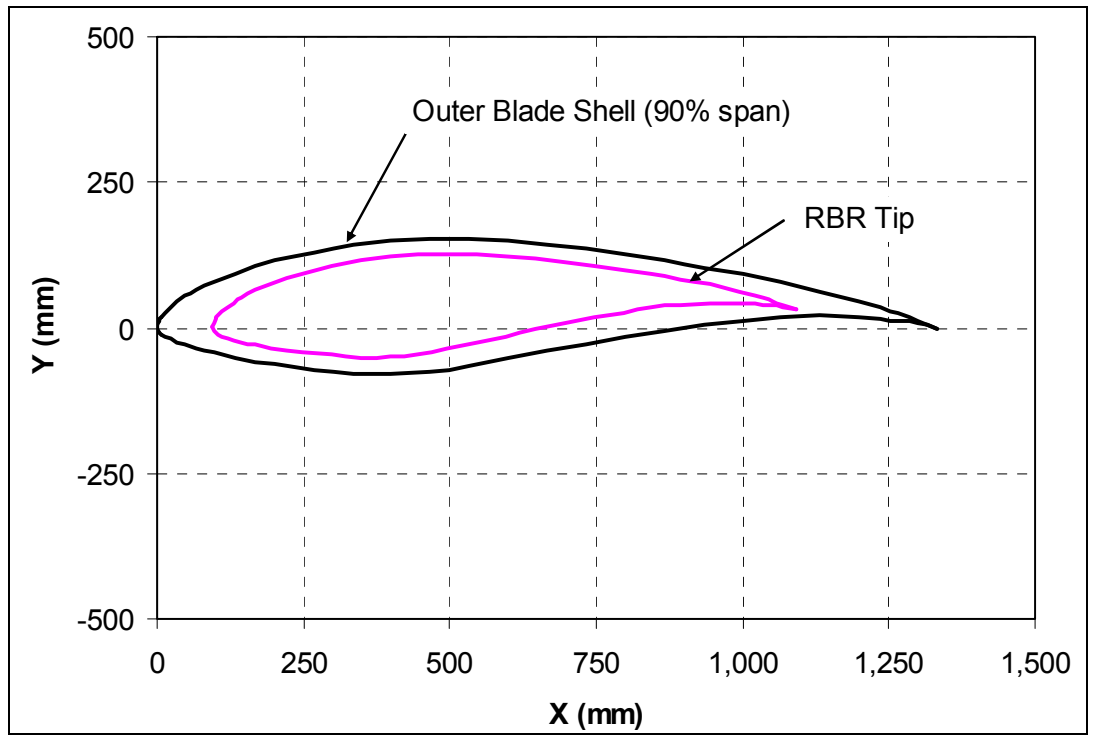

Figure 13. Clearance between RBR tip and inner-blade profile for configuration 12

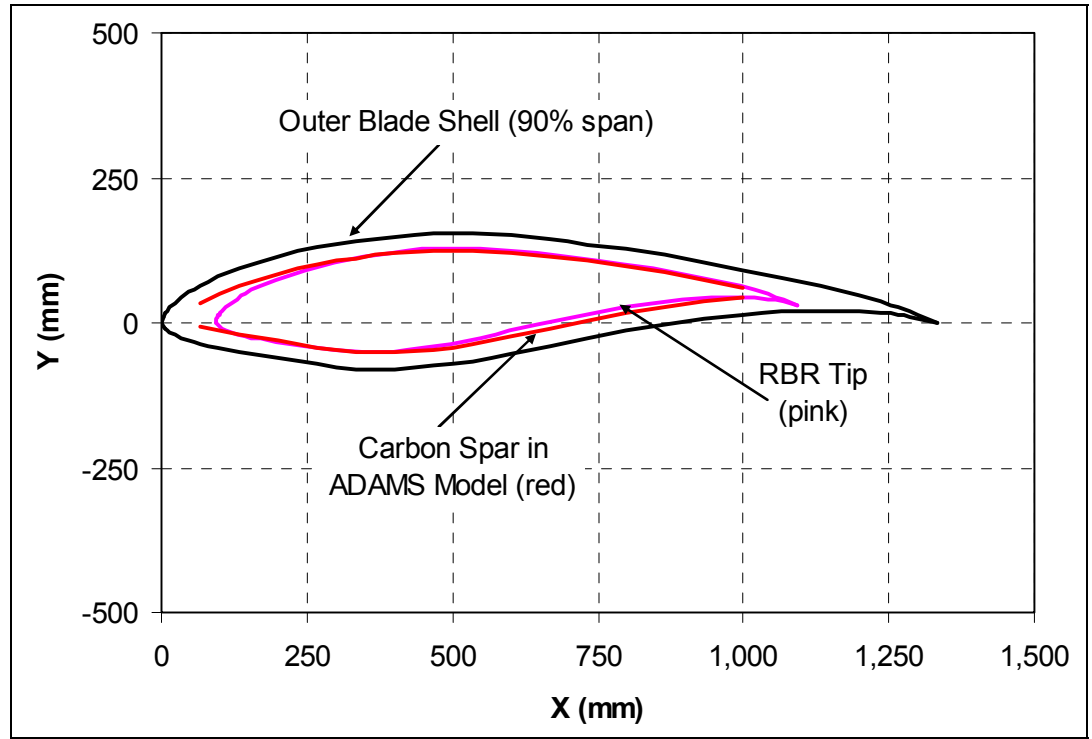

Figure 14. Comparison of RBR tip profile with inner-blade spar for configuration 12

\section{Tip Retraction Mechanism Modeling}

A rack and pinion with a servo motor was selected as the (virtual) mechanism to drive the extendable/retractable blade tip. This mechanism has a desirable property in that the motor inertia, when geared down to obtain low speeds of blade tip extension, acts as a large inertial lag on the deployment of the tip. As a result, a control algorithm design can be used that can maintain a tight tolerance on the blade tip extension length without requiring very high gain. Table 15 lists the properties of the mechanism. 


\section{Tip Servo Control}

The tip position demand is calculated as a function of wind speed that has been filtered with a low pass filter. The position demand is corrected in a command generator that imposes a rate limit, then fed to the servo motor control. The tip servomotor is controlled with a state-spacetype controller with an appended integral on the position error. The state-space model is a simple rigid body model of the tip mass plus servo motor inertia. The motor torque is the control input. The gains were selected using the linear quadratic regulator (LQR) function in MATLAB. Table 15 lists the controller parameters.

Table 15. RBR Tip Mechanism and Control Description

\begin{tabular}{|l|l|}
\hline \multicolumn{1}{|c|}{ Parameter } & \multicolumn{1}{c|}{ Value } \\
\hline Total mechanism mass per blade $(\mathrm{kg})$ & 520.0 \\
\hline Motor inertia $\left(\mathrm{kg} \cdot \mathrm{m}^{2}\right)$ & 0.00225 \\
\hline Motor to pinion gear ratio & $1000: 1$ \\
\hline Pinion radius $(\mathrm{m})$ & 0.15 \\
\hline Tip extension rate limit (iter\#1, iter\#2; $\mathrm{m} / \mathrm{s})$ & $0.10,0.02$ \\
\hline Wind speed filter time constant $(\mathrm{s})$ & 30.0 \\
\hline Wind speed to tip retraction function & $\mathrm{R}=37 \mathrm{~m}-4.2^{*}$ wind speed \\
\hline Time constant for tip retraction command generator $(\mathrm{s})$ & 50.0 \\
\hline Tip extension position state gain $(\mathrm{N} \cdot \mathrm{m} / \mathrm{m})$ & 382.3 \\
\hline Tip extension velocity state gain $[\mathrm{N} \cdot \mathrm{m} /(\mathrm{m} / \mathrm{s})]$ & 486.3 \\
\hline Tip extension position error integral gain $[\mathrm{N} \cdot \mathrm{m} /(\mathrm{m} \cdot \mathrm{s})]$ & 150.0 \\
\hline
\end{tabular}

\section{ADAMS Model}

The ADAMS model of the RBR is a modification of the model for the baseline turbine. The blade has been altered to incorporate changes to the structural properties. The tip section is attached to the inboard blade sections via a linear translational joint.

One drawback to the ADAMS model is that the bearings for the tip mechanism are not modeled with complete accuracy. For example, ADAMS cannot track the changing contact locations for a linear bearing. As a result, the bearing reaction forces are not applied in the correct locations if the tip has changed position from its initial definition. This has implications for the load transfer between the tip spar and the shell of the inboard part of the blade. As an approximate fix, GEC placed spring elements in the model to assist in the load transfer between tip spar and blade shell.

\section{Controls}

The standard turbine controls were modified to include a torque speed curve that is dependent on both rotor radius and rpm and a PI control for speed regulation with blade pitch. Figure 15 depicts an example of operation in moderate winds. 


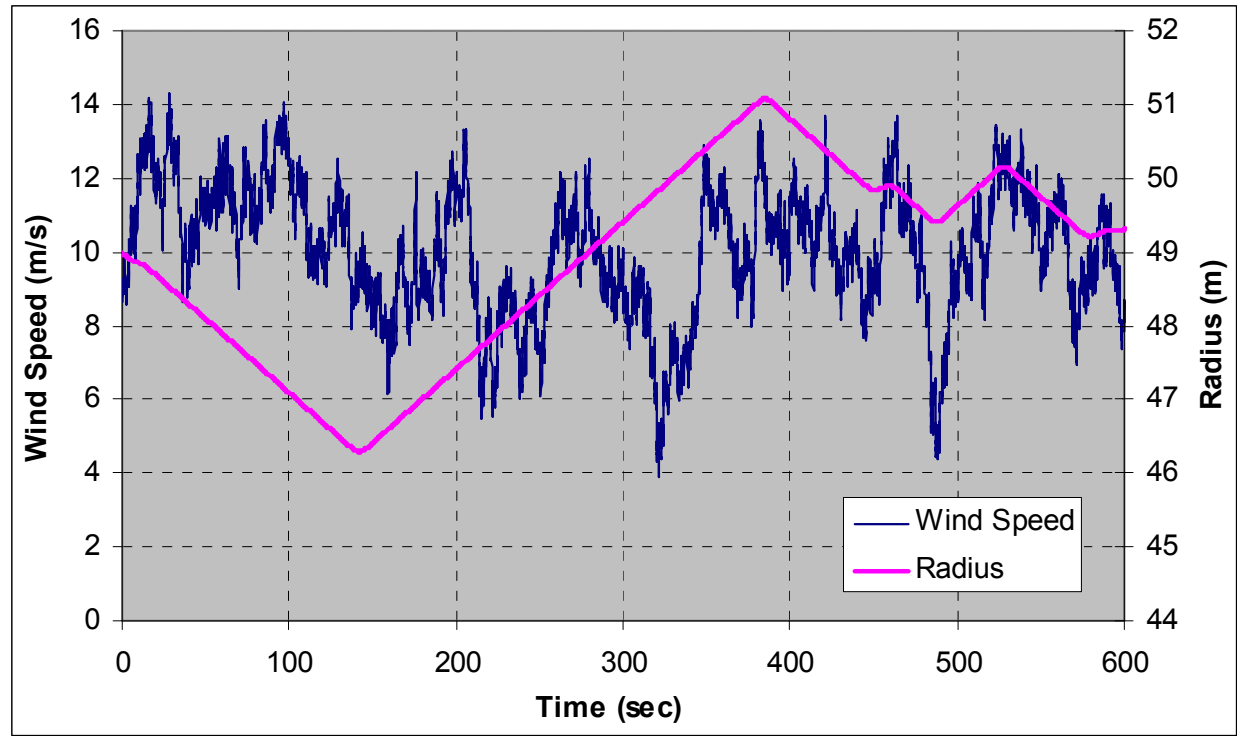

Figure 15. RBR operation in moderate winds.

\section{Loads and COE Results}

Using the modified model, GEC ran a selected set of IEC load cases in ADAMS for the baseline turbine. These cases included load cases $1 \mathrm{a}$ and $1 \mathrm{~b}$ for normal operation in turbulence, extreme 50 -year return wind speed with turbulence, and most of the extreme deterministic gust cases. Specifically for the RBR, many of the extreme gust cases were run at a range of wind speeds to accommodate the range of diameters at which the turbine can operate. Figures 16 and 17 compare the loads to the baseline. The load cases that result in the maximum values for specific loads are compared in Table 16. Appendix D summarizes IEC coordinate definitions and abbreviations used for load cases.

The added component cost and associated $\mathrm{AEP}_{\text {net }}$ are input to the $\mathrm{COE}$ model for the selected configurations. Table 17 shows the results.

The net AEP is based on the gross AEP calculated from the power curve shown in Figure 12 minus the losses prescribed by the National Wind Technology Center (NWTC) COE model plus the losses from control and turbulence effects. The O\&M increase is the amount above the baseline O\&M cost of $\$ 25 /$ rated $\mathrm{kW} /$ year that is assessed for the RBR (and was prescribed in the NREL RFP).

The baseline and RBR power curves are ideal quasi-static curves based on WT PERF calculations. Investigators used the results from the ADAMS simulations to estimate control and turbulence losses. The losses applied to the gross AEP results from Tables 7 and 10 are detailed in Table 18. The control and turbulence losses for the RBR configuration are considerably higher than for the baseline because of the averaging effect on the rotor diameter. Because the rotor diameter is constrained to be a maximum, all deviations are downward in wind speeds below about $10 \mathrm{~m} / \mathrm{s}$. In wind speeds above $10 \mathrm{~m} / \mathrm{s}$ the diameter can be either side of nominal and so average out. In high winds the turbine power output is regulated with pitch despite the diameter. 
Control and turbulence losses, then, extend into wind speeds that are lower than just the "knee" of the curve.

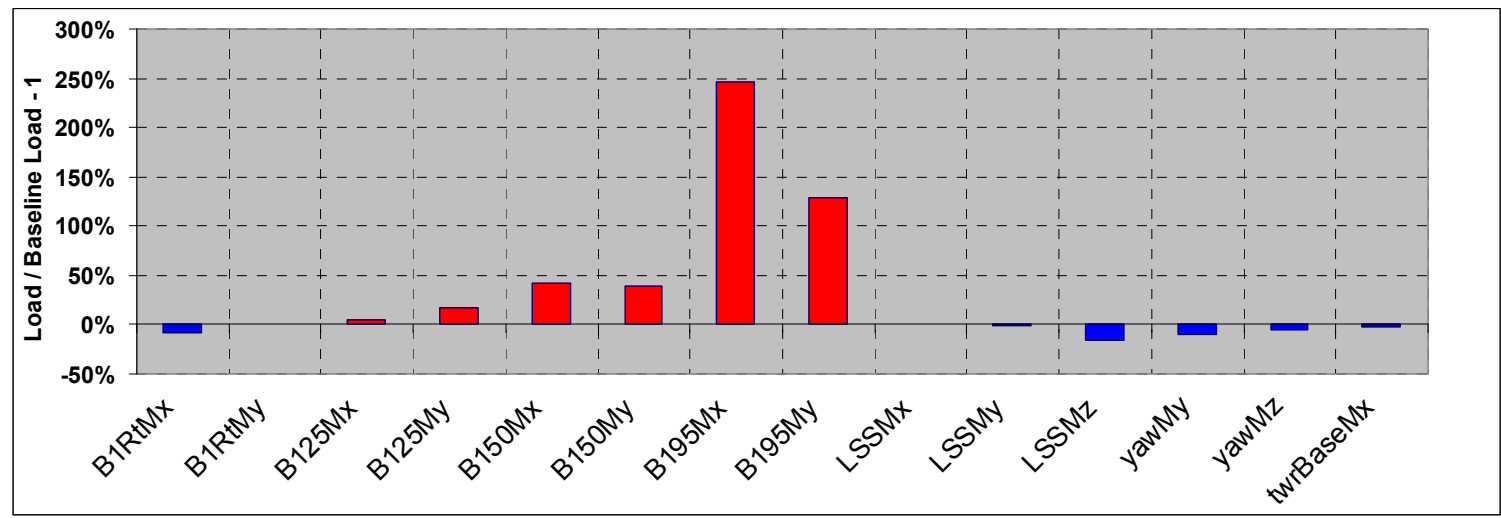

Figure 16. Change in peak loads relative to baseline for RBR

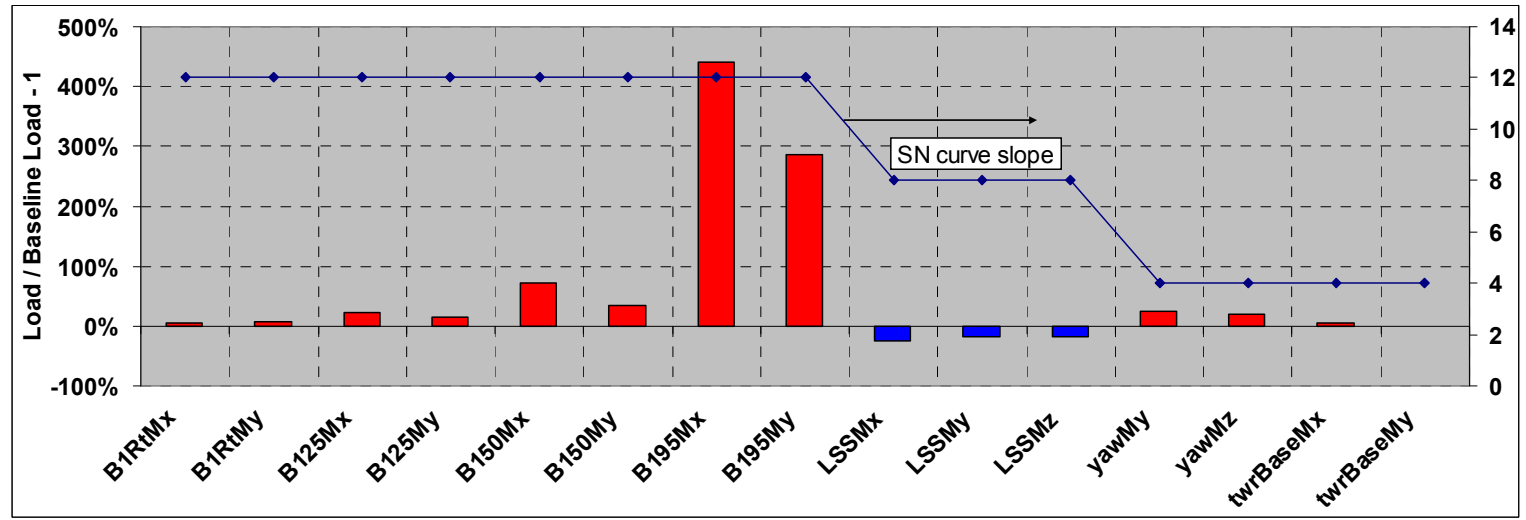

Figure 17. Change in fatigue loads relative to baseline for RBR

Table 16. Load Cases for Maximum Loads: RBR versus Baseline

\begin{tabular}{|l|l|l|}
\hline \multicolumn{1}{|c|}{ Load } & $\begin{array}{c}\text { Baseline } \\
\text { Load Case for } \\
\text { Maximum }\end{array}$ & \multicolumn{1}{c|}{$\begin{array}{c}\text { RBR } \\
\text { Load Case for } \\
\text { Maximum }\end{array}$} \\
\hline B1rtMx & ECDPR & 22ms3 \\
\hline B1rtMy & ECDPR & ECDNR_10ms \\
\hline B125Mx & EOG50R & $22 m s 3$ \\
\hline B125My & ECDNR & $8 \mathrm{~ms} 4$ \\
\hline B150Mx & ECDPR & $22 \mathrm{ms3}$ \\
\hline B150My & ECDPR & $8 \mathrm{~ms} 4$ \\
\hline B195Mx & ECDPR & ECGR_10ms \\
\hline B195My & ECDPR & ewm015 \\
\hline IsshubMx & $24 m s 4$ & $24 m s 6$ \\
\hline IsshubMy & ECDPR & ECDNR_10ms \\
\hline IsshubMz & ECDPR & ECDNR_10ms \\
\hline yawbrgMy & $22 m s 5$ & $22 m s 1$ \\
\hline yawbrgMz & $20 m s 1$ & $24 m s 5$ \\
\hline twrbaseMx & ewm501 & ewm506 \\
\hline
\end{tabular}




\begin{tabular}{|l|l|l|}
\hline \multicolumn{1}{|c|}{ Load } & \multicolumn{1}{|c|}{$\begin{array}{c}\text { Baseline } \\
\text { Load Case for } \\
\text { Maximum }\end{array}$} & $\begin{array}{c}\text { RBR } \\
\text { Load Case for } \\
\text { Maximum }\end{array}$ \\
\hline twrbaseMy & ewm013 & ewm013 \\
\hline Tip deflection & ECDPR & $8 \mathrm{~ms} 4$ \\
\hline
\end{tabular}

Table 17. COE Results for RBR

\begin{tabular}{|c|c|c|c|c|c|c|}
\hline \multirow{2}{*}{ Configuration } & \multirow{2}{*}{$\begin{array}{l}\text { Mechanism } \\
\text { Cost }(\$, \text { total) }\end{array}$} & \multirow{2}{*}{$\begin{array}{c}\text { O\&M Cost } \\
\text { Increase (\%) }\end{array}$} & \multicolumn{2}{|c|}{ COE $(\$ / k W h)$} & \multirow{2}{*}{\multicolumn{2}{|c|}{$\begin{array}{c}\% \text { Change from } \\
\text { Baseline }\end{array}$}} \\
\hline & & & Class 4 & Class 6 & & \\
\hline Baseline & 0 & 0 & 0.0513 & 0.0493 & 0.0 & 0.0 \\
\hline RBR 12 & 300,000 & 10 & 0.0418 & 0.0416 & -3.9 & 0.6 \\
\hline
\end{tabular}

Table 18. Losses Used for Net AEP Calculations

\begin{tabular}{|l|l|l|}
\hline \multicolumn{1}{|c|}{ Item } & Value for Baseline & Value for RBR \\
\hline Soiling losses & 0.035 & 0.035 \\
\hline Wake losses & 0.050 & 0.050 \\
\hline Controls/turbulence & 0.005 & 0.022 \\
\hline Availability & 0.980 & 0.980 \\
\hline Total & 0.106 & 0.121 \\
\hline
\end{tabular}

\section{Discussion and Conclusions}

As this discussion has described, numerous challenges must be overcome in implementing the RBR technology. A primary issue is achieving the required stiffness within the limits of costeffective materials and manufacturing processes. Using the baseline blade OML as the available structural envelope, the structural modeling conducted in this study indicates that achieving the needed stiffness is feasible, but that optimizing for structural and manufacturing efficiency will present difficulties.

The laminate properties used for structural modeling of configuration 12 (see Table 11) assume a carbon-spar fiber-volume fraction that is characteristic of many aerospace applications, but higher than typical for current commercial wind turbines. Although this is not an insurmountable issue, it does imply that some advancement in blade manufacturing processes may be required to facilitate the cost-effective manufacture of blade structure with very stiff laminate.

The scaling and fit of the retractable tip is another issue to consider. Figure 13 illustrates that self-similar scaling of the airfoil at the cutline does not result in a favorable shape to nest with the inner blade. GEC investigated this issue by using CAD modeling to create an airfoil shape with a near-constant surface normal offset. The results are depicted in Figure 18, which indicates two significant changes in the aerodynamic shapes. First, there is a noticeable reduction in the "reflex" at the trailing edge, which will reduce the effective camber of the tip airfoil. Second, there is an approximate $1.8^{\circ}$ rotation of the chord line toward a lower AOA. Decambering and reduced AOA would have a compounding effect because each would tend to reduce lift. 


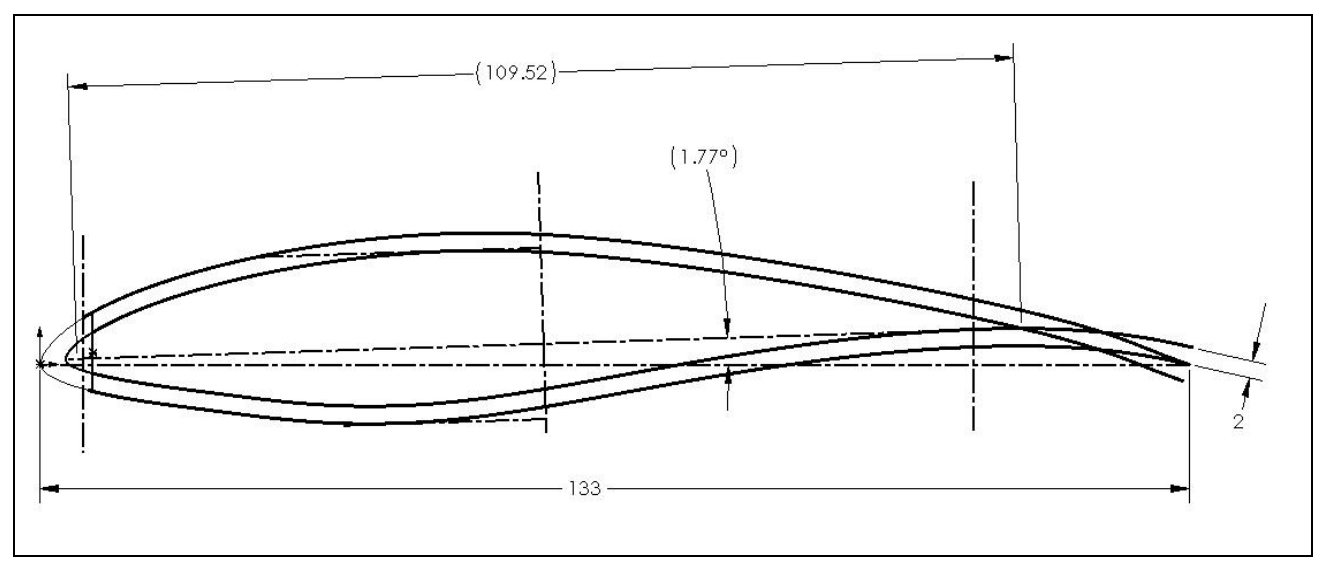

Figure 18. CAD modeling of tip aerodynamic profile

GEC used the XFOIL code (Drela 2001) to evaluate the effect of the shape modification on the S826 aerodynamics. The results are shown in Figure 19. As expected, the decambering results in a downward shift of the lift curve at a given AOA. Note that XFOIL overpredicts the maximum lift coefficient, which is typical for viscous-inviscid interaction codes. For this study, though, the most important effect is the reduction in lift in the pre-stall region of the lift curve, which is reliably modeled with XFOIL. Also note that XFOIL predicts an unrealistically low drag value for the modified airfoil. This was ignored in the following calculations (i.e., the baseline S826 drag was assumed).

WT PERF analyses were performed to evaluate the effect of these airfoil modifications on RBR performance. The resulting $\mathrm{C}_{\mathrm{P}}$-TSR curves are shown in Figure 20. The WT_PERF models include both the effects on the aerodynamic coefficients (as seen in Figure 19) and the change in effective twist of approximately $1.8^{\circ}$.

The reduction in rotor performance is meaningful. Using the original $\mathrm{S} 826$ shape, the peak $\mathrm{C}_{\mathrm{P}}$ is nearly 0.49 . With the shape modified to reflect a near-constant inset, the peak $\mathrm{C}_{\mathrm{P}}$ is reduced to slightly above 0.45 , a reduction of about $7.5 \%$ in peak efficiency. Note that the comparison of Figure 20 was generated for RBR configuration 12 with the tip fully extended, and that the effect of the S826 shape modifications on rotor efficiency would diminish as the blade was retracted. Taking the various operating regions into account, if the S826 shape modifications of Figure 18 were implemented, GEC estimates that the reduction in AEP would be in the range from 3\% to $4 \%$.

Because WT_PERF (and all blade element momentum [BEM]-type analyses) assumes independent annuli in the rotor disk, the actual performance loss for the geometry considered would be larger than the estimates described in this section. The reduced chord dimension, the decambering of the airfoil shape, and the step changes in twist angle all combine in the direction of reduced blade loading. The discontinuity in loading would in turn result in a shed vortex, which would generally be undesirable because it would lower power performance and raise aeroacoustic noise.

The aerodynamic impact of the shape changes required to obtain good "nesting" characteristics for the S826 is significant enough to motivate the consideration of alternative airfoil shapes. In 
particular, an optimized RBR design might employ a purpose-designed family of airfoil shapes to facilitate structural nesting while mitigating unfavorable aerodynamic effects.

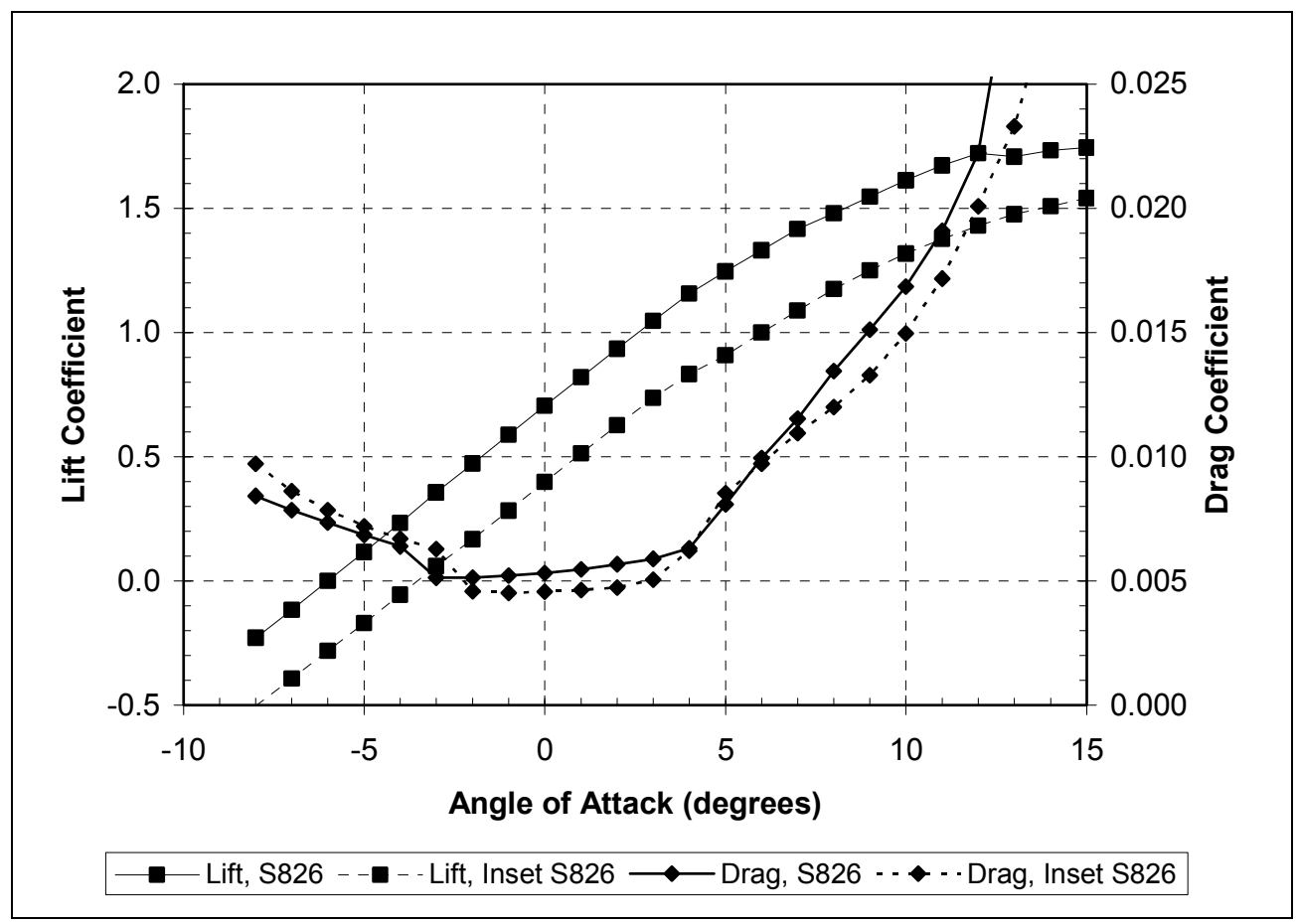

Figure 19. Aerodynamic effect of S826 shape modification (constant inset)

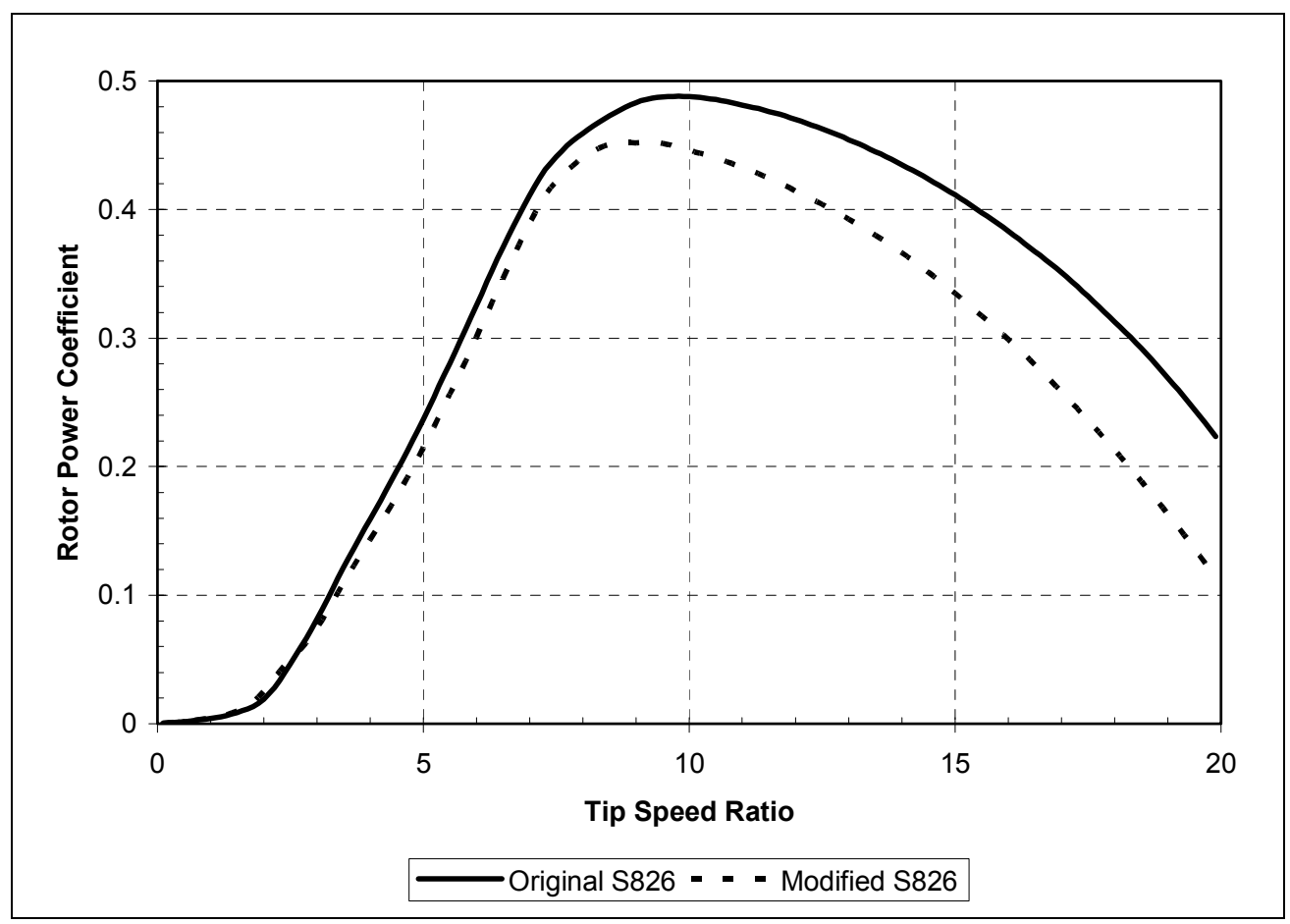

Figure 20. Effect of S826 shape on rotor efficiency for RBR configuration 12. 
The bearing and actuation mechanisms also present major challenges for successful implementation of RBR technology. Integration of these mechanisms includes the design of the hardware and hard points for attachment, along with consideration of the load transfer between parts. The bearing/sliding mechanism would need to operate without binding under load conditions varied by human operators. The internal structure of the inner blade part would need to accommodate the tip section when it is fully retracted and adequately support the tip when it is fully extended. To minimize associated noise, the interface between the two parts would also need to be smooth.

Addressing the bending compliance of the two nested parts is closely related to designing appropriate bearings. The bending stiffness of the tip and the inner blade would have differing magnitudes and spanwise variations. In general, the inner blade would be substantially stiffer than the retractable tip and would have a different shape for given bending loads. When the RBR tip is retracted, bending of the main blade structure would tend to bend the nested tip as well. The extent of this bending and shape under load will depend on the design of the bearing/reaction points. This mismatch in bending compliance and associated load transfer will need to be accommodated at every position in the tip extension/retraction range.

The modeling of configuration 12 indicates that the RBR technology holds some promise for enabling meaningful COE reductions. This conclusion, however, is highly dependent on the development and demonstration of the associated structure, mechanisms, and control strategies. The COE benefits of this technology would depend heavily on the impact of O\&M costs and turbine availability. Although GEC expects that the 10\% O\&M increase used in the current modeling would be achievable, the complexity of this system introduces risk for higher penalties.

This modeling indicated that achieving sufficient stiffness while allowing the integration of the RBR tip and the main structure presents significant technical challenges. Realizing a commercially optimal RBR would likely be facilitated by a design approach that integrates aerodynamic, structural, and mechanism design considerations from the start instead of trying to retrofit an RBR into an existing blade profile. A fully optimized RBR might require that new purpose-designed airfoils be developed to facilitate structural nesting while mitigating performance losses. 


\section{Active Aerodynamic Devices}

GEC's work in this area evaluated devices or methods that can be used to actively alter the local aerodynamic properties of the rotor blade. Recent technological advancements in controls, sensors, mechanisms, materials, and manufacturing motivated this new look at general concepts that are under consideration for aerospace and other applications. These devices would typically have response times on the order of, or faster than, a full-span variable-pitch system.

\section{Device Review}

Early in the study, GEC performed an extensive literature review to identify candidate devices. In addition, GEC continued to review and evaluate alternative control technologies throughout the duration of the project, both by keeping up with the literature and by having discussions with numerous developers and vendors of active control technologies.

Although a wide range of technologies is available, GEC considered aerodynamic control mechanisms that fall mainly into two categories: boundary layer control and effective camber change.

\section{Boundary Layer Control}

A major mechanism for aerodynamic control is boundary layer modification, which can be achieved with vortex generators (Figure 21), leading-edge slats, trip strips, or other methods for adding or removing kinetic energy to the boundary layer. The effect of this control method is shown in Figure 22, which indicates a general trend of increasing $\mathrm{C}_{\mathrm{L}, \mathrm{Max}}$ with boundary layer "augmentation." This presumes that the modification delays the onset of trailing-edge separation and subsequent stall. An opposite effect on lift curves might be realized with boundary layer tripping. Although the effect of vortex generators and boundary layer tripping is wellestablished, the application to commercial designs has so far been passive (i.e., use of fixedgeometry vortex generators).

GEC investigators considered the feasibility of using active boundary layer modification of local airfoil sections to control turbine loads. The technologies that fall under this heading include leading edge slats, active vortex generators, plasma actuators (Post and Corke 2004), and boundary layer suction/blowing. Circulation control technology does not strictly fit in the category of boundary layer control, but it has similar effect on lift characteristics (Trevelyan et al. 2001). Figure 22 is a generic representation of the effect of boundary layer control devices on the lift coefficient. Note that these devices do not have a significant effect on the linear portion of the lift curve.

Modern variable-speed, pitch-to-feather wind turbines tend to operate predominantly in the linear region of the lift curve. Figure 23 shows the nominal steady operating points on the lift curves for the baseline blade design for several spanwise locations. At each spanwise location, points are shown on the lift curves for wind speeds from 4 to $24 \mathrm{~m} / \mathrm{s}$ in $1 \mathrm{~m} / \mathrm{s}$ increments. Note that at low wind speeds the points are on top of each other because the turbine is operating at a fixed tip speed ratio and blade pitch. As wind speed increases, the pitch moves to feather to regulate power. The arrows indicate the trend of the points with increasing wind speed. These trends are generally monotonic. 
Except for the most inboard sections, as wind speed increases, the operating points trend toward lower angles of attack and hence move farther from the region of the lift curve affected by boundary layer control. This occurs because the pitch changes toward feather dominate angle of attack changes toward stall because of increasing wind speed (RPM is constant once the operating point is above rated power). This is a necessary effect to realize power regulation in increasing wind. At the $25 \%$ span, the low value of the velocity vector caused by rotation causes the angle of attack to move to stall faster than the pitch changes compensate. In general, the airfoils will operate near these nominal points except where large wind speed transients are present. The baseline blade design is representative of typical industry practice.

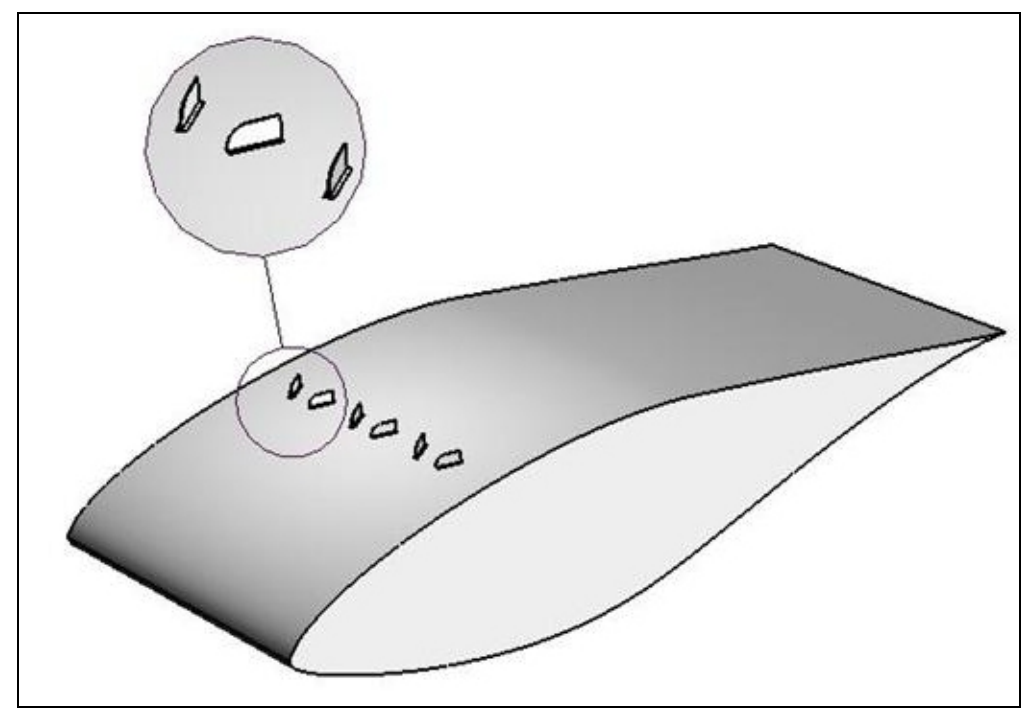

Figure 21. Vortex generators (counter-rotating array)

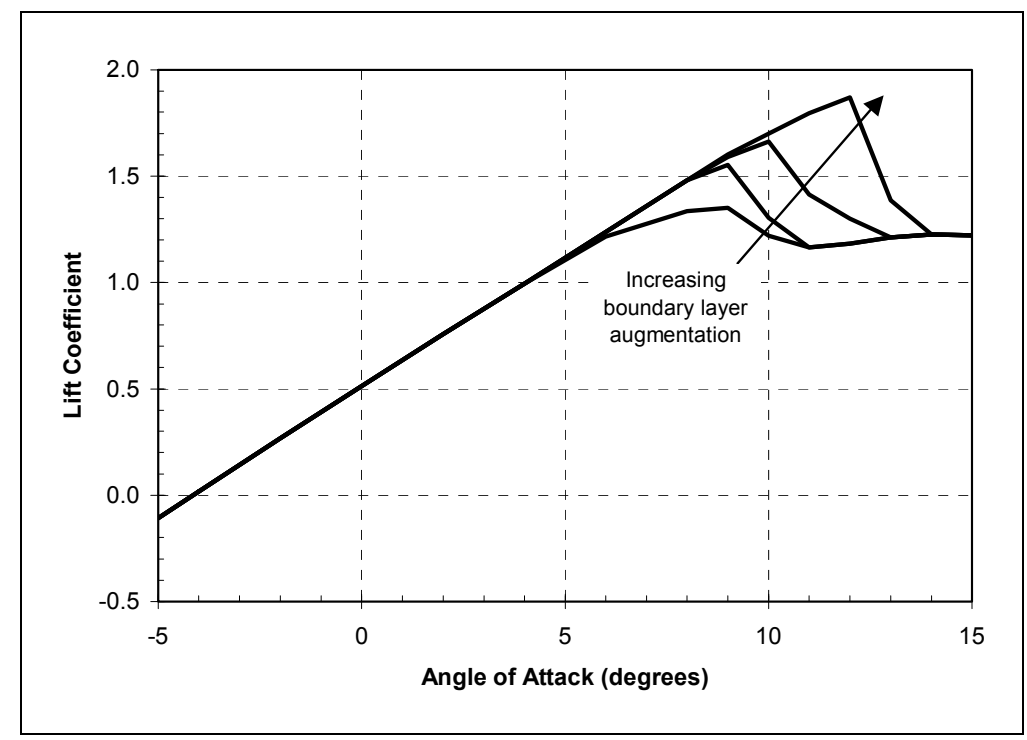

Figure 22. Lift curve changes resulting from boundary layer modification 

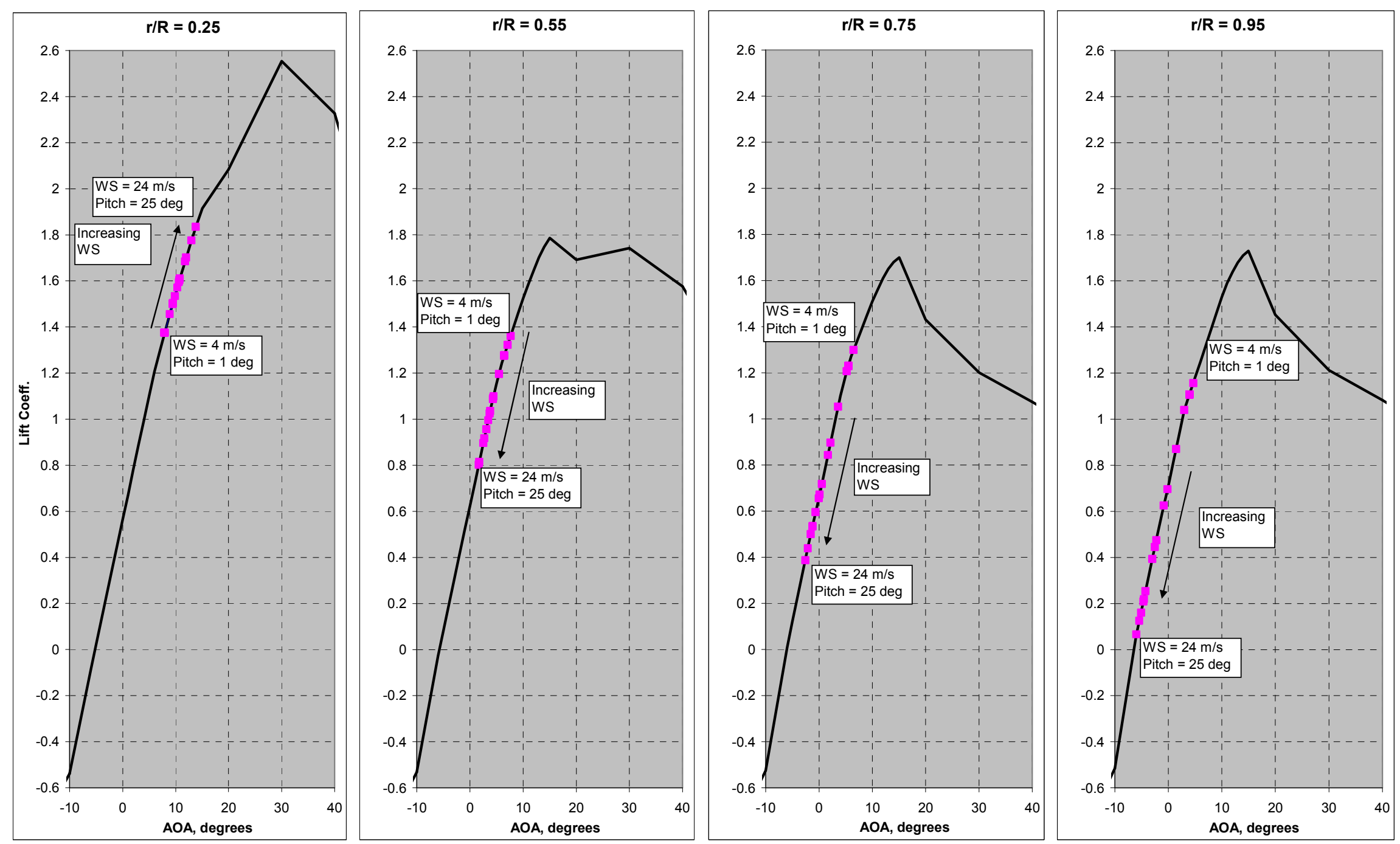

Figure 23. Nominal operating points on the lift curves for selected spanwise locations 
Although the properties and trends described here do leave open some opportunity for loads control, exploiting these opportunities would be quite challenging. Most control design and implementation approaches require the system to exhibit reasonably linear behavior, particularly in the neighborhood of the system's nominal operating point(s). Using boundary layer modification devices to control loads would require highly nonlinear control analysis and implementation. It would also likely require accurate measurement or estimation of the instantaneous aerodynamic state of the airfoil. Any control algorithm would have to detect increases in the angle of attack that are sufficiently within the range of effect of the control devices.

The control techniques that are currently being researched by the wind industry are still mostly based on design methods that require linear behavior. These approaches will not accommodate actuators that do not have a linear effect near the nominal operating point of the turbine.

A possible alternative might enable better exploitation of these aerodynamic devices for loads control-redesigning the blade so that the operating points are closer to stall. This strategy, however, poses its own risks. A blade designed in this way would likely be less than optimal from a performance standpoint. In addition, operation near stall is likely to result in a less wellbehaved aerodynamic response and possibly in reduced energy capture.

\section{Camber Modifications}

A change in effective camber can be achieved with conventional control devices such as flaps, ailerons, Gurney flaps, and trailing-edge wedges (Kentfield 1993, 1994). Figure 24 illustrates typical changes in airfoil lift curve characteristics resulting from changes in effective camber. In general, increased camber will reduce the angle for zero lift and increase the maximum lift coefficient $\left(\mathrm{C}_{\mathrm{L}, \mathrm{Max}}\right)$. The general behavior shown in Figure 24 is representative for a wide range of devices. Changes to the lift-drag polar (i.e., effect on magnitude of, and angle of incidence for, maximum lift/drag), though, will depend strongly on both the original airfoil characteristics and details of the camber modification method.

Figure 25 shows "microtab" devices that can be used to achieve effective camber changes. Aerodynamically, the devices act in the same way as a Gurney flap. A tab protruding from the lower (high-pressure) surface would cause an effective increase in airfoil camber, and a tab protruding from the upper (low-pressure) surface would result in decreased effective camber. Significant work has been done to evaluate the potential use of microtabs for aerodynamic control, using MEM-based technology to actively extend and retract the devices (Yen Nakafuji et al. 2001; Yen Nakafuji et al. 2002; vanDam et al. 2004).

Another method for achieving active change in camber falls under the category of "shapemorphing" technologies. This is illustrated conceptually in Figure 26. The aerodynamics of this method are essentially the same as those of an airfoil trailing-edge flap. But morphing technologies may offer the promise of eliminating the hinges and gaps associated with conventional flaps, which in turn would maintain smoother aerodynamic surfaces with reduced drag. These technologies might also be smaller, with associated benefits of greater ease of integration into the blade structure, faster deployment, and reduced actuation forces. 
Kota and coauthors (2003) discuss the development of compliant mechanisms for use in shape changing of wings. Risø National Laboratory has also been investigating the potential for load reductions via variable trailing-edge geometry (Buhl, Gaunaa, and Bak 2005).

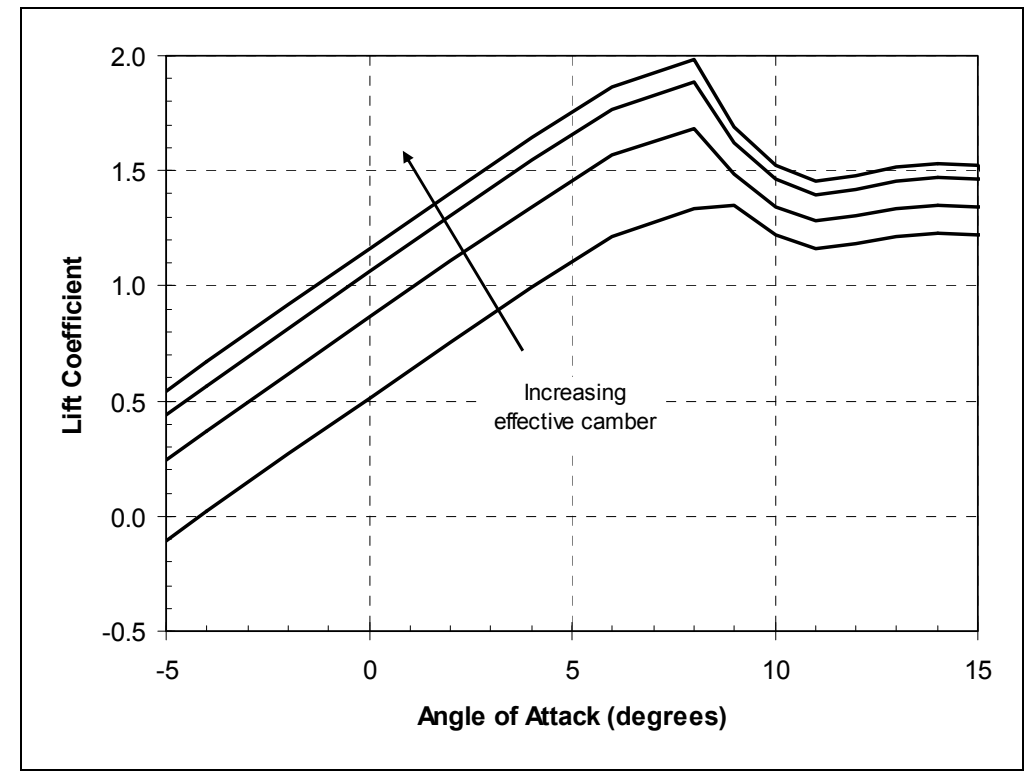

Figure 24. Lift curve changes resulting from increased effective camber

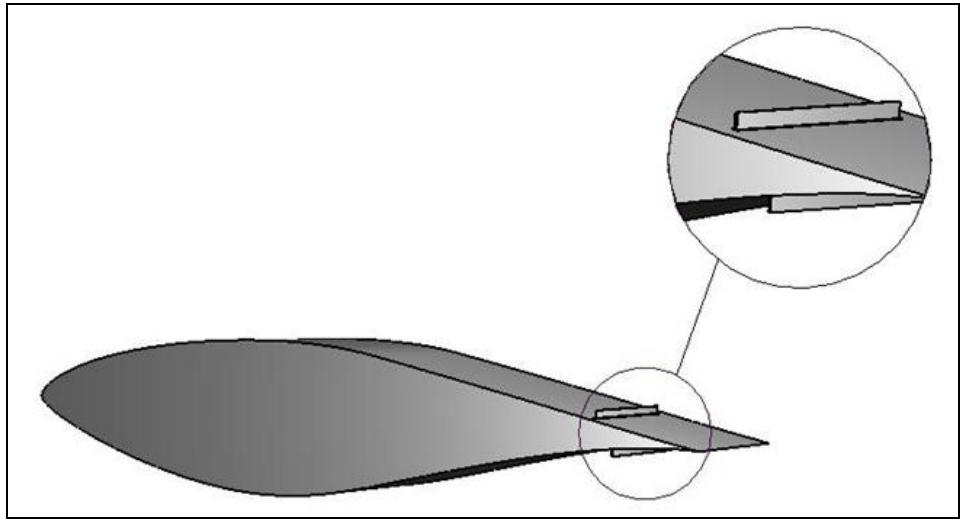

Figure 25. Microtab devices

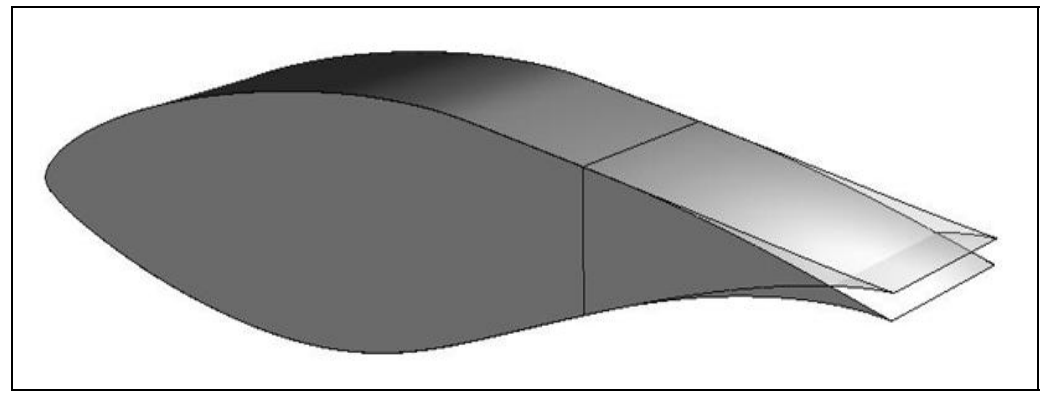

Figure 26. Morphing trailing-edge shape 


\section{Generic Aerodynamic Properties (Camber Modification)}

Because many of the aerodynamic devices considered have very similar effects on the lift curves, GEC decided to model these effects generically. After an extensive literature review, GEC manually developed a set of lift-and-drag curves to represent the camber modification class of devices. An example of these lift and drag curves is shown in Figure 27
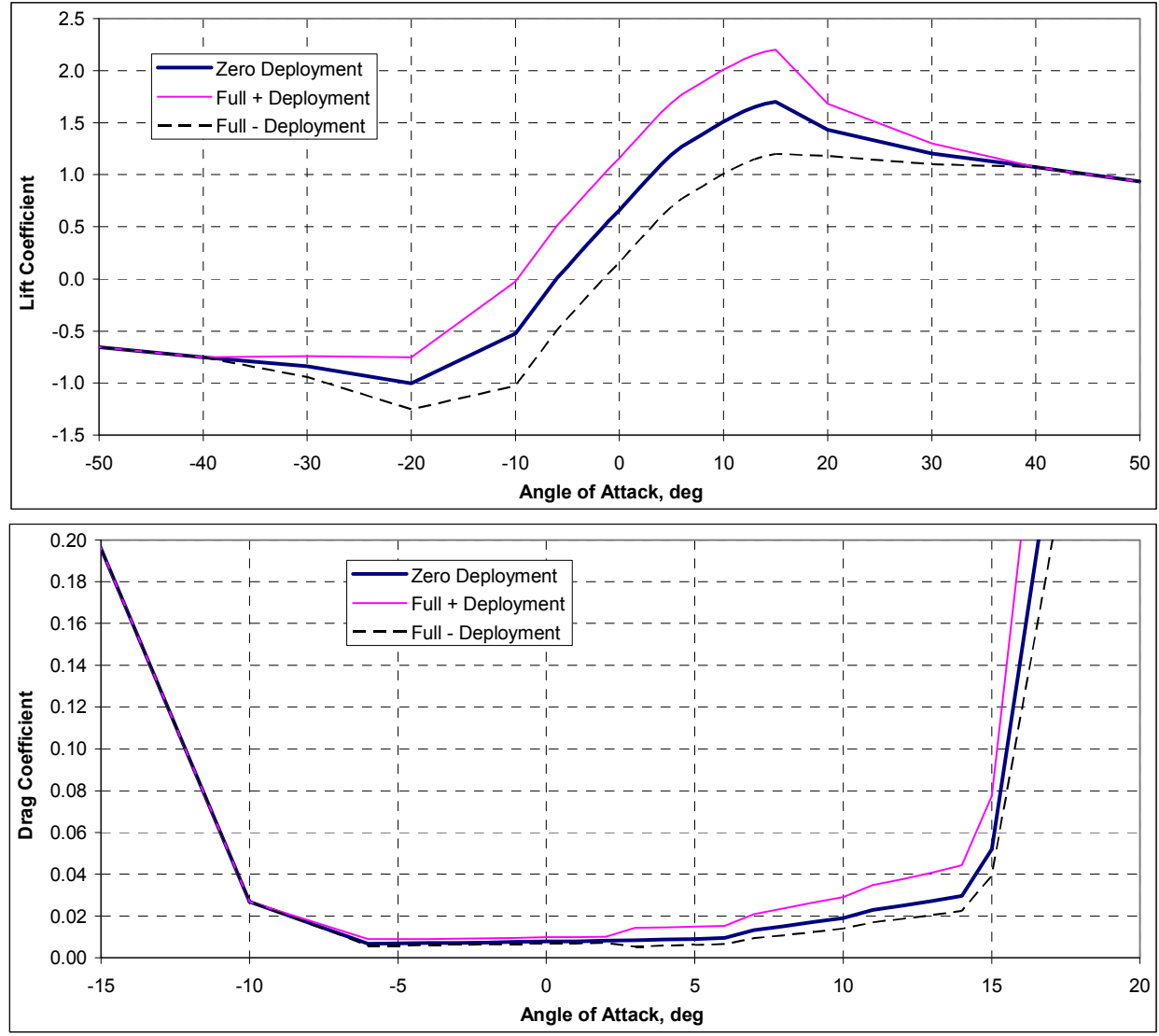

Figure 27. Lift and drag for the $\mathbf{S 8 2 5}$ airfoil with generic camber modification

Developing these curves presented some challenges. Modern commercial wind turbine airfoils tend to be designed to achieve a relatively high lift-to-drag (L/D) ratio, which is realized by maintaining low drag at the design lift condition. The extent to which additional drag is introduced depends on the specific mechanism used to effect the camber change. For devices that mimic a Gurney flap (e.g., microtabs), a drag penalty is inevitable. In theory, morphing trailingedge shapes could be achieved with little or no drag penalty. Although some of the literature reports increasing L/D by using devices such as Gurney flaps, GEC concluded that this was primarily found for airfoils that began with low values of L/D.

After reviewing the literature for candidate devices, GEC established the following guidelines for developing the generic aerodynamic curves:

- A camber change that increased lift was accompanied by an increase in drag.

- A change that decreased lift was accompanied by a decrease in drag, but of smaller magnitude than the drag change associated with lift increase. 
- For the region above $\mathrm{L} / \mathrm{D}=100$, increased lift was not allowed to result in an $\mathrm{L} / \mathrm{D}$ higher than the original airfoil. In practice, this was implemented by first introducing the lift increment, then calculating the associated drag such that the L/D constraint was enforced.

This approach was intended to represent the broadest class of devices under consideration, and to remain consistent with the known properties of current wind turbine airfoil designs. Note that in terms of this study, the load mitigation effects are strongly dominated by lift. GEC took great care in modeling drag, primarily to ensure that the airfoil characteristics were realistic. In addition, note that the baseline airfoil modification curves, as shown in Figure 27, assume relatively high aerodynamic authority (i.e., magnitude of lift change) for the size of device under consideration. To investigate this issue, though, GEC has also performed simulations with reduced aerodynamic authority.

Note that in Figure 27 the imposed limit for lift over drag $(L / D=100)$ was reached at about $3^{\circ}$ angle of attack. At this point, the incremental change in drag becomes noticeably larger. For negative values of angle of attack, the limit $(-\mathrm{L} / \mathrm{D}=100)$ was never reached, and so the baseline drag increment was held constant.

\section{Controls}

When many independently controllable aerodynamic devices are used for turbine control, a multi-input, multioutput control design approach must be employed. GEC used modern statespace-control design methodologies for this research to design controller gains that meet the objectives of load reduction. Specifically, the investigators used the linear quadratic regulator (LQR) method available in MATLAB extensively.

Although the LQR methodology is both powerful and convenient, it does have limitations, and assumptions must be made to employ this method. An LQR controller requires a linear model of the system to be controlled. It also requires knowledge of the values of all states in the model at all times. In practice, the latter requirement is very restrictive. For the purposes of this research, the ADAMS simulation was able to provide the state values necessary for the LQR controller, and the researchers did not use any state estimates.

The requirement for linearity is more of a challenge. The aerodynamic forces that act on the turbine are highly nonlinear functions of the turbine operating states (e.g., RPM, pitch, and wind speed). In addition, the aerodynamic devices themselves are highly nonlinear, particularly in that they have lower and upper bounds to their effectiveness. These bounds are fairly tight, unlike the blade pitch, for example, which can operate across a wide range of pitch angles.

To deal with the nonlinearity in these aerodynamics, the operating range of the turbine was divided into three regions: low wind, above rated wind, and high wind to cutout. In addition, the low wind region was divided into two subregions: operation below maximum rpm and operation at maximum rpm. Controller gains were calculated in each of these regions.

The limitation of the aerodynamic device range of effectiveness is handled by tuning the controller so that these limits are not typically reached during normal operation.

State-space models to be used for control design were derived from the ADAMS model through a linearization procedure (McCoy 2004). In this study, this procedure was supplied with a 
linearization of the aerodynamic effects that result from changes in wind speed, rotor rpm, blade pitch, and aerodynamic device deployment. Figures 28 and 29 show the net shaft aerodynamic thrust and torque derivatives for these variables.. The resulting large state-space model is reduced to the essential fundamental modes listed in Table 19. Additional states are appended for disturbances and error integrals.

The structure of the state-space model and the tuning of the gains were designed to meet the following objectives:

- Regulate rpm at least as well as the baseline PI controller. The addition of the rpm error integral ensures good regulation of the rpm to the specified set point.

- Regulate tower motion at least as well as the baseline tower damping algorithm.

- Reduce fatigue loading of the blades. For example, the vertical and horizontal out-ofplane displacement of the rotor - as expressed in multiblade coordinates - is a steady nonzero value in response to wind shear. This steady value corresponds to a one-per-rotor revolution oscillation in tip displacement on each individual blade. By appending integrals of the vertical and horizontal displacement to the state-space model, the amplitude of the one-per-rotor revolution oscillations can be regulated to zero. This, in turn, leads to more effective cancellation of disturbances such as wind shear.

- Because the LQR control design methodology assumes unbounded linear behavior of the plant and controls, the actuation of the aero devices has a tendency to drift away from a mean of zero in the presence of disturbances such as wind speed. To counter this tendency and keep the aerodynamic devices within their active range with a mean of zero, integrals of device position were appended to the state model. This approach has the added benefit of forcing the independent blade pitch (IBP) to control the more steady disturbances of mean wind speed and wind shear, while the aero devices act on the more rapid turbulence transient disturbances.

A plot of the plant and the closed loop eigenvalues is shown in Figure 30. 

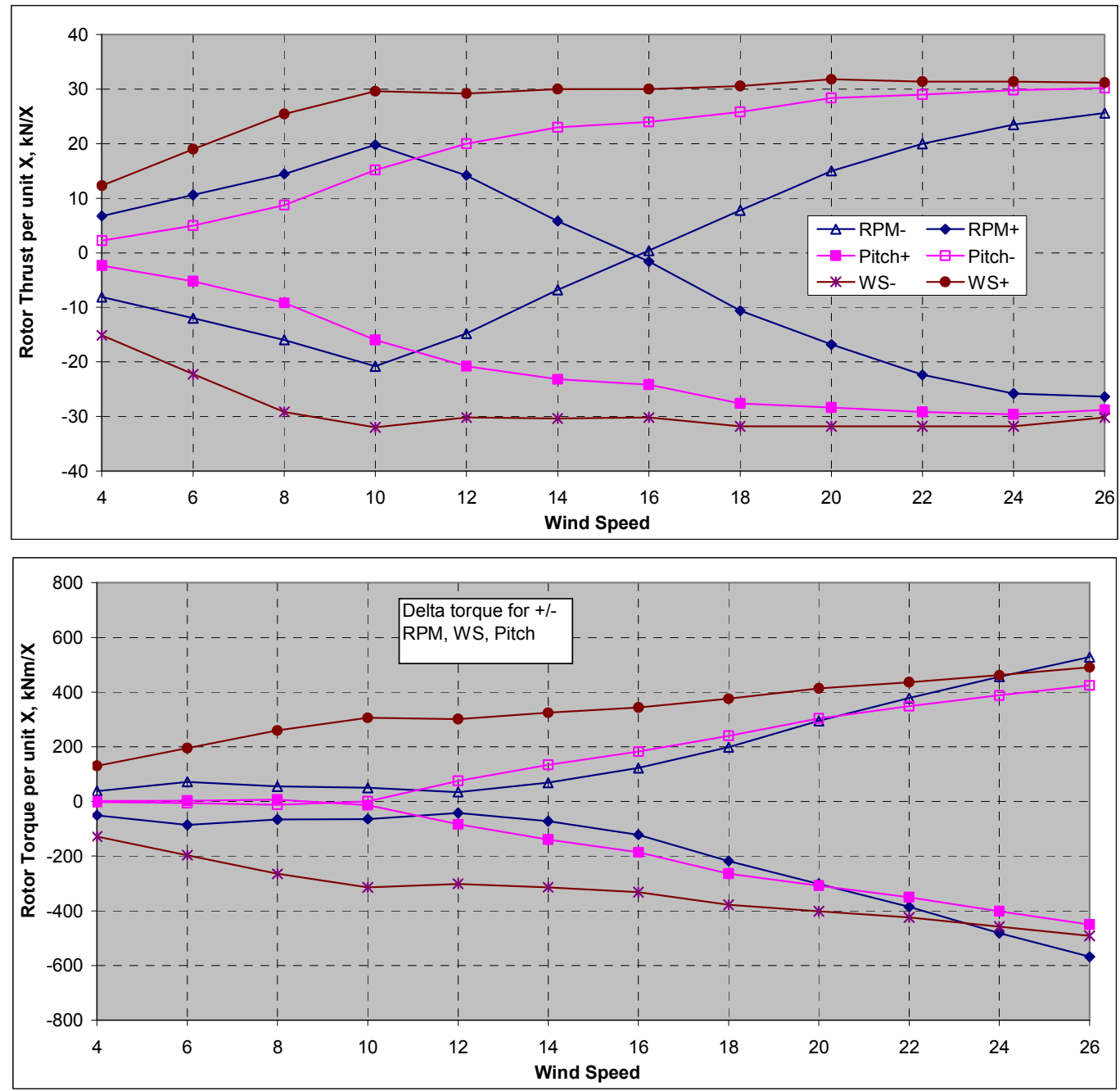

Figure 28. Aerodynamic derivatives versus wind speed for turbine operating variables 

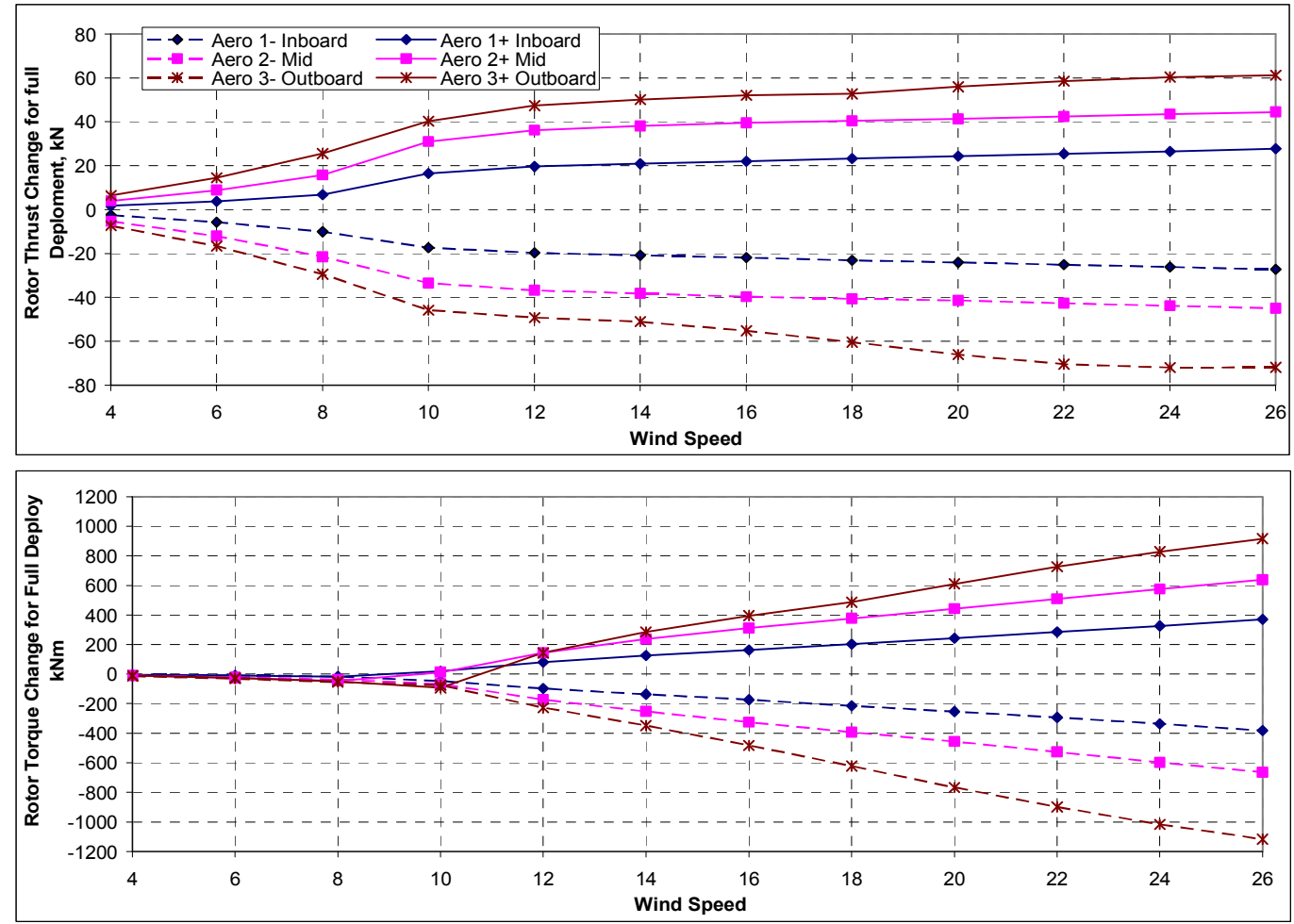

Figure 29. Aerodynamic derivatives versus wind speed for camber modification devices

Appendix C contains example MATLAB code for the control gain selection. The gains calculated by MATLAB were used in the ADAMS simulations. In ADAMS, initial testing of selected controller gains looked at the response of the pitch, blade tip deflection, and RPM to a step change in the wind shear from a shear exponent of 0 up to $100 \mathrm{~s}$ to a shear exponent of 0.2 after $100 \mathrm{~s}$. Figure 31 shows a comparison of the response using the original PI controller to the response with IBP alone, and combined with aerodynamic devices. As intended, the aero devices control the initial transient response to the step in shear. The blade pitch takes over slowly because the shear becomes a persistent disturbance. This allows the aero device to "retract" to the zero deployed condition instead of having the deployed position become the stable operating point. 
Table 19. States for Linear Control Design Model

\begin{tabular}{|l|l|l|}
\hline \multicolumn{1}{|c|}{ Plant State } & \multicolumn{1}{c|}{$\begin{array}{c}\text { Eigenvalue } \\
\text { (at 14 m/s) }\end{array}$} & \multicolumn{1}{c|}{ Description } \\
\hline Tower & $-0.167 \pm 2.014 \mathrm{i}$ & Tower top fore-aft position and velocity \\
\hline Rotor out of plane & $-2.037 \pm 5.321 \mathrm{i}$ & $\begin{array}{l}\text { Rotor asymmetric out of plane position and } \\
\text { velocity in the fixed frame multiblade coordinates }\end{array}$ \\
\hline Rotor out of plane & $-2.071 \pm 6.215 \mathrm{i}$ & $\begin{array}{l}\text { Rotor symmetric out of plane position and } \\
\text { velocity in the fixed frame multiblade coordinates }\end{array}$ \\
\hline Rotor out of plane & $-2.017 \pm 14.395 \mathrm{i}$ & $\begin{array}{l}\text { Rotor asymmetric out of plane position and } \\
\text { velocity in the fixed frame multiblade coordinates }\end{array}$ \\
\hline Rotor in plane & $-1.7759+2.9416 \mathrm{i}$ & Rotor symmetric in plane position and velocity \\
\hline Rotor & -0.182 & Rotor + drivetrain rigid body \\
\hline Blade pitch & -6.25 & Pitch system response \\
\hline & \multicolumn{2}{|c|}{ Controller States } \\
\hline Wind speed & -2.0 & $\begin{array}{l}\text { Three filtered wind speeds: mean, vertical shear, } \\
\text { and horizontal shear (in multiblade coordinates) }\end{array}$ \\
\hline RPM error & 0.0 & Integral \\
\hline $\begin{array}{l}\text { Vertical and horizontal } \\
\text { rotor out of plane } \\
\text { displacement }\end{array}$ & 0.0 & Integral \\
\hline Aero device position & 0.0 & Integral \\
\hline
\end{tabular}

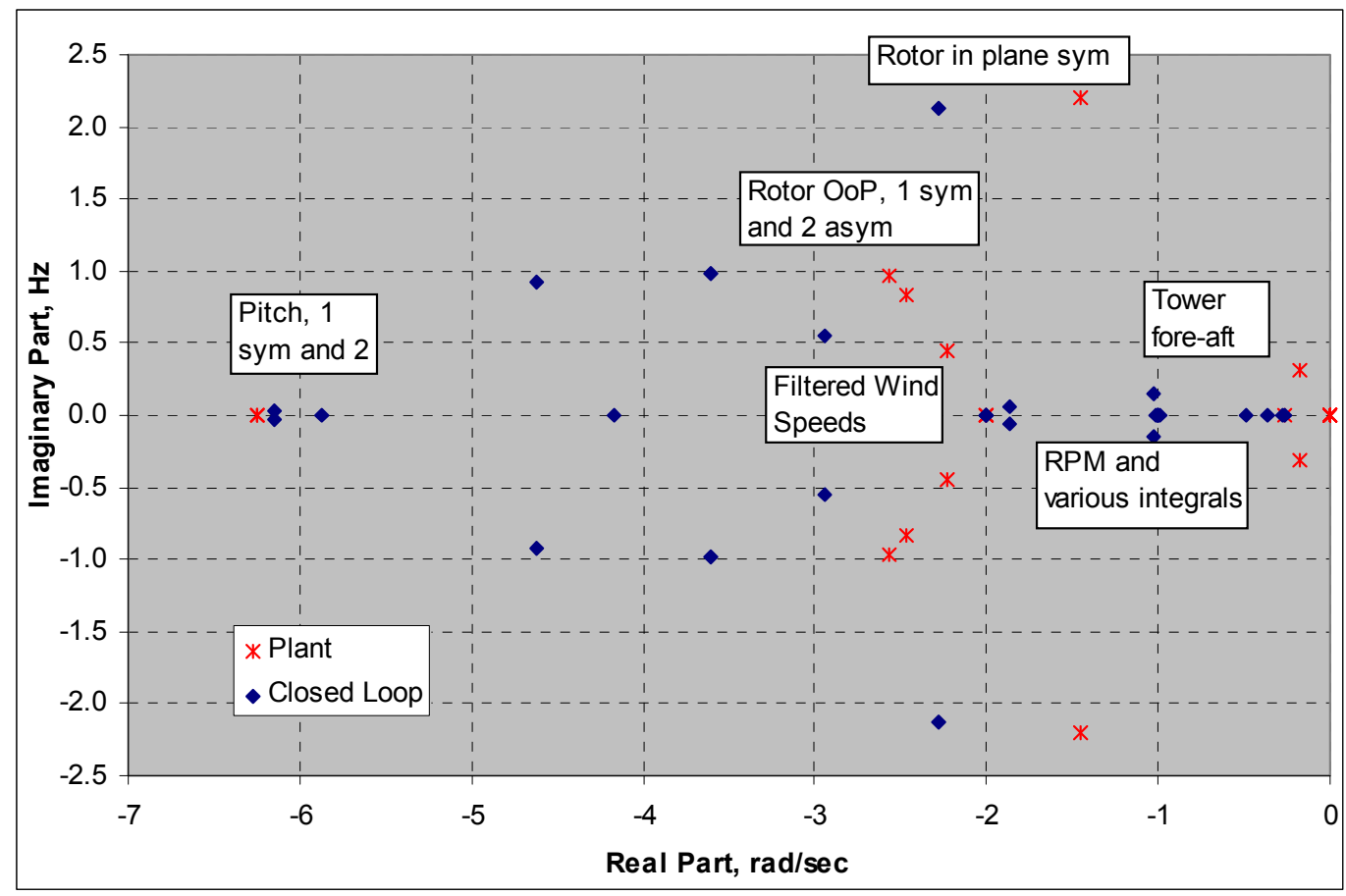

Figure 30. Plant and closed loop eigenvalues at $14 \mathrm{~m} / \mathrm{s}$ 

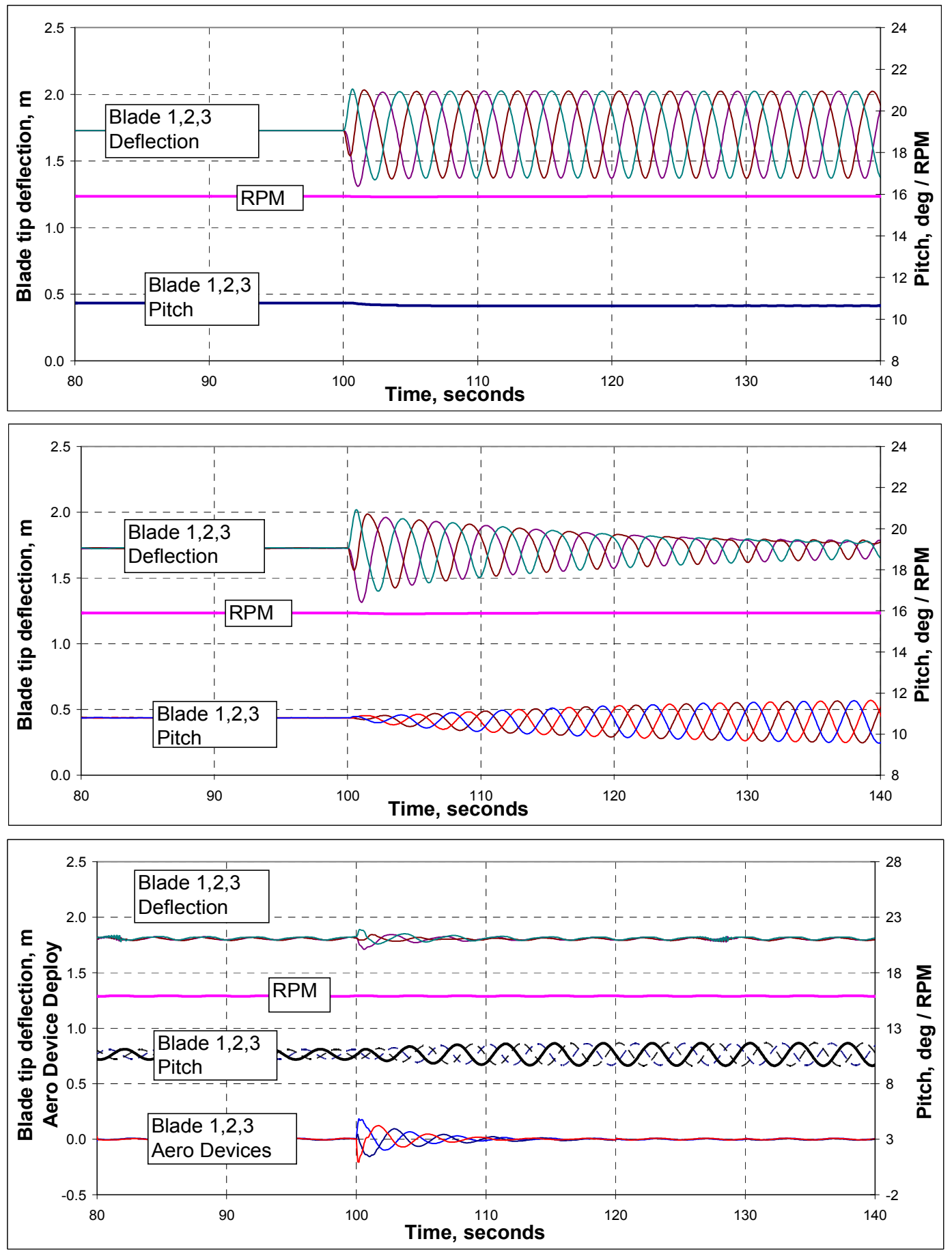

Figure 31. Comparison of load reduction at $14 \mathrm{~m} / \mathrm{s}$ using (from top to bottom) the PI, IBP, and aero controls for a step change in wind shear occurring at $100 \mathrm{sec}$ 


\section{Load and COE Results}

\section{Independent Blade Pitch}

Independent blade pitch is one of the near-term control approaches that can be used to reduce wind turbine loads. Any advanced control strategy is likely to include IBP as a component, even on a rotor that includes advanced aerodynamic control devices. Most of the aerodynamic control devices addressed in this study have a limited range of authority. Blade pitch, although likely slower, has a wide range of control authority. As a result, GEC assumed for this study that the primary control configuration would include IBP in addition to aerodynamic devices controlled independently for each blade. The first step then for this study was to design a controller that uses IBP only as a comparison to the primary control configuration that includes both IBP and aerodynamic devices.

Both active aero devices and independent blade pitch were included in the primary control configuration for this study. Researchers made several assumptions about the aerodynamic devices:

- Aerodynamic response would be instantaneous, although this would be tempered somewhat by using Aerodyn's dynamic inflow option.

- Linear behavior would be continuous within the defined function range of the devices. Specifically, any position could be achieved between the positive and negative limits.

- The devices were grouped into three regions of each blade as shown in Figure 32. Each region is controlled as one unit. The regions for the primary configuration are inboard ( $12.25 \mathrm{~m}$ to $22.50 \mathrm{~m})$; mid-span ( $22.50 \mathrm{~m}$ to $33.75 \mathrm{~m})$; and outboard ( $33.75 \mathrm{~m}$ to $45.0 \mathrm{~m})$.

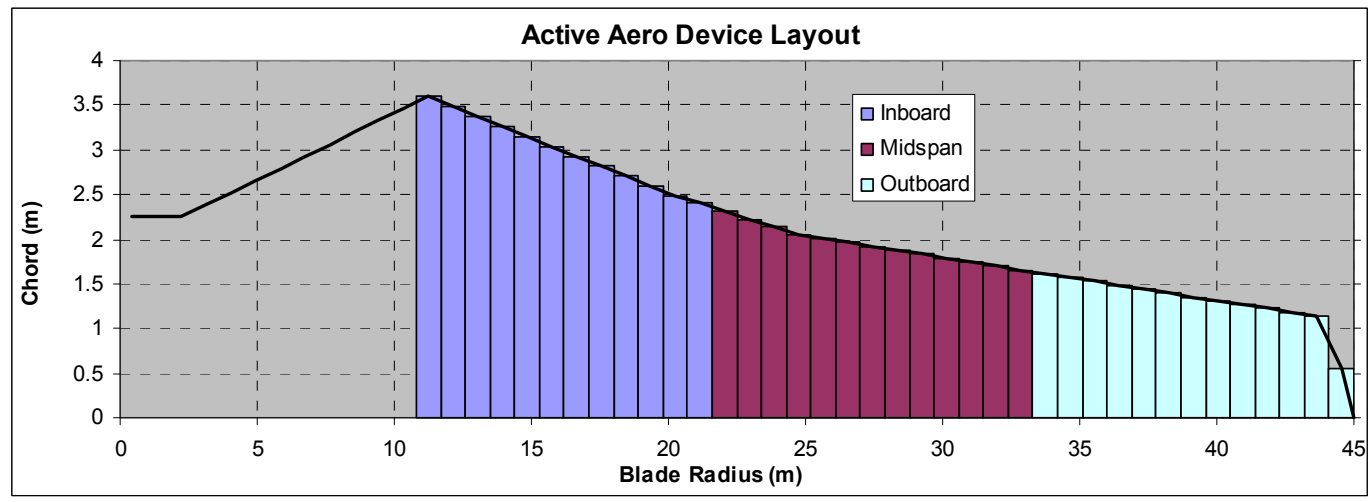

Figure 32. Active aero device groupings 


\section{Active Aero Only}

The list that follows briefly describes each configuration:

- In the active aero only configuration only collective blade pitch plus aerodynamic devices are used (no IBP).

- In the active aero with time delay configuration, the response of the active aero devices is lagged by using a first-order low pass filter with a time constant of $0.08 \mathrm{~s}(2 \mathrm{~Hz})$.

- In the active aero with reduced authority configuration, the range of authority of the active aero devices is reduced to half of the primary configuration shown in Figure 27.

- In the active aero mid-span and outboard only configuration, the inboard active aero devices are not used. The mid-span and outboard devices are used in addition to the IBP.

- In the active aero outboard only configuration, the inboard and mid-span active aero devices are not used. Only the outboard devices and the IBP are used.

\section{Loads and COE Summary}

For each of these control configurations, GEC performed simulations of the IEC load cases in ADAMS. Figures 33 and 34 compare the changes in peak and fatigue loads to the baseline loads, and Table 21 gives the load cases that produced the peaks. Note that each of these figures is shown as a different type of chart to aid in interpreting this large data set. Depending on the loading location, different values for the fatigue slope (shown in Figure 34) were used to calculate the fatigue equivalent loads. Appendix D gives abbreviations for the loads and associated components.

Note that load reductions occurred primarily in the blade flapwise direction and in the shaft and bedplate loads. This is true for both peak and fatigue loads. For peak loads, the figures show that blade edgewise bending loads have gone up, in some cases considerably. These peak increases result from the extreme direction change with gust (ECD) inflow cases. For such a large change in yaw error, the control laws are not consistent with the turbine behavior and the response is detrimental. Pursuing alternative control strategies for these cases was beyond the scope of this study.

As described in the WindPACT rotor study (Malcom and Hansen 2003), the peak and fatigue loads results were imported into a costing spreadsheet that applied structural sizing and other related functions based on the loads. Weights, sizes, and other parameters that feed into costs were calculated in this spreadsheet. After this costing was done for all major structural components and subsystems - including the balance-of-station items - these costs were summed to reach the ICC used in the COE model. 

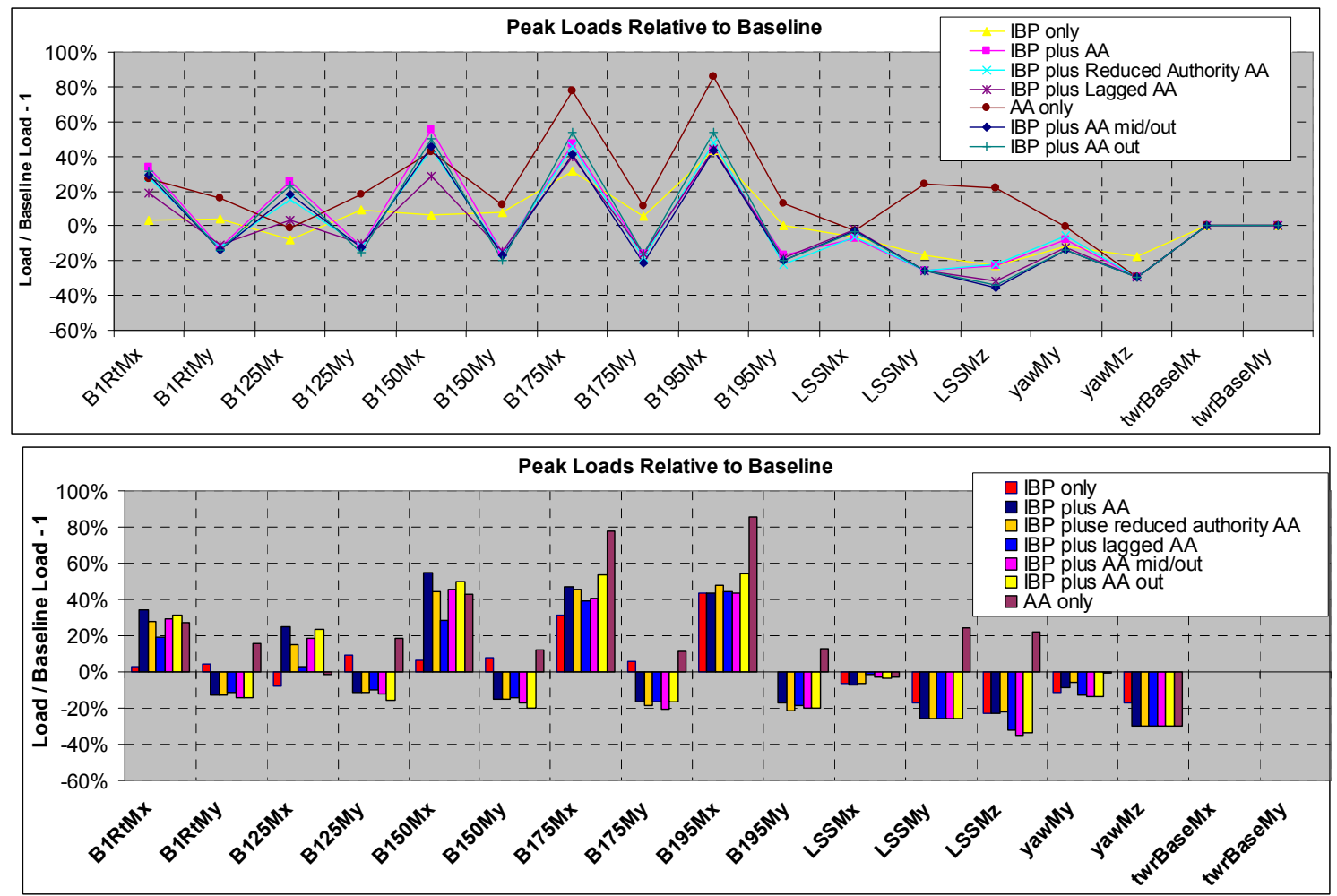

Figure 33. Change in peak loads relative to baseline for IBP and active aero control
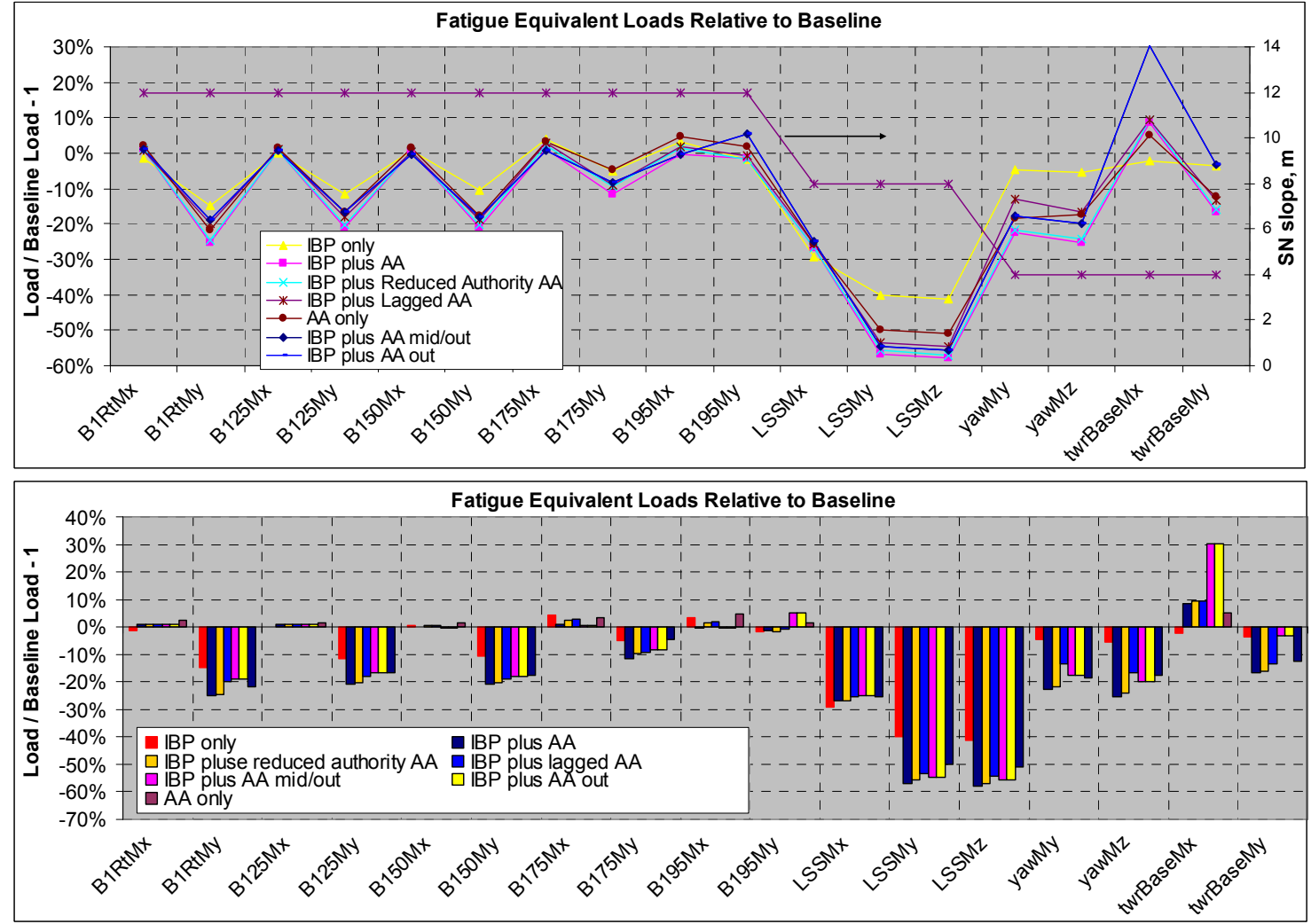

Figure 34. Change in fatigue loads relative to baseline for IBP and active aero control 
An additional benefit of active aerodynamic device control is illustrated in Figure 35. This figure shows that use of independent blade pitch drives the pitch activity up considerably. This increase in duty cycle of the pitch system can be ameliorated by using aerodynamic device controls. These load results were used to modify the size and mass of turbine structural components which, when combined with material costs, were used to calculate the turbine capital. This capital cost was then input to the COE calculation.

Table 20 shows the resulting COE for the different control configurations. These results are also plotted in Figure 36, which further compares them to the RBR results.

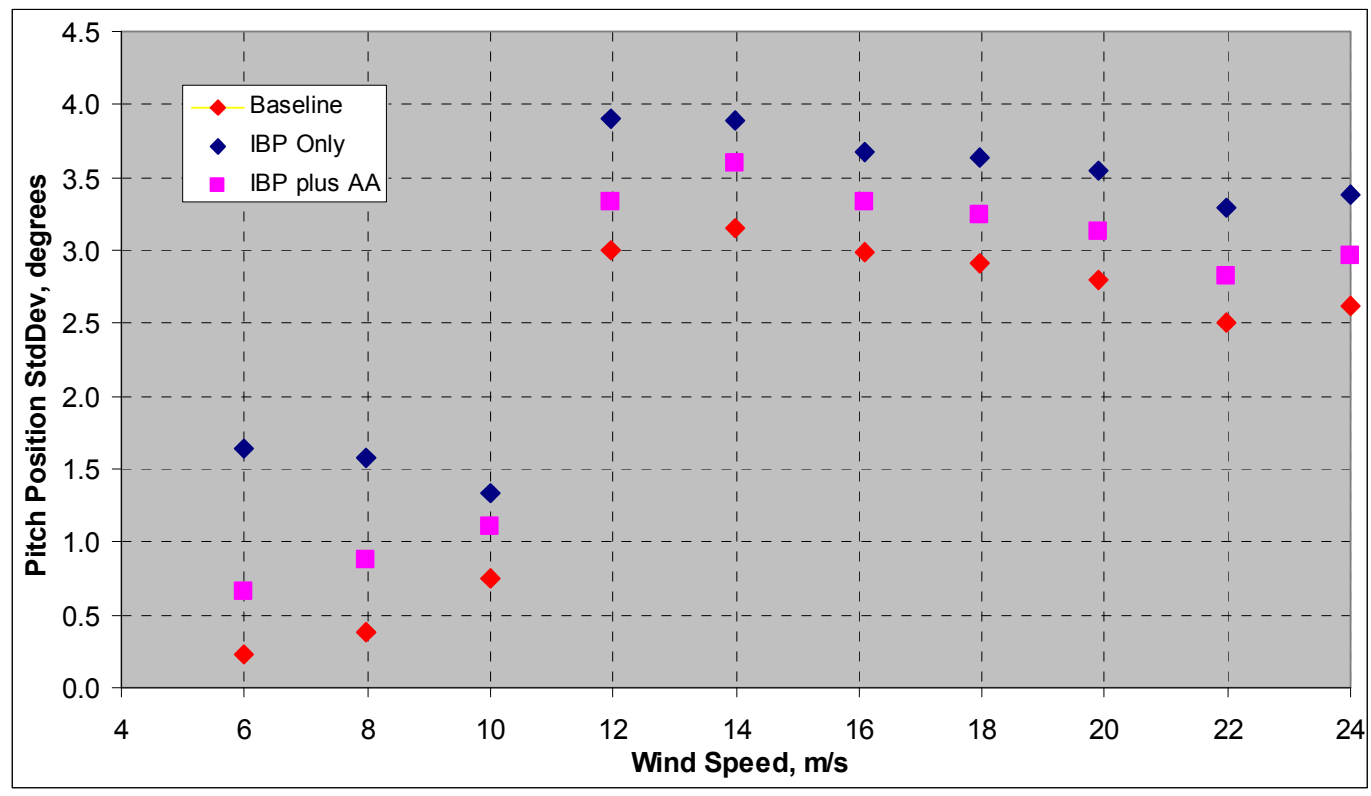

Figure 35. Blade pitch activity comparison

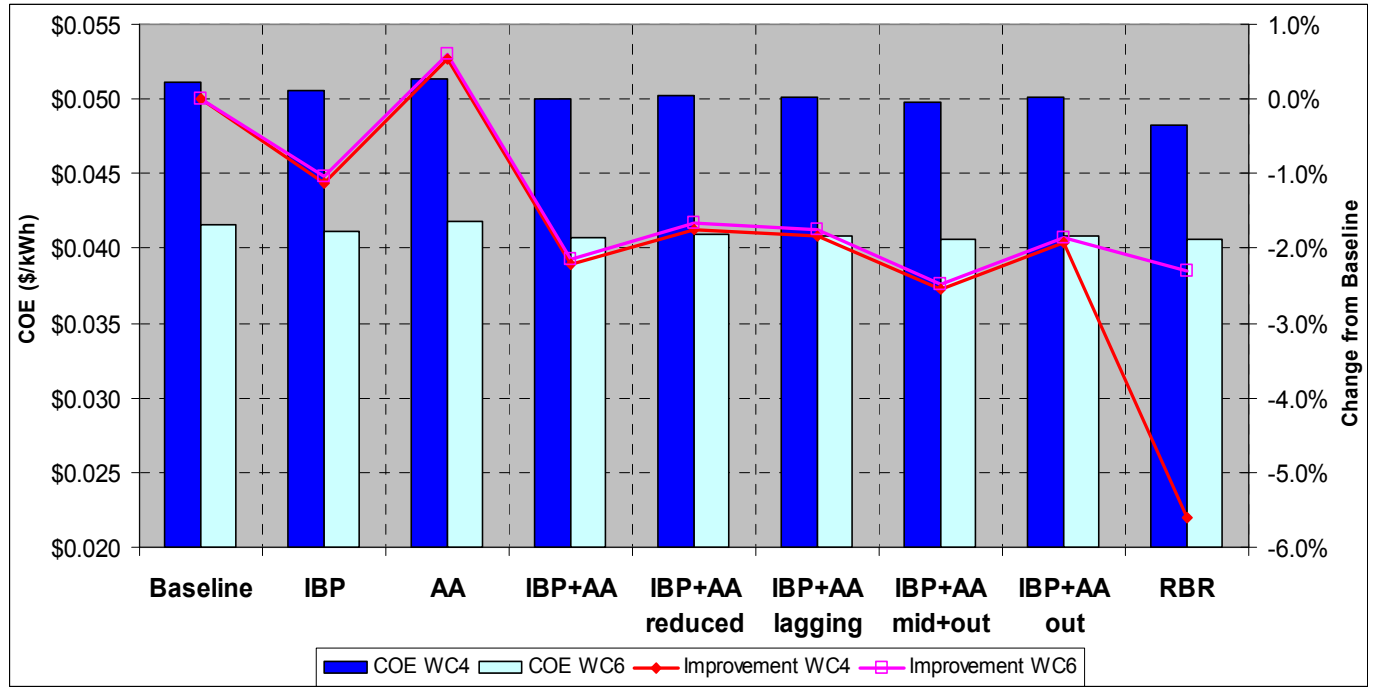

Figure 36. Active aero and RBR COE comparison 
Table 20. COE results for Active Aero Control

\begin{tabular}{|c|c|c|c|c|c|c|}
\hline \multirow[t]{2}{*}{ Configuration } & \multirow{2}{*}{$\begin{array}{c}\text { Active Aero } \\
\text { System Cost } \\
(\$)\end{array}$} & \multirow{2}{*}{$\begin{array}{c}\text { O\&M Cost } \\
\text { Increase } \\
(\%)\end{array}$} & \multicolumn{2}{|c|}{$\begin{array}{c}\text { COE } \\
(\$ / k W h)\end{array}$} & \multirow{2}{*}{\multicolumn{2}{|c|}{$\begin{array}{c}\text { \% Change from } \\
\text { Baseline }\end{array}$}} \\
\hline & & & Class 4 & Class 6 & & \\
\hline Baseline & 0 & 0 & 0.0511 & 0.0416 & 0.0 & 0.0 \\
\hline IBP only & 10,000 & 0 & 0.0505 & 0.0412 & -1.1 & -1.0 \\
\hline Active aero only & 40,000 & 5 & 0.0514 & 0.0419 & 0.5 & 0.6 \\
\hline $\begin{array}{l}\text { IBP and full-blade } \\
\text { active aero }\end{array}$ & 40,000 & 5 & 0.0500 & 0.0407 & -2.2 & -2.1 \\
\hline $\begin{array}{l}\text { IBP and full-blade, } \\
\text { reduced authority } \\
\text { active aero }\end{array}$ & 40,000 & 5 & 0.0502 & 0.0409 & -1.7 & -1.7 \\
\hline $\begin{array}{l}\text { IBP and full-blade } \\
\text { active aero with time } \\
\text { lag }\end{array}$ & 40,000 & 5 & 0.0502 & 0.0409 & -1.8 & -1.8 \\
\hline $\begin{array}{l}\text { IBP and mid- to tip- } \\
\text { blade active aero }\end{array}$ & 33,000 & 5 & 0.0498 & 0.0406 & -2.6 & -2.5 \\
\hline $\begin{array}{l}\text { IBP and tip active } \\
\text { aero }\end{array}$ & 26,000 & 5 & 0.0501 & 0.0408 & -0.9 & -1.8 \\
\hline
\end{tabular}

Table 21. Load Cases for Maximum Load: Active Aero versus Baseline*

\begin{tabular}{|c|c|c|c|c|c|c|c|c|}
\hline Load & Baseline & IBP Only & $\begin{array}{c}\text { Active } \\
\text { Aero } \\
\text { Only }\end{array}$ & $\begin{array}{c}\text { Full } \\
\text { Active } \\
\text { Aero }\end{array}$ & $\begin{array}{c}\text { Full } \\
\text { Active } \\
\text { Aero with } \\
50 \% \\
\text { Authority }\end{array}$ & $\begin{array}{c}\text { Full } \\
\text { Active } \\
\text { Aero } \\
\text { with Lag }\end{array}$ & $\begin{array}{c}\text { Outer } \\
\text { Two- } \\
\text { Thirds } \\
\text { Active } \\
\text { Aero }\end{array}$ & $\begin{array}{c}\text { Outer } \\
\text { One- } \\
\text { Third } \\
\text { Active } \\
\text { Aero }\end{array}$ \\
\hline B1rtMx & ECDPR & ECDNR & ECDNR & ECDPR & ECDPR & ECDPR & ECDPR & ECDPR \\
\hline B1rtMy & ECDPR & ECDNR & ECDNR & $12 \mathrm{~ms} 5$ & $12 \mathrm{~ms} 5$ & $12 \mathrm{~ms} 5$ & $12 \mathrm{~ms} 5$ & $18 \mathrm{~ms} 4$ \\
\hline $\mathrm{B} 125 \mathrm{Mx}$ & EOG50R & ECDPR & 22ms4 & ECDPR & ECDPR & ECDPR & ECDPR & ECDPR \\
\hline B125My & ECDNR & ECDNR & ECDNR & $12 \mathrm{~ms} 5$ & $12 \mathrm{~ms} 5$ & $12 \mathrm{~ms} 5$ & $12 \mathrm{~ms} 5$ & $16 \mathrm{~ms} 3$ \\
\hline B150Mx & ECDPR & ECDNR & ECDNR & ECDPR & ECDPR & ECDPR & ECDPR & ECDPR \\
\hline B150My & ECDPR & ECDNR & ECDNR & $12 \mathrm{~ms} 3$ & $12 \mathrm{~ms} 5$ & $12 \mathrm{~ms} 5$ & $12 \mathrm{~ms} 5$ & $12 \mathrm{~ms} 4$ \\
\hline B175Mx & ECDNR & ECDNR & ECDNR & ECDPR & ECDNR & ECDNR & ECDNR & ECDNR \\
\hline B175My & ECDPR & ECDNR & ECDNR & $12 \mathrm{~ms} 3$ & $12 \mathrm{~ms} 3$ & $12 \mathrm{~ms} 4$ & $12 \mathrm{~ms} 4$ & $12 \mathrm{~ms} 4$ \\
\hline B195Mx & ECDPR & ECDNR & ECDNR & ECDNR & ECDNR & ECDNR & ECDNR & ECDNR \\
\hline B195My & ECDPR & ECDNR & ECDNR & ECDPR & $12 \mathrm{~ms} 5$ & $14 \mathrm{~ms} 5$ & $8 \mathrm{~ms} 4$ & $8 \mathrm{~ms} 4$ \\
\hline LSShubMx & $24 \mathrm{~ms} 4$ & $24 \mathrm{~ms} 1$ & $24 \mathrm{~ms} 3$ & $18 \mathrm{~ms} 4$ & $22 \mathrm{~ms} 1$ & $24 \mathrm{~ms} 3$ & $24 \mathrm{~ms} 6$ & $24 \mathrm{~ms} 6$ \\
\hline LSShubMy & ECDPR & ECDNR & ECDNR & ewm015 & ewm015 & ewm015 & ewm015 & ewm015 \\
\hline LSShubMz & ECDPR & ECDNR & ECDNR & ECDPR & ECDPR & ECDNR & ECDPR & ECDPR \\
\hline YawbrgMy & $22 \mathrm{~ms} 5$ & ECDNR & ECDNR & ECDNR & ECDNR & ECDNR & ECDNR & ECDNR \\
\hline YawbrgMz & $20 \mathrm{~ms} 1$ & ewm016 & $24 \mathrm{~ms} 6$ & ewm016 & ewm016 & ewm016 & ewm016 & ewm016 \\
\hline TwrbaseMx & ewm501 & ewm501 & ewm501 & ewm501 & ewm501 & ewm501 & ewm501 & ewm501 \\
\hline TwrbaseMy & ewm013 & ewm013 & ewm013 & ewm013 & ewm013 & ewm013 & ewm013 & ewm013 \\
\hline
\end{tabular}

* See Table 9 for a description of the load cases and the acronyms. 


\section{Discussion and Conclusions}

The use of active aero devices for wind turbine load reduction presented several challenges and required many assumptions. For the purposes of this study, GEC categorized these devices into two primary groups: boundary layer control and camber modification. The former approach was reviewed briefly and the investigators concluded that boundary layer control did not offer much advantage for the variable-speed, variable-pitch baseline turbine design. This is because these types of controls operate on the upper portion of the lift curve near and beyond stall, a region where the baseline turbine does not typically operate.

For the camber modification devices, the GEC researchers created a representative set of liftand-drag curves, basing their development on the more optimistic levels of authority that these devices might provide as found in the literature. GEC further assumed that the devices could be operated in a linear continuous fashion, although this would limit the maximum authority. This assumption allowed control design to be simplified significantly by enabling the use of linear state-space-control design techniques.

The results of this study indicate that deploying active aero devices on the blades has some potential for reducing rotor and turbine structural loads. The load reductions will depend on the assumptions made about the device behavior — specifically, the authority of the devices and their time-domain responsiveness.

Keep in mind that using BEM theory to make the aerodynamic calculations in this study introduced a significant amount of uncertainty. Blade element momentum theory assumes 2-D flow conditions, but it is well understood that 3-D flow conditions exist. In addition, inherent in many of the results was the assumption that the aerodynamic forces developed instantaneously when the devices were activated.

Beyond the development and characterization of the devices themselves, the primary challenge in creating controls that rely on these devices is their nonlinear behavior. If devices can be fashioned that have a large linear range of authority, the control design will be more straightforward and robust. If the devices exhibit significant nonlinear behavior, however, the control challenge increases considerably.

Even though the COE improvements gained by using these devices appear favorable, researchers emphasize that these results are highly sensitive to assumptions about initial capital cost and operations and maintenance costs. Relatively small increases in O\&M costs in particular can wipe out the benefits of the load reductions. For this study, the costs of the devices and their maintenance were roughly estimated, but calculated to present a realistic target for designers and researchers. 


\section{Recommendations}

As stated in the sections above for the RBR and the active aerodynamic controls, both of these approaches show promise but are not without their challenges. The challenges are wide ranging and include materials, structures, design, aerodynamic characterization and control algorithm development. Cost issues are not insignificant either, particularly costs associated with operations and maintenance. Any mechanism or device must be reliable and have a long life to avoid these costs overwhelming their benefits.

GEC presents the following recommendations for continued R\&D on the RBR concept:

- Develop and evaluate an RBR turbine design using an approach that integrates aerodynamic, structural, and mechanism considerations from the outset.

- Evaluate the potential for purpose-designed airfoils to facilitate structural nesting while mitigating aerodynamic losses.

- Evaluate materials and manufacturing approaches for maximizing stiffness in a costeffective structure.

- Conduct subscale demonstrations of key technology elements, including materials, manufacturing, and mechanisms.

For continued R\&D on active aero controls, GEC recommends the following:

- Perform further detailed characterization of the effects on lift and drag including wind tunnel and computational fluid dynamics studies.

- Characterize the time response characteristics in additional detail.

- Develop devices and strategies that can linearize aerodynamic behavior.

- Investigate ways to increase the authority of these devices.

- Assess control methodologies that can take better advantage of the nonlinear nature of these devices.

- Begin developing fabrication techniques specific to integration of these devices into wind turbine blade structures.

- Begin small-scale atmospheric testing.

In summary, both the RBR and active aero approaches show promise, but are not without wideranging challenges in the areas of materials, structures, design, aerodynamic characterization, and control algorithm development. Costs can also be significant, particularly for O\&M. Any mechanisms or devices must be reliable over a long life span so that their costs do not overwhelm their benefits. 


\section{References}

Buhl, T.; Gaunaa, M.; Bak, C. (2005). "Load Reduction Potential Using Airfoils with Variable Trailing Edge Geometry." Proceedings of the 2005 ASME Wind Energy Symposium. AIAA2005-1183. Reston, VA: American Institute of Aeronautics and Astronautics (AIAA).

Coleman, R.P.; Feingold, A.M. (1958). "Theory of Self-Excited Mechanical Oscillations of Helicopter Rotors with Hinged Blades.” NACA Technical Report TR 1351.

Drela, M. (2001). XFOIL 6.94 User Guide. Cambridge, MA: Massachusetts Institute of Technology Department of Aeronautics and Astronautics.

Du, Z.; Selig, M.S. (1998). “A 3-D Stall-Delay Model for Horizontal Axis Wind Turbine Performance Prediction. Proceedings of the 1998 ASME Wind Energy Symposium. AIAA 980021. Reston, VA: AIAA.

Eggars, A.J.; Chaney, K.; Digumarthi, R. (2003). “An Assessment of Approximate Modeling of Aerodynamic Loads on the UAE Rotor." Proceedings of the 2003 ASME Wind Energy Symposium. AIAA 2003-0868. Reston, VA: AIAA.

Eppler, R.; Somers, D.M. (1980). A Computer Program for the Design and Analysis of LowSpeed Airfoils. NASA TM-80210. Hampton, VA: NASA Langley Research Center.

Griffin, D.A. (1996). "Performance Augmentation with Vortex Generators: Design and Testing for Stall-Regulated AWT-26 Turbine.” Proceedings of WindPower '96. Washington, DC: American Wind Energy Association (AWEA).

Griffin, D.A. (2000). NREL Advanced Research Turbine (ART) Aerodynamic Design of ART-2B Rotor Blades. NREL/SR-500-28473. Golden, CO: National Renewable Energy Laboratory (NREL).

Griffin, D.A. (2001). WindPACT Turbine Design Scaling Studies Technical Area 1 - Composite Blades for 80- to 120-Meter Rotor. NREL/SR-500-29492. Golden, CO: NREL.

Griffin, D.A. (2004). Blade System Design Studies Volume II: Preliminary Blade Designs and Recommended Test Matrix. SAND2004-0073. Albuquerque, NM: Sandia National Laboratories.

Hansen, C. (2007). NWTC Design Codes: AirfoilPrep.

http://wind.nrel.gov/designcodes/preprocessors/airfoilprep/.

Janiszewska, J.; Gregorek, G.; Lee, J. (2003). “Aerodynamic Characteristics of the LS(1)0417MOD Airfoil Model." Proceedings of the 2003 ASME Wind Energy Symposium. AIAA 2003-0349. Reston, VA: AIAA.

Kentfield, J.A.C. (1993). "A Simple, Approximate, Procedure for Predicting the Aerodynamic Performance of Turbine Blades Employing Gurney Flaps.” WindPower '93 Conference Proceedings. Washington, DC: AWEA. 
Kentfield, J.A.C. (1994). "Theoretically and Experimentally Obtained Performances of GurneyFlap Equipped Wind Turbines." Proceedings of the 1994 ASME Wind Energy Symposium.. New York: American Society of Mechanical Engineers (ASME).

Kota, S., Hetrick, J.A.; Osborn, R.; Paul, D.; Pendleton, E.; Flick, P.; Tilmann, C. (2003). "Design and Application of Compliant Mechanisms for Morphing Aircraft Structures." Proceedings of SPIE 5054, 24.

Laino, D.J.; Hansen, A.C. (2002). User's Guide to the Wind Turbine Aerodynamics Computer Software AeroDyn. Salt Lake City, UT: Windward Engineering. Available at http://wind.nrel.gov/designcodes/simulators/aerodyn/AeroDyn.pdf.

Laird, D.L. (2000). “A Numerical Manufacturing and Design Tool Odyssey." Proceedings of AIAA/ASME Wind Energy Symposium. Reston, VA: AIAA.

Malcolm, D.J.; Hansen, A.C. (2003). WindPACT Turbine Rotor Design Study. NREL/SR-50032497. Golden, CO: NREL.

Malcolm, D.J.; Laird, D.L. (2003). "Modeling of Blades as Equivalent Beams for Aeroelastic Analysis." Proceedings of the 2003 ASME Wind Energy Symposium. AIAA-2003-0870. Reston, VA: AIAA.

McCoy, T.J. (2004). "Wind Turbine ADAMS Model Linearization Including Rotational and Aerodynamic Effects." Proceedings of the 42nd AIAA Aerospace Sciences Meeting and Exhibit. AIAA 2004-1370. Reston, VA: AIAA.

Perivoralis, Y.G.; Voutsinas, S.G. (2001). "A CFD Performance Analysis of Vortex Generators used for Boundary Layer Control on Wind Turbine Blades." Proceedings of the European Wind Energy Conference. Brussels, Belgium: European Wind Energy Association (EWEA).

Post, M.L.; Corke, T.C. (2004). "Separation Control Using Plasma Actuators - Stationary \& Oscillating Airfoils.” AIAA 2004-0841.

Rueger, M.L.; Gregorek, G. (1991). An Experimental Investigation of the Effect of Vortex Generators on the Aerodynamic Characteristics of a NACA 0021 Airfoil Undergoing Large Amplitude Pitch Oscillations. SAND90-7111. Albuquerque, NM: Sandia National Laboratories.

Selig, M.S.; Tangler, J.L. (1994). “A Multipoint Inverse Design Method for Horizontal Axis Wind Turbines." Presented at the AWEA Windpower '94 Conference, Minneapolis, Minnesota, May 9-12.

Stuart, J.; Wright, A.; Butterfield, C. (1996). "Considerations for and Integrated Wind Turbine Controls Capability at the NWTC: An Aileron Control Case Study for Power Regulation and Load Mitigation." Proceedings of WindPower '96. Washington, DC: AWEA.

Tangler, J.L.; Somers, D.M. (1995). "NREL Airfoil Families for HAWTs." Presented at the American Wind Energy Association Windpower '95 Conference, Washington, DC, March 2630 . 
Timmer, W.; van Rooij, R.P.J.O.M. (2003). "Summary of the Delft University Wind Turbine Dedicated Airfoils." Proceedings of the 2003 ASME Wind Energy Symposium. AIAA 20030352. Reston, VA: AIAA.

Trevelyan, C.; Sharpe, D.J.; Michelsen, J.A.; Infield, D.G. (2001). “Application of Circulation Control Aerofoils to Utility Scale Wind Turbines." Proceedings of the European Wind Energy Conference 2001.

van Dam, C.P.; Yen Nakafuji, D.T.; Bauer, C.; Chao, D.; Standish, K. (2004). Computational and Experimental Investigation into the Effectiveness of a Microtab Aerodynamic Load Control System. Sandia National Laboratories, August, 2004, https://e-reportsext.1lnl.gov/pdf/243928.pdf.

Yen Nakafuji, D.T.; van Dam, C.P.; Michel, J.; Morrison, P. (2002). "Load Control for Turbine Blades: A Non-Traditional Microtab Approach." Proceedings of the 2002 ASME Wind Energy Symposium. AIAA 2002-0054. Reston, VA: AIAA.

Yen Nakafuji, D.; van Dam, C.P.; Smith, R.L.; Collins, S.D. (2001). “Active Load Control for Wind Turbine Blades Using MEM Translational Tabs." Proceedings of the 2001 ASME Wind Energy Symposium. AIAA 2001-0031. Reston, VA: AIAA. 
Appendix A: AEP Calculations 


\begin{tabular}{|c|c|c|c|c|c|c|c|c|c|c|c|}
\hline \multirow{3}{*}{$\begin{array}{c}\text { WS Bin } \\
(\mathrm{m} / \mathrm{s})\end{array}$} & \multirow{2}{*}{\multicolumn{2}{|c|}{ \# of hours per year }} & \multicolumn{3}{|c|}{ Baseline } & \multicolumn{3}{|c|}{ Config. \#1 95/45/50_85 } & \multicolumn{3}{|c|}{ Config. \#2 95/45/55_85 } \\
\hline & & & \multirow{2}{*}{$\begin{array}{c}P_{\text {System }} \\
(\mathrm{kW})\end{array}$} & \multicolumn{2}{|c|}{ Energy (kWh) } & \multirow{2}{*}{$\frac{P_{\text {System }}}{(\mathrm{kW})}$} & \multicolumn{2}{|c|}{ Energy (kWh) } & \multirow{2}{*}{$\frac{P_{\text {System }}}{(k W)}$} & \multicolumn{2}{|c|}{ Energy (kWh) } \\
\hline & $7.81 \mathrm{~m} / \mathrm{s}$ & $8.98 \mathrm{~m} / \mathrm{s}$ & & $7.81 \mathrm{~m} / \mathrm{s}$ & $8.98 \mathrm{~m} / \mathrm{s}$ & & $7.81 \mathrm{~m} / \mathrm{s}$ & $8.98 \mathrm{~m} / \mathrm{s}$ & & $7.81 \mathrm{~m} / \mathrm{s}$ & $8.98 \mathrm{~m} / \mathrm{s}$ \\
\hline 3.0 & 301.2 & 234.2 & 0.0 & 0 & 0 & 0.0 & 0 & 0 & 0.0 & 0 & 0 \\
\hline 3.5 & 37.0 & 64.7 & 4.5 & 1,500 & 1,178 & 24.9 & 8,401 & 6,597 & 45.1 & 15,202 & 11,938 \\
\hline 4.0 & 67.0 & 91.7 & 47.1 & 17,288 & 13,737 & 79.2 & 29,078 & 23,106 & 112.8 & 41,397 & 32,895 \\
\hline 4.5 & 90.9 & 14.8 & 102.6 & 40,124 & 32,312 & 148.9 & 58,219 & 46,884 & 198.2 & 77,482 & 62,398 \\
\hline 5.0 & 08.6 & 334.0 & 168.6 & 68,885 & 56,309 & 228.5 & 93,367 & 76,322 & 293.9 & 120,087 & 98,165 \\
\hline 5.5 & 20.1 & 49.1 & 242.3 & 101,782 & 84,587 & 320.2 & 134,529 & 111,802 & 405.8 & 170,477 & 141,677 \\
\hline 6.0 & 25.6 & 60.1 & 330.7 & 140,729 & 119,091 & 430.3 & 183,114 & 154,958 & 540.1 & 229,831 & 194,492 \\
\hline 6.5 & 25.4 & 67.1 & 435.1 & 185,091 & 159,742 & 560.3 & 238,332 & 205,692 & 698.6 & 297,193 & 256,492 \\
\hline 7.0 & 420.0 & 370.3 & 556.9 & 233,888 & 206,190 & 711.9 & 298,974 & 263,569 & 883.6 & 371,092 & 327,147 \\
\hline 7.5 & 409.9 & 369.7 & 697.4 & 285,848 & 257,813 & 886.7 & 363,467 & 327,820 & 1096.9 & 449,617 & 405,521 \\
\hline 8.0 & 395.7 & 365.7 & 857.9 & 339,472 & 313,737 & 1086.6 & 429,954 & 397,361 & 1337.2 & 529,116 & 489,006 \\
\hline 8.5 & 378.1 & 358.6 & 1039.8 & 393,114 & 372,870 & 1313.0 & 496,401 & 470,838 & 1585.7 & 599,487 & 568,616 \\
\hline 9.0 & 357.7 & 348.7 & 1244.4 & 445,076 & 433,942 & 1561.1 & 558,318 & 544,353 & 1833.7 & 655,844 & 639,439 \\
\hline 9.5 & 35.1 & 336.4 & 1473.1 & 493,691 & 495,560 & 1815.7 & 608,530 & 610,834 & 2045.0 & 685,362 & 687,957 \\
\hline 10.0 & 11.2 & 322.1 & 1727.1 & 537,420 & 556,265 & 2068.2 & 643,557 & 666,122 & 2068.2 & 643,557 & 666,122 \\
\hline 10.5 & 36.3 & 306.1 & 1986.5 & 568,800 & 608,046 & 2250.0 & 644,246 & 688,698 & 2250.0 & 644,246 & 688,698 \\
\hline 11.0 & 1.2 & 88.8 & 248.3 & 237 & 649,356 & 2250.0 & 587,693 & $649,861 \mid$ & 2250.0 & 587,693 & 649,861 \\
\hline 11.5 & 6.3 & 70.7 & 000.0 & 626 & 676,642 & 2500.0 & 590,626 & \begin{tabular}{|l|}
676,642 \\
\end{tabular} & 2500.0 & 590,626 & 676,642 \\
\hline 12 & 1.9 & 51.9 & 00.0 & ,785 & 629,805 & 2500.0 & 529,785 & \begin{tabular}{|l|}
629,805 \\
\end{tabular} & 2500.0 & 529,785 & 629,805 \\
\hline 12.5 & 8.5 & 232.9 & 00.0 & ,343 & $\overline{582,3}$ & 2500.0 & 471,343 & 582,353 & 2500.0 & 471,343 & 582,353 \\
\hline 13.0 & 6.4 & 214.0 & 00.0 & & 535, & 2500.0 & 415,990 & 535,006 & 2500.0 & 415,990 & 535,006 \\
\hline 13.5 & 45.7 & 195.4 & 500.0 & 364,243 & 488,401 & 2500.0 & 364,243 & 488,401 & 2500.0 & 364,243 & 488,401 \\
\hline 14.0 & 26.6 & 177.2 & 00.0 & 316 & 443,0 & 2500.0 & 316,451 & 443,084 & 2500.0 & 316,451 & 443,084 \\
\hline 14.5 & 09.1 & 159.8 & 500.0 & 272,818 & 399,511 & 2500.0 & 272,818 & 399,511 & 2500.0 & 272,818 & 399,511 \\
\hline 15.0 & 3.4 & 143.2 & 2500.0 & 233,414 & 358,049 & 2500.0 & 233,414 & 358,049 & 2500.0 & 233,414 & 358,049 \\
\hline 15.5 & 79.3 & 127.6 & 2500.0 & 198,199 & 318,979 & 2500.0 & 198,199 & 318,979 & 2500.0 & 198,199 & 318,979 \\
\hline 16.0 & 66.8 & 113.0 & 500.0 & 167,043 & 282,498 & 2500.0 & 167,043 & 282,498 & 2500.0 & 167,043 & 282,498 \\
\hline 16.5 & 55.9 & 99.5 & 2500.0 & 139,745 & 248,733 & 2500.0 & 139,745 & \begin{tabular}{|l|}
248,733 \\
\end{tabular} & 2500.0 & 139,745 & 248,733 \\
\hline 17.0 & 46.4 & 87.1 & 2500.0 & 116,051 & 217,741 & 2500.0 & 116,051 & 217,741 & 2500.0 & 116,051 & 217,741 \\
\hline 17.5 & 38.3 & 75.8 & 2500.0 & $\begin{array}{l}95,674 \\
\end{array}$ & 189,522 & 2500.0 & 95,674 & \begin{tabular}{l|}
189,522 \\
\end{tabular} & 2500.0 & 95,674 & 189,522 \\
\hline 18.0 & 31.3 & 65.6 & 2500.0 & 78,304 & 164,026 & 2500.0 & 78,304 & 164,026 & 2500.0 & 78,304 & 164,026 \\
\hline 18.5 & 25.5 & 56.5 & 2500.0 & 3,627 & 141,162 & 2500.0 & 63,627 & 141,162 & 2500.0 & 63,627 & 141,162 \\
\hline 19.0 & 20.5 & 48.3 & 2500.0 & 51,332 & 120,807 & 2500.0 & 51,332 & \begin{tabular}{|l|}
120,807 \\
\end{tabular} & 2500.0 & 51,332 & 120,807 \\
\hline 19.5 & 16.4 & 41.1 & 2500.0 & 41,119 & 102,814 & 2500.0 & 41,119 & 102,814 & 2500.0 & 41,119 & 102,814 \\
\hline 20.0 & 13.1 & 34.8 & 2500.0 & 32,705 & 87,020 & 2500.0 & 32,705 & 87,020 & 2500.0 & 32,705 & 87,020 \\
\hline 20.5 & 10.3 & 29.3 & 2500.0 & 25,830 & 73,248 & 2500.0 & 25,830 & 73,248 & 2500.0 & 25,830 & 73,248 \\
\hline 21.0 & & 24.5 & 2500.0 & 20,257 & 61,321 & 2500.0 & 20,257 & 61,321 & 2500.0 & 20,257 & 61,321 \\
\hline 21.5 & & 20.4 & & 15,775 & 51,058 & 2500.0 & 15,775 & 51,058 & 2500.0 & 15,775 & 51,058 \\
\hline 22.0 & & 16.9 & & 12,200 & 42,283 & 2500.0 & 12,200 & 42,283 & 2500.0 & 12,200 & 42,283 \\
\hline 22.5 & & 13.9 & 500.0 & 9,369 & 34,828 & 2500.0 & 9,369 & 34,828 & 2500.0 & 9,369 & 34,828 \\
\hline 23.0 & & 11.4 & 2500.0 & 7,146 & 28,535 & 2500.0 & 7,146 & 28,535 & 2500.0 & 7,146 & 28,535 \\
\hline 23.5 & & 9.3 & 2500.0 & 5,412 & 23,254 & 2500.0 & 5,412 & 23,254 & 2500.0 & 5,412 & 23,254 \\
\hline 24.0 & & 7 & 2500.0 & 4,071 & 18,850 & 2500.0 & 4,071 & 18,850 & 2500.0 & 4,071 & 18,850 \\
\hline 24.5 & & & 2500.0 & 3,042 & 15,199 & 2500.0 & 3,042 & 15,199 & 2500.0 & 3,042 & 15,199 \\
\hline 25.0 & 0.9 & 4.9 & 2500.0 & 2,257 & 12,191 & 2500.0 & 2,257 & 12,191 & 2500.0 & 2,257 & 12,191 \\
\hline
\end{tabular}




\begin{tabular}{|c|c|c|c|c|c|c|c|c|c|c|c|}
\hline \multirow{3}{*}{$\begin{array}{c}\text { WS Bin } \\
(\mathrm{m} / \mathrm{s})\end{array}$} & \multirow{2}{*}{\multicolumn{2}{|c|}{ \# of hours per year }} & \multicolumn{3}{|c|}{ Config. \#3 90/45/50_85 } & \multicolumn{3}{|c|}{ Config. \#4 90/45/55_85 } & \multicolumn{3}{|c|}{ Config. \#5 90/42.75/50_85 } \\
\hline & & & \multirow{2}{*}{$\frac{P_{\text {System }}}{(k W)}$} & \multicolumn{2}{|c|}{ Energy (kWh) } & \multirow{2}{*}{$\frac{P_{\text {System }}}{(\mathrm{kW})}$} & \multicolumn{2}{|c|}{ Energy (kWh) } & \multirow{2}{*}{$\frac{P_{\text {System }}}{(k W)}$} & \multicolumn{2}{|c|}{ Energy (kWh) } \\
\hline & $7.81 \mathrm{~m} / \mathrm{s}$ & $8.98 \mathrm{~m} / \mathrm{s}$ & & $7.81 \mathrm{~m} / \mathrm{s}$ & $8.98 \mathrm{~m} / \mathrm{s}$ & & $7.81 \mathrm{~m} / \mathrm{s}$ & $8.98 \mathrm{~m} / \mathrm{s}$ & & $7.81 \mathrm{~m} / \mathrm{s}$ & $8.98 \mathrm{~m} / \mathrm{s}$ \\
\hline 3.0 & 301.2 & 234.2 & $\begin{array}{l}0.0 \\
\end{array}$ & 0 & 0 & 0.0 & 0 & 0 & 0.0 & 0 & 0 \\
\hline 3.5 & 37.0 & 264.7 & 17.9 & 6,025 & 4,731 & 33.4 & 11,257 & 8,840 & 17.9 & 6,025 & 4,731 \\
\hline 4.0 & 67.0 & 291.7 & 72.0 & 26,439 & 21,009 & 100.7 & 36,977 & 29,383 & 72.0 & 26,439 & 21,009 \\
\hline 4.5 & 90.9 & 314.8 & 142.6 & 55,748 & 44,894 & 188.7 & 73,751 & 59,393 & 142.6 & 55,748 & 44,894 \\
\hline 5.0 & 08.6 & 334.0 & 227.3 & 92,856 & 75,905 & 293.3 & 119,859 & 97,978 & 227.3 & 92,856 & 75,905 \\
\hline 5.5 & 20.1 & 349.1 & 320.2 & 134,529 & 111,802 & 406.7 & 170,863 & 141,998 & 320.2 & 134,529 & 111,802 \\
\hline 6.0 & 25.6 & 360.1 & 430.3 & 183,114 & 154,958 & 541.2 & 230,339 & 194,922 & 430.3 & 83,114 & 154,958 \\
\hline 6.5 & 25.4 & 67.1 & 560.3 & 238,332 & 205,692 & 700.1 & 297,838 & 257,048 & 560.3 & 38,332 & 205,692 \\
\hline 7.0 & 0.0 & 70.3 & 711.9 & 298,974 & 263,569 & 885.5 & 371,887 & 327,848 & 711.9 & 98,974 & 263,569 \\
\hline 7.5 & 9.9 & 369.7 & 886.7 & 363,467 & 327,820 & 1099.3 & 450,572 & 406,382 & 886.7 & 63,467 & 327,820 \\
\hline 8.0 & 95.7 & 365.7 & 1086.6 & 429,954 & 397,361 & 1342.1 & 531,074 & 490,815 & 1086.6 & 429,954 & 397,361 \\
\hline 8.5 & 378.1 & 358.6 & 1313.0 & 496,401 & 470,838 & 1601.6 & 605,516 & 574,334 & 1313.0 & 496,401 & 470,838 \\
\hline 9.0 & 357.7 & 348.7 & 1562.2 & 558,716 & 544,740 & 1859.2 & 664,961 & 648,327 & 1562.2 & 558,716 & 544,740 \\
\hline 9.5 & 35.1 & 336.4 & 1820.5 & 610,116 & 612,426 & 2045.0 & 685,362 & 687,957 & 1820.5 & 610,116 & 612,426 \\
\hline 10.0 & 11.2 & 322.1 & 2077.3 & 646,396 & 669,061 & 2077.3 & 646,396 & 669,061 & 2077.3 & 646,396 & 669,061 \\
\hline 10.5 & 286.3 & 306.1 & 2250.0 & 644,246 & 688,698 & 2250.0 & 644,246 & 688,698 & 2250.0 & 644,246 & 688,698 \\
\hline 11.0 & 261.2 & 288.8 & 2250.0 & 587,693 & 649,861 & 2250.0 & 587,693 & 649,861 & 2250.0 & 587,693 & 649,861 \\
\hline 11.5 & 236.3 & 270.7 & 2500.0 & 590,626 & 676,642 & 2500.0 & 590,626 & 676,642 & 2500.0 & 590,626 & 676,642 \\
\hline 12.0 & & 251.9 & 2500.0 & 529,785 & 629,805 & 2500.0 & 529,785 & 629,805 & 2556.6 & 541,787 & 644,073 \\
\hline 12.5 & 8.5 & 232.9 & 2500.0 & 471,343 & 582,353 & 2500.0 & 471,343 & 582,353 & 2632.0 & 496,230 & 613,101 \\
\hline 13.0 & 6.4 & 14.0 & 2500.0 & 415,990 & 535,006 & 2500.0 & 415,990 & 535,006 & 2632.0 & 437,955 & 563,255 \\
\hline 13.5 & 5.7 & 95.4 & 2500.0 & 364,243 & 488,401 & 2500.0 & 364,243 & 488,401 & 2632.0 & 383,475 & 514,189 \\
\hline 14 & & 77.2 & 2500.0 & 316,451 & 443,084 & 2500.0 & 451 & 084 & 2632.0 & 3,160 & 466,479 \\
\hline 14.5 & 9.1 & 9.8 & 2500.0 & 272,818 & & 2500.0 & 818 & 511 & 2632.0 & 7,223 & 420,605 \\
\hline 15.0 & 3.4 & 143.2 & 2500.0 & 233,414 & 358,049 & 2500.0 &, 414 & 358,049 & 2632.0 & 5,738 & 376,954 \\
\hline 15.5 & 9 & 127.6 & 2500.0 & 198,199 & 318,979 & 2500.0 & 198,199 & 318,979 & 2632.0 & 208,664 & 335,821 \\
\hline 16.0 & .8 & 113.0 & 2500.0 & 167,043 & 282,498 & 2500.0 &, 043 & 282,498 & 2632.0 & 5,863 & 297,414 \\
\hline 16.5 & .9 & 9.5 & 2500.0 & 139,745 & 248,733 & 2500.0 & 139,745 & 248,733 & 2632.0 & 147,124 & 261,867 \\
\hline 17.0 & 46.4 & 87.1 & 2500.0 & 116,051 & 217,741 & 2500.0 & 116,051 & 217,741 & 2632.0 & 122,179 & 229,238 \\
\hline 17.5 & 38.3 & 75.8 & 2500.0 & 95,674 & 189,522 & 2500.0 & 95,674 & 189,522 & 2632.0 & 100,725 & 199,529 \\
\hline 18.0 & 31.3 & 65.6 & 2500.0 & 78,304 & 164,026 & 2500.0 & 78,304 & 164,026 & 2632.0 & 82,438 & 172,686 \\
\hline 18.5 & .5 & 56.5 & 2500.0 & 63,627 & 141,162 & 2500.0 & 63,627 & 141,162 & 2632.0 & |6,987 & 148,615 \\
\hline 19.0 & 20.5 & 48.3 & 2500.0 & 51,332 & 120,807 & 2500.0 & 51,332 & 120,807 & 2632.0 & 54,043 & 127,185 \\
\hline 19.5 & 16.4 & 41.1 & 2500.0 & 41,119 & 102,814 & 2500.0 & 41,119 & 102,814 & 2632.0 & 43,290 & 108,243 \\
\hline 20.0 & 13.1 & 34.8 & 2500.0 & 32,705 & 87,020 & 2500.0 & 32,705 & 87,020 & 2632.0 & 34,432 & 91,614 \\
\hline 20.5 & 10.3 & 29.3 & 2500.0 & 25,830 & 73,248 & 2500.0 & 25,830 & 73,248 & 2632.0 & 27,193 & 77,116 \\
\hline 21.0 & 8.1 & 24.5 & 2500.0 & 20,257 & 61,321 & 2500.0 & 20,257 & 61,321 & 2632.0 & 21,326 & 64,559 \\
\hline 21.5 & 6.3 & 20.4 & 2500.0 & 15,775 & 51,058 & 2500.0 & 15,775 & 51,058 & 2632.0 & 16,608 & 53,753 \\
\hline 22.0 & 4.9 & 16.9 & 2500.0 & 12,200 & 42,283 & 2500.0 & 12,200 & 42,283 & 2632.0 & 12,844 & 44,515 \\
\hline 22.5 & & 13.9 & 2500.0 & 9,369 & 34,828 & 2500.0 & 9,369 & 34,828 & 2632.0 & 9,864 & 36,667 \\
\hline 23.0 & & 11.4 & 2500.0 & 7,146 & 28,535 & 2500.0 & 7,146 & 28,535 & 2632.0 & 7,523 & 30,041 \\
\hline 23.5 & & & 2500.0 & 5,412 & & 2500.0 & 5,412 & 23,254 & 2632.0 & 5,698 & 24,482 \\
\hline 24.0 & 1.6 & 7.5 & 2500.0 & 4,071 & 18,850 & 2500.0 & 4,071 & 18,850 & 2632.0 & 4,286 & 19,845 \\
\hline 24.5 & 1.2 & 6.1 & 2500.0 & 3,042 & 15,199 & 2500.0 & 3,042 & 15,199 & 2632.0 & 3,202 & 16,002 \\
\hline 25.0 & 0.9 & 4.9 & 2500.0 & 2,257 & 12,191 & 2500.0 & 2,257 & 12,191 & 2632.0 & 2,376 & 12,835 \\
\hline
\end{tabular}




\begin{tabular}{|c|c|c|c|c|c|c|c|c|c|c|c|}
\hline \multirow{3}{*}{$\begin{array}{c}\text { WS Bin } \\
(\mathrm{m} / \mathrm{s})\end{array}$} & \multirow{2}{*}{\multicolumn{2}{|c|}{ \# of hours per year }} & \multicolumn{3}{|c|}{ Config. \#6 90/42.75/55_85 } & \multicolumn{3}{|c|}{ Config. \#7 85/45/50_85 } & \multicolumn{3}{|c|}{ Config. \#8 85/45/55_85 } \\
\hline & & & \multirow{2}{*}{$\frac{P_{\text {System }}}{(\mathrm{kW})}$} & \multicolumn{2}{|c|}{ Energy (kWh) } & \multirow{2}{*}{$\frac{P_{\text {System }}}{(\mathrm{kW})}$} & \multicolumn{2}{|c|}{ Energy (kWh) } & \multirow{2}{*}{$\frac{P_{\text {System }}}{(\mathrm{kW})}$} & \multicolumn{2}{|c|}{ Energy (kWh) } \\
\hline & $7.81 \mathrm{~m} / \mathrm{s}$ & $8.98 \mathrm{~m} / \mathrm{s}$ & & $7.81 \mathrm{~m} / \mathrm{s}$ & $8.98 \mathrm{~m} / \mathrm{s}$ & & $7.81 \mathrm{~m} / \mathrm{s}$ & $8.98 \mathrm{~m} / \mathrm{s}$ & & $7.81 \mathrm{~m} / \mathrm{s}$ & $8.98 \mathrm{~m} / \mathrm{s}$ \\
\hline 3.0 & 301.2 & 234.2 & 0.0 & 0 & 0 & 0.0 & 0 & 0 & 0.0 & 0 & 0 \\
\hline 3.5 & 37.0 & 64.7 & 33.4 & 11,257 & 8,840 & 9.5 & 3,199 & 2,512 & 21.6 & 7,281 & 5,718 \\
\hline 4.0 & 67.0 & 91.7 & 100.7 & 36,977 & 29,383 & 64.0 & 23,492 & 18,667 & 89.0 & 32,677 & 25,966 \\
\hline 4.5 & 90.9 & 14.8 & 188.7 & 73,751 & 59,393 & 134.4 & 52,525 & 42,299 & 176.4 & 68,950 & 55,526 \\
\hline 5.0 & 8.6 & 34.0 & 293.3 & 119,859 & 97,978 & 221.9 & 90,657 & 74,107 & 285.6 & 116,685 & 95,383 \\
\hline 5.5 & 20.1 & 49.1 & 406.7 & 170,863 & 141,998 & 320.2 & 134,529 & 111,802 & 406.7 & 170,863 & 141,998 \\
\hline 6.0 & 5.6 & 60.1 & 541.2 & 230,339 & 194,922 & 430.3 & 183,114 & 154,958 & 541.2 & 230,339 & 194,922 \\
\hline 6.5 & 25.4 & 67.1 & 700.1 & 297,838 & 257,048 & 560.3 & 238,332 & 205,692 & 700.1 & 297,838 & 257,048 \\
\hline 7.0 & 20.0 & 370.3 & 885.5 & 371,887 & 327,848 & 711.9 & 298,974 & 263,569 & 885.5 & 371,887 & 327,848 \\
\hline 7.5 & 409.9 & 69.7 & 1099.3 & 450,572 & 406,382 & $\begin{array}{l}886.7 \\
\end{array}$ & 363,467 & 327,820 & 1099.3 & 450,572 & 406,382 \\
\hline 8.0 & 395.7 & 365.7 & 1342.1 & 531,074 & 490,815 & 1086.6 & 429,954 & \begin{tabular}{|l|}
397,361 \\
\end{tabular} & 1342.1 & 531,074 & 490,815 \\
\hline 8.5 & 78.1 & 358.6 & 1601.6 & 605,516 & 574,334 & 1313.0 & 496,401 & 470,838 & 1601.6 & 605,516 & 574,334 \\
\hline 9.0 & 57.7 & 348.7 & 1859.2 & 664,961 & 648,327 & 1562.2 & 558,716 & 544,740 & 1860.6 & 665,441 & 648,796 \\
\hline 9.5 & 35.1 & 36.4 & 2045.0 & 685,362 & 687,957 & 1820.5 & 610,116 & 612,426 & 2045.0 & 685,362 & 687,957 \\
\hline 10.0 & 11.2 & 322.1 & 2077.3 & 646,396 & 669,061 & 2077.3 & 646,396 & 669,061 & 2077.3 & 646,396 & 669,061 \\
\hline & 36.3 & & 2250.0 & 644,246 & 688,698 & 2250.0 & 644,246 & 688,698 & 2250.0 & 644,246 & 688,698 \\
\hline 11 & & .8 & 2250.0 & 587,693 & 649,861 & 2250.0 & 587,693 & 649,861 & 2250.0 & 587,693 & 649,861 \\
\hline 11 & 6.3 & 0.7 & 2500.0 & 590,626 & 676,642 & 2491.2 & 588,557 & $\begin{array}{l}674,271 \\
\end{array}$ & 2491.2 & 588,557 & 674,271 \\
\hline & & 51.9 & 2556.6 & 541,787 & 644,073 & 2500.0 & 529,785 & \begin{tabular}{|l|}
629,805 \\
\end{tabular} & 2500.0 & 529,785 & 629,805 \\
\hline 12.5 & 8.5 & 32.9 & 2632.0 & 496,230 & 613,101 & 2500.0 & 471,343 & 582,353 & 2500.0 & 471,343 & 582,353 \\
\hline 13.0 & 6.4 & 214.0 & 2632.0 & 437,955 & 563,255 & 2500.0 & 415,990 & 535 , & 2500.0 & 415,990 & 535,006 \\
\hline 13.5 & 45.7 & 195.4 & 2632.0 & 383,475 & 514,189 & 2500.0 & 364,243 & 488,401 & 2500.0 & 364,243 & 488,401 \\
\hline 14.0 & 26.6 & 177.2 & 2632.0 & 333,160 & 466,479 & 2500.0 & 316,451 & 443,084 & 2500.0 & 316,451 & 443,084 \\
\hline 14.5 & 9.1 & 159.8 & 2632.0 & 287,223 & 420,605 & 2500.0 & 272,818 & 399,511 & 2500.0 & 272,818 & 399,511 \\
\hline 15.0 & 3.4 & 143.2 & 2632.0 & 245,738 & 376,954 & 2500.0 & 233,414 & 358,049 & 2500.0 & 233,414 & 358,049 \\
\hline 15.5 & 79.3 & 127.6 & 2632.0 & 208,664 & 335,821 & 2500.0 & 198,199 & 318,979 & 2500.0 & 198,199 & 318,979 \\
\hline 16.0 & 66.8 & 113.0 & 2632.0 & 175,863 & 297,414 & 2500.0 & 167,043 & 282,498 & 2500.0 & 167,043 & 282,498 \\
\hline 16.5 & 55.9 & 99.5 & 2632.0 & 147,124 & 261,867 & 2500.0 & 139,745 & \begin{tabular}{|l|}
248,733 \\
\end{tabular} & 2500.0 & 139,745 & 248,733 \\
\hline 17.0 & 46.4 & 87.1 & 2632.0 & 122,179 & 229,238 & 2500.0 & 116,051 & \begin{tabular}{|l||}
217,741 \\
\end{tabular} & 2500.0 & 116,051 & 217,741 \\
\hline 17.5 & 38.3 & 75.8 & 2632.0 & 100,725 & 199,529 & 2500.0 & 95,674 & $\begin{array}{l}189,522 \\
\end{array}$ & 2500.0 & 95,674 & 189,522 \\
\hline 18.0 & 31.3 & 65.6 & 2632.0 & 82,438 & 172,686 & 2500.0 & 78,304 & $\begin{array}{l}164,026 \\
\end{array}$ & 2500.0 & 78,304 & 164,026 \\
\hline 18.5 & 25.5 & 56.5 & 2632.0 & 66,987 & 148,615 & 2500.0 & 63,627 & 141,162 & 2500.0 & 63,627 & 141,162 \\
\hline 19.0 & 20.5 & 48.3 & 2632.0 & 54,043 & 127,185 & 2500.0 & 51,332 & 120,807 & 2500.0 & 51,332 & 120,807 \\
\hline 19.5 & 16.4 & 41.1 & 2632.0 & 43,290 & 108,243 & 2500.0 & 41,119 & 102,814 & 2500.0 & 41,119 & 102,814 \\
\hline 20.0 & 13.1 & 34.8 & 2632.0 & 34,432 & 91,614 & 2500.0 & 32,705 & 87,020 & 2500.0 & 32,705 & 87,020 \\
\hline 20.5 & 10.3 & 29.3 & 2632.0 & 27,193 & 77,116 & 2500.0 & 25,830 & 73,248 & 2500.0 & 25,830 & 73,248 \\
\hline 21.0 & & 24.5 & 2632.0 & 21,326 & 64,559 & 2500.0 & 20,257 & 61,321 & 2500.0 & 20,257 & 61,321 \\
\hline 21.5 & & 20.4 & 2632.0 & 16,608 & 53,753 & 2500.0 & 15,775 & 51,058 & 2500.0 & 15,775 & 51,058 \\
\hline 22.0 & & & 2632.0 & 12,844 & 44,515 & 2500.0 & 12,200 & 42,283 & 2500.0 & 12,200 & 42,283 \\
\hline 22.5 & & 13.9 & 2632.0 & 9,864 & 36,667 & 2500.0 & 9,369 & 34,8 & 2500.0 & 9,369 & 34,828 \\
\hline 23.0 & & 11.4 & 2632.0 & 7,523 & 30,041 & 2500.0 & 7,146 & 28,535 & 2500.0 & 7,146 & 28,535 \\
\hline 23.5 & & & 2632.0 & 5,698 & 24,482 & 2500.0 & 5,412 & 23,254 & 2500.0 & 5,412 & 23,254 \\
\hline 24.0 & & & 2632.0 & 4,286 & 19,845 & 2500.0 & 4,071 & 18,850 & 2500.0 & 4,071 & 18,850 \\
\hline 24.5 & & & 2632.0 & 3,202 & 16,002 & 2500.0 & 3,042 & 15,199 & 2500.0 & 3,042 & 15,199 \\
\hline 25.0 & 0.9 & 4.9 & 2632.0 & 2,376 & 12,835 & 2500.0 & 2,257 & 12,191 & 2500.0 & 2,257 & 12,191 \\
\hline
\end{tabular}




\begin{tabular}{|c|c|c|c|c|c|c|c|c|c|c|c|}
\hline \multirow{3}{*}{$\begin{array}{c}\text { WS Bin } \\
(\mathrm{m} / \mathrm{s})\end{array}$} & \multirow{2}{*}{\multicolumn{2}{|c|}{ \# of hours per year }} & \multicolumn{3}{|c|}{ Config. \#9 85/40.5/50_85 } & \multicolumn{3}{|c|}{ Config. \#10 85/40.5/55_85 } & \multicolumn{3}{|c|}{ Config. \#11 90/42.75/55_80 } \\
\hline & & & \multirow{2}{*}{$\frac{P_{\text {System }}}{(k W)}$} & \multicolumn{2}{|c|}{ Energy (kWh) } & \multirow{2}{*}{$\frac{P_{\text {System }}}{(\mathrm{kW})}$} & \multicolumn{2}{|c|}{ Energy (kWh) } & \multirow{2}{*}{$\frac{P_{\text {System }}}{(k W)}$} & \multicolumn{2}{|c|}{ Energy (kWh) } \\
\hline & $7.81 \mathrm{~m} / \mathrm{s}$ & $8.98 \mathrm{~m} / \mathrm{s}$ & & $7.81 \mathrm{~m} / \mathrm{s}$ & $8.98 \mathrm{~m} / \mathrm{s}$ & & $7.81 \mathrm{~m} / \mathrm{s}$ & $8.98 \mathrm{~m} / \mathrm{s}$ & & $7.81 \mathrm{~m} / \mathrm{s}$ & $8.98 \mathrm{~m} / \mathrm{s}$ \\
\hline 3.0 & 301.2 & 234.2 & $\begin{array}{l}0.0 \\
\end{array}$ & 0 & 0 & 0.0 & 0 & 0 & 0.0 & 0 & 0 \\
\hline 3.5 & 37.0 & 64.7 & 9.5 & 3,199 & 2,512 & 21.6 & 7,281 & 5,718 & 35.2 & 11,861 & 9,314 \\
\hline 4.0 & 7.0 & & 64.0 & 23,492 & 18,667 & 89.0 & 32,677 & 25,966 & 103.2 & 37,885 & 30,104 \\
\hline 4.5 & 0.9 & 14.8 & 134.4 & 52,525 & 42,299 & 176.4 & 68,950 & 55,526 & 191.1 & 74,714 & 60,168 \\
\hline 5.0 & 8.6 & 334.0 & 221.9 & 90,657 & 74,107 & 285.6 & 116,685 & 95,383 & 293.1 & 119,747 & 97,886 \\
\hline 5.5 & 0.1 & 49.1 & 320.2 & 134,529 & 111,802 & 406.7 & 170,863 & 141,998 & 405.8 & 170,477 & 141,677 \\
\hline 6.0 & 5.6 & 360.1 & 430.3 & 183,114 & 154,958 & 541.2 & 230,339 & 194,922 & 540.1 & 229,831 & 194,492 \\
\hline 6.5 & 5.4 & 37.1 & 560.3 & 238,332 & 205,692 & 700.1 & 297,838 & 257,048 & 698.6 & 297,193 & 256,492 \\
\hline 7.0 & 0.0 & 70.3 & 711.9 & 298,974 & 263,569 & 885.5 & 371,887 & 327,848 & 883.6 & 371,092 & 327,147 \\
\hline 7.5 & 9.9 & 69.7 & 886.7 & 363,467 & 327,820 & 1099.3 & 450,572 & 406,382 & 1096.9 & 449,617 & 405,521 \\
\hline 8.0 & 5.7 & 65.7 & 1086.6 & 429,954 & 397,361 & 1342.1 & 531,074 & 4490,815 & 1338.6 & 529,676 & 489,523 \\
\hline 8.5 & 8.1 & 358.6 & 1313.0 & 496,401 & 470,838 & 1601.6 & 605,516 & 574,334 & 1592.5 & 602,051 & 571,047 \\
\hline 9.0 & 357.7 & 348.7 & 1562.2 & 558,716 & 544,740 & 1860.6 & 665,441 & 648,796 & 1843.1 & 659,203 & 642,714 \\
\hline 9.5 & 35.1 & 336.4 & 1820.5 & 610,116 & 612,426 & 2045.0 & 685,362 & 687,957 & 2045.0 & 685,362 & 687,957 \\
\hline 10.0 & 1.2 & 322.1 & 2077.3 & 646,396 & 669,061 & 2077.3 & 646,396 & 669,061 & 2063.7 & 642,137 & 664,653 \\
\hline 10.5 & 36.3 & 306.1 & 2250.0 & 644,246 & 688,698 & 2250.0 & 644,246 & 688,698 & 2250.0 & 644,246 & 688,698 \\
\hline 11.0 & 51.2 & 288.8 & 2250.0 & 587,693 & 649,861 & 2250.0 & 587,693 & 649,861 & 2250.0 & 587,693 & 649,861 \\
\hline 11.5 & 36.3 & 270.7 & 2491.2 & 588,557 & 674,271 & 2491.2 & 588,557 & 674,271 & 2500.0 & 590,626 & 676,642 \\
\hline 12.0 & & & 2500.0 & 529,785 & 629,805 & 2500.0 & 529,785 & 629,805 & 2562.4 & 543,009 & 645,525 \\
\hline 12.5 & & & 2617.5 & 493,499 & 609,727 & 2617.5 & 493,499 & 609,727 & 2632.0 & 496,230 & 613,101 \\
\hline 13.0 & & .0 & 2778.0 & 462,248 & 594,499 & 2778.0 & 462,248 & 594,499 & 2632.0 & 437,955 & 563,255 \\
\hline 13.5 & 5.7 & 95.4 & 2778.0 & 404,746 & 542,711 & 2778.0 & 404,746 & 542,711 & 2632.0 & 383,475 & 514,189 \\
\hline 14 & & & 2778.0 & 351,641 & 492,355 & 2778.0 & 351,641 & 492,355 & 2632.0 & 333,160 & 466,479 \\
\hline 14.5 & 9.1 & & 2778.0 & 303,155 & 443,937 & 2778.0 & 303,155 & 443,937 & 2632.0 & 287,223 & 420,605 \\
\hline 15.0 & .4 & 43.2 & 2778.0 & 259,369 & 397,864 & 2778.0 & 259,369 & 397,864 & 2632.0 & 245,738 & 376,954 \\
\hline 15.5 & .3 & 127.6 & 2778.0 & 220,239 & 354,449 & 2778.0 & 220,239 & 354,449 & 2632.0 & 208,664 & 335,821 \\
\hline 16.0 & .8 & 13.0 & 2778.0 & 185,619 & 313,912 & 2778.0 & 185,619 & 313,912 & 2632.0 & 175,863 & 297,414 \\
\hline 16.5 & .9 & .5 & 2778.0 & 155,285 & 276,393 & 2778.0 & 155,285 & 276,393 & 2632.0 & 147,124 & 261,867 \\
\hline 17.0 & 3 & 7.1 & 2778.0 & 128,956 & 241,954 & 2778.0 & 128,956 & 241,954 & 2632.0 & 122,179 & 229,238 \\
\hline 17.5 & 3.3 & 5.8 & 2778.0 & 106,312 & 210,597 & 2778.0 & 106,312 & 210,597 & 2632.0 & 100,725 & 199,529 \\
\hline 18.0 & 31.3 & 65.6 & 2778.0 & 87,011 & 182,265 & 2778.0 & 87,011 & 182,265 & 2632.0 & 82,438 & 172,686 \\
\hline 18.5 & & 56.5 & 2778.0 & 70,703 & 156,859 & 2778.0 & 70,703 & 156,859 & 2632.0 & 66,987 & 148,615 \\
\hline 19.0 & 20.5 & 48.3 & 2778.0 & 57,041 & 134,241 & 2778.0 & 57,041 & 134,241 & 2632.0 & 54,043 & 127,185 \\
\hline 19.5 & 16.4 & 41.1 & 2778.0 & 45,691 & 114,247 & 2778.0 & 45,691 & 114,247 & 2632.0 & 43,290 & 108,243 \\
\hline 20.0 & 13.1 & 34.8 & 2778.0 & 36,342 & 96,696 & 2778.0 & 36,342 & 96,696 & 2632.0 & 34,432 & 91,614 \\
\hline 20.5 & 10.3 & 29.3 & 2778.0 & 28,702 & 81,394 & 2778.0 & 28,702 & 81,394 & 2632.0 & 27,193 & 77,116 \\
\hline 21.0 & 8.1 & 24.5 & 2778.0 & 22,509 & 68,140 & 2778.0 & 22,509 & 68,140 & 2632.0 & 21,326 & 64,559 \\
\hline 21.5 & 6.3 & 20.4 & 2778.0 & 17,529 & 56,735 & 2778.0 & 17,529 & 56,735 & 2632.0 & 16,608 & 53,753 \\
\hline 22.0 & 4.9 & 16.9 & 2778.0 & 13,556 & 46,985 & 2778.0 & 13,556 & 46,985 & 2632.0 & 12,844 & 44,515 \\
\hline 22.5 & & 13.9 & 2778.0 & 10,411 & 38,701 & 2778.0 & 10,411 & 38,701 & 2632.0 & 9,864 & 36,667 \\
\hline 23.0 & & 11.4 & 2778.0 & 7,940 & 31,708 & 2778.0 & 7,940 & 31,708 & 2632.0 & 7,523 & 30,041 \\
\hline 23.5 & & & 2778.0 & 6,014 & 25,840 & 2778.0 & 6,014 & 25,840 & 2632.0 & 5,698 & 24,482 \\
\hline 24.0 & & 7.5 & 2778.0 & 4,524 & 20,946 & 2778.0 & 4,524 & 20,946 & 2632.0 & 4,286 & 19,845 \\
\hline 24.5 & 1.2 & & 2778.0 & 3,380 & 16,890 & 2778.0 & 3,380 & 16,890 & 2632.0 & 3,202 & 16,002 \\
\hline 25.0 & 0.9 & 4.9 & 2778.0 & 2,508 & 13,547 & 2778.0 & 2,508 & 13,547 & 2632.0 & 2,376 & 12,835 \\
\hline
\end{tabular}




\begin{tabular}{|c|c|c|c|c|c|c|c|c|}
\hline \multirow{3}{*}{$\begin{array}{c}\text { WS Bin } \\
(\mathrm{m} / \mathrm{s})\end{array}$} & \multirow{2}{*}{\multicolumn{2}{|c|}{ \# of hours per year }} & \multicolumn{3}{|c|}{ Config. \#12 90/42.75/55 75} & \multicolumn{3}{|c|}{ Config. \#13 90/42.75/55 70} \\
\hline & & & \multirow{2}{*}{$\frac{P_{\text {System }}}{(\mathrm{kW})}$} & \multicolumn{2}{|c|}{ Energy (kWh) } & \multirow{2}{*}{$\frac{P_{\text {System }}}{(\mathrm{kW})}$} & \multicolumn{2}{|c|}{ Energy (kWh) } \\
\hline & $7.81 \mathrm{~m} / \mathrm{s}$ & $8.98 \mathrm{~m} / \mathrm{s}$ & & $7.81 \mathrm{~m} / \mathrm{s}$ & $8.98 \mathrm{~m} / \mathrm{s}$ & & $7.81 \mathrm{~m} / \mathrm{s}$ & $8.98 \mathrm{~m} / \mathrm{s}$ \\
\hline 3.0 & 301.2 & 234.2 & 0.0 & 0 & 0 & 0.0 & 0 & 0 \\
\hline 3.5 & 337.0 & 264.7 & 37.9 & 12,784 & 10,039 & 40.7 & 13,707 & 10,764 \\
\hline 4.0 & 367.0 & 291.7 & 106.0 & 38,922 & 30,928 & 108.9 & 39,976 & 31,766 \\
\hline 4.5 & 390.9 & 314.8 & 192.5 & 75,263 & 60,611 & 193.0 & 75,439 & 60,753 \\
\hline 5.0 & 408.6 & 334.0 & 291.5 & 119,101 & 97,358 & 289.1 & 118,114 & 96,551 \\
\hline 5.5 & 420.1 & 349.1 & 402.6 & 169,127 & 140,555 & 399.4 & 167,777 & 139,433 \\
\hline 6.0 & 425.6 & 360.1 & 535.9 & 228,055 & 192,989 & 531.7 & 226,279 & 191,486 \\
\hline 6.5 & 425.4 & 367.1 & 693.3 & 294,936 & 254,544 & 688.0 & 292,678 & 252,596 \\
\hline 7.0 & 420.0 & 370.3 & 877.0 & 368,309 & 324,693 & 870.3 & 365,525 & 322,239 \\
\hline 7.5 & 409.9 & 369.7 & 1088.8 & 446,276 & 402,508 & 1080.6 & 442,935 & 399,494 \\
\hline 8.0 & 395.7 & 365.7 & 1330.8 & 526,600 & 486,680 & 1316.7 & 521,008 & 481,512 \\
\hline 8.5 & 378.1 & 358.6 & 1575.5 & 595,642 & 564,969 & 1557.4 & 588,783 & 558,462 \\
\hline 9.0 & 357.7 & 348.7 & 1821.7 & 651,526 & 635,229 & 1796.2 & 642,409 & 626,340 \\
\hline 9.5 & 335.1 & 336.4 & 2045.0 & 685,362 & 687,957 & 2034.4 & 681,795 & 684,377 \\
\hline 10.0 & 311.2 & 322.1 & 2045.4 & 636,459 & 658,776 & 2045.0 & 636,330 & 658,643 \\
\hline 10.5 & 286.3 & 306.1 & 2250.0 & 644,246 & 688,698 & 2250.0 & 644,246 & 688,698 \\
\hline 11.0 & 261.2 & 288.8 & 2250.0 & 587,693 & 649,861 & 2250.0 & 587,693 & 649,861 \\
\hline 11.5 & 236.3 & 270.7 & 2496.9 & 589,885 & 675,793 & 2491.0 & 588,498 & 674,204 \\
\hline 12.0 & 211.9 & 251.9 & 2579.7 & 546,672 & 649,880 & 2553.8 & 541,177 & 643,347 \\
\hline 12.5 & 188.5 & 232.9 & 2632.0 & 496,230 & 613,101 & 2632.0 & 496,230 & 613,101 \\
\hline 13.0 & 166.4 & 214.0 & 2632.0 & 437,955 & 563,255 & 2632.0 & 437,955 & 563,255 \\
\hline 13.5 & 145.7 & 195.4 & 2632.0 & 383,475 & 514,189 & 2632.0 & 383,475 & 514,189 \\
\hline 14.0 & 126.6 & 177.2 & 2632.0 & 333,160 & 466,479 & 2632.0 & 333,160 & 466,479 \\
\hline 14.5 & 109.1 & 159.8 & 2632.0 & 287,223 & 420,605 & 2632.0 & 287,223 & 420,605 \\
\hline 15.0 & 93.4 & 143.2 & 2632.0 & 245,738 & 376,954 & 2632.0 & 245,738 & 376,954 \\
\hline 15.5 & 79.3 & 127.6 & 2632.0 & 208,664 & 335,821 & 2632.0 & 208,664 & 335,821 \\
\hline 16.0 & 66.8 & 113.0 & 2632.0 & 175,863 & 297,414 & 2632.0 & 175,863 & 297,414 \\
\hline 16.5 & 55.9 & 99.5 & 2632.0 & 147,124 & 261,867 & 2632.0 & 147,124 & 261,867 \\
\hline 17.0 & 46.4 & 87.1 & 2632.0 & 122,179 & 229,238 & 2632.0 & 122,179 & 229,238 \\
\hline 17.5 & 38.3 & 75.8 & 2632.0 & 100,725 & 199,529 & 2632.0 & 100,725 & 199,529 \\
\hline 18.0 & 31.3 & 65.6 & 2632.0 & 82,438 & 172,686 & 2632.0 & 82,438 & 172,686 \\
\hline 18.5 & 25.5 & 56.5 & 2632.0 & 66,987 & 148,615 & 2632.0 & 66,987 & 148,615 \\
\hline 19.0 & 20.5 & 48.3 & 2632.0 & 54,043 & 127,185 & 2632.0 & 54,043 & 127,185 \\
\hline 19.5 & 16.4 & 41.1 & 2632.0 & 43,290 & 108,243 & 2632.0 & 43,290 & 108,243 \\
\hline 20.0 & 13.1 & 34.8 & 2632.0 & 34,432 & 91,614 & 2632.0 & 34,432 & 91,614 \\
\hline 20.5 & 10.3 & 29.3 & 2632.0 & 27,193 & 77,116 & 2632.0 & 27,193 & 77,116 \\
\hline 21.0 & 8.1 & 24.5 & 2632.0 & 21,326 & 64,559 & 2632.0 & 21,326 & 64,559 \\
\hline 21.5 & 6.3 & 20.4 & 2632.0 & 16,608 & 53,753 & 2632.0 & 16,608 & 53,753 \\
\hline 22.0 & 4.9 & 16.9 & 2632.0 & 12,844 & 44,515 & 2632.0 & 12,844 & 44,515 \\
\hline 22.5 & 3.7 & 13.9 & 2632.0 & 9,864 & 36,667 & 2632.0 & 9,864 & 36,667 \\
\hline 23.0 & 2.9 & 11.4 & 2632.0 & 7,523 & 30,041 & 2632.0 & 7,523 & 30,041 \\
\hline 23.5 & 2.2 & 9.3 & 2632.0 & 5,698 & 24,482 & 2632.0 & 5,698 & 24,482 \\
\hline 24.0 & 1.6 & 7.5 & 2632.0 & 4,286 & 19,845 & 2632.0 & 4,286 & 19,845 \\
\hline 24.5 & 1.2 & 6.1 & 2632.0 & 3,202 & 16,002 & 2632.0 & 3,202 & 16,002 \\
\hline 25.0 & 0.9 & 4.9 & 2632.0 & 2,376 & 12,835 & 2632.0 & 2,376 & 12,835 \\
\hline
\end{tabular}




\section{Appendix B: COE Calculations}




\section{COE Calculation for RBR Configuration 12}

\section{COE PROJECTION SHEET}

Baseline Turbine: $2.5 \mathrm{MW}$ - 3 Bladed Upwind/Pitch Controlled Improved Turbine: $2.5 \mathrm{MW}$ - 3 Bladed Upwind/Pitch Controlled - with Retractable Blade Rotor (RBR) Global Energy Concepts, LLC NREL contract \# YAM-4-33200-08

\begin{tabular}{|c|c|c|c|c|}
\hline Rating (kW) & 2500 & 2500 & & \\
\hline Component & $\begin{array}{c}\text { Baseline } \\
\text { Component } \\
\text { Costs } \$ 1000 \\
\end{array}$ & \begin{tabular}{|c|} 
Projected \\
Component \\
Costs $\$ 1000$
\end{tabular} & \begin{tabular}{|c|} 
Component \\
Percent \\
Improvement \\
\end{tabular} & $\begin{array}{c}\text { Major } \\
\text { Cost Element } \\
\% \text { Improvement }\end{array}$ \\
\hline Rotor & 481 & 883 & $-83.6 \%$ & \\
\hline Blades & 341 & 443 & $-29.9 \%$ & \\
\hline Hub & 84 & 84 & $0.0 \%$ & \\
\hline Pitch mchnsm \& bearings & 57 & 57 & $-0.5 \%$ & \\
\hline RBR mchnsm \& bearings & 0 & 300 & \#DIV/0! & \\
\hline Drive train,nacelle & 954 & 960 & $-0.6 \%$ & \\
\hline Low speed shaft & 48 & 48 & $0.0 \%$ & \\
\hline Bearings & 30 & 30 & $0.0 \%$ & \\
\hline Gearbox & 301 & 304 & $-0.9 \%$ & \\
\hline Mech brake, HS cpling etc & 5 & 5 & $0.0 \%$ & \\
\hline Generator & 130 & 130 & $0.0 \%$ & \\
\hline Variable spd electronics & 135 & 135 & $0.0 \%$ & \\
\hline Yaw drive \& bearing & 21 & 21 & $2.7 \%$ & \\
\hline Main frame & 117 & 122 & $-3.5 \%$ & \\
\hline Electrical connections & 100 & 100 & $0.0 \%$ & \\
\hline Hydraulic system & 11 & 11 & $0.0 \%$ & \\
\hline Nacelle cover & 56 & 55 & $0.7 \%$ & \\
\hline Control, safety system & 10 & 10 & $0.0 \%$ & \\
\hline Tower & 242 & 259 & $-6.9 \%$ & \\
\hline TURBINE CAPITAL COST (TCC) & 1,688 & 2,112 & $-25.2 \%$ & $-20.1 \%$ \\
\hline Foundations & 78 & 80 & $-2.3 \%$ & \\
\hline Transportation & 149 & 149 & $0.0 \%$ & \\
\hline Roads, civil works & 117 & 117 & $0.0 \%$ & \\
\hline Assembly \& installation & 90 & 90 & $0.0 \%$ & \\
\hline Elect interfc/connect & 191 & 191 & $0.0 \%$ & \\
\hline Permits, engineering & 57 & 57 & $0.0 \%$ & \\
\hline BALANCE OF STATION COST (BOS) & 682 & 684 & $-0.3 \%$ & $-0.3 \%$ \\
\hline Project Uncertainty & 270 & 270 & $0.0 \%$ & \\
\hline & & & & \\
\hline Initial capital cost (ICC) & 2,640 & 3,066 & $-16.2 \%$ & \\
\hline $\begin{array}{l}\text { Installed Cost per kW for } 2.5 \text { MW turbine } \\
\text { (cost in \$) }\end{array}$ & 1,056 & 1,227 & $-16.2 \%$ & \\
\hline $\begin{array}{l}\text { Turbine Capital per kW sans BOS } \\
\text { (cost in \$) }\end{array}$ & 675 & 845 & $-25.2 \%$ & \\
\hline LEVELIZED REPLACEMENT COSTS (LRC) & 25 & 25 & $0.0 \%$ & $0.0 \%$ \\
\hline O\&M \$25/kW/Yr (O\&M) & 63 & 69 & $-10.0 \%$ & $-9.1 \%$ \\
\hline Net $5.8 \mathrm{~m} / \mathrm{s}$ at $10 \mathrm{~m}$ ANNUAL ENERGY PRODUCTION MWh (AEP) & 7,838 & 9,476 & $20.9 \%$ & $20.9 \%$ \\
\hline Net $8.4 \mathrm{~m} / \mathrm{s}$ at $50 \mathrm{~m}$ ANNUAL ENERGY PRODUCTION MWh (AEP) & 9,620 & 11,247 & $16.9 \%$ & $16.9 \%$ \\
\hline Fixed Charge Rate & $11.85 \%$ & & & \\
\hline COE at $5.8 \mathrm{~m} / \mathrm{s} \$ / \mathrm{kWh}$ & 0.0511 & 0.0482 & $5.5 \%$ & \\
\hline $\mathrm{COE}$ at $8.4 \mathrm{~m} / \mathrm{s} \$ / \mathrm{kWh}$ & 0.0416 & 0.0406 & $2.3 \%$ & \\
\hline
\end{tabular}


COE Calculation for IBP Plus Full Active Aero

COE PROJECTION SHEET

\begin{tabular}{|c|c|c|c|c|}
\hline \multicolumn{5}{|c|}{$\begin{array}{l}\text { Baseline Turbine: } 2.5 \mathrm{MW}-3 \text { Bladed Upwind/Pitch Controlled } \\
\text { Improved Turbine: } 2.5 \mathrm{MW} \text { - } 3 \text { Bladed Upwind/Pitch Controlled - Active Aerodynamic Devices } \\
\text { Global Energy Concepts, LLC NREL contract \# YAM-4-33200-08 }\end{array}$} \\
\hline \multirow[t]{2}{*}{ Rating (kW) } & 2500 & 2500 & & \\
\hline & \begin{tabular}{c||} 
Baseline \\
Component \\
Costs $\$ 1000$
\end{tabular} & \begin{tabular}{||c||} 
Projected \\
Component \\
Costs $\$ 1000$
\end{tabular} & \begin{tabular}{|c|} 
Component \\
Percent \\
Improvement
\end{tabular} & $\begin{array}{c}\text { Major } \\
\text { Cost Element } \\
\% \text { Improvement }\end{array}$ \\
\hline Rotor & 481 & 445 & $7.4 \%$ & \\
\hline Blades & 341 & 281 & $17.5 \%$ & \\
\hline Hub & 84 & 73 & $12.6 \%$ & \\
\hline Pitch mchnsm \& bearings & 57 & 51 & $9.4 \%$ & \\
\hline Active Aero Hardware & 0 & 40 & \#DIV/0! & \\
\hline Drive train,nacelle & 954 & 921 & $3.5 \%$ & \\
\hline Low speed shaft & 48 & 42 & $12.0 \%$ & \\
\hline Bearings & 30 & 30 & $0.0 \%$ & \\
\hline Gearbox & 301 & 302 & $-0.3 \%$ & \\
\hline Mech brake, HS cpling etc & 5 & 5 & $0.0 \%$ & \\
\hline Generator & 130 & 130 & $0.0 \%$ & \\
\hline Variable spd electronics & 135 & 135 & $0.0 \%$ & \\
\hline Yaw drive \& bearing & 21 & 19 & $11.1 \%$ & \\
\hline Main frame & 117 & 97 & $17.5 \%$ & \\
\hline Electrical connections & 100 & 100 & $0.0 \%$ & \\
\hline Hydraulic system & 11 & 11 & $0.0 \%$ & \\
\hline Nacelle cover & 56 & 50 & $10.4 \%$ & \\
\hline Control, safety system & 10 & 10 & $0.0 \%$ & \\
\hline Tower & 242 & 212 & $12.4 \%$ & \\
\hline TURBINE CAPITAL COST (TCC) & 1,688 & 1,588 & $5.9 \%$ & $6.3 \%$ \\
\hline Foundations & 78 & 78 & $0.0 \%$ & \\
\hline Transportation & 149 & 149 & $0.0 \%$ & \\
\hline Roads, civil works & 117 & 117 & $0.0 \%$ & \\
\hline Assembly \& installation & 90 & 90 & $0.0 \%$ & \\
\hline Elect interfc/connect & 191 & 191 & $0.0 \%$ & \\
\hline Permits, engineering & 57 & 57 & $0.0 \%$ & \\
\hline BALANCE OF STATION COST (BOS) & 682 & 682 & $0.0 \%$ & $0.0 \%$ \\
\hline Project Uncertainty & 270 & 270 & & \\
\hline & & & & \\
\hline Initial capital cost (ICC) & 2,640 & 2,540 & $3.8 \%$ & \\
\hline $\begin{array}{l}\text { Installed Cost per kW for } 2.5 \text { MW turbine } \\
\text { (cost in \$) } \\
\text { Turbine Capital per kW sans BOS } \\
\text { (cost in \$) }\end{array}$ & $\begin{array}{r}1,056 \\
675\end{array}$ & $\begin{array}{r}1,016 \\
635\end{array}$ & $\begin{array}{l}3.8 \% \\
5.9 \%\end{array}$ & \\
\hline $\begin{array}{r}\text { LEVELIZED REPLACEMENT COSTS (LRC) } \\
\text { O\&M } \$ 25 / \mathrm{kW} / \mathrm{Yr}(\mathrm{O} \& \mathrm{M}) \\
\end{array}$ & $\begin{array}{l}25 \\
63 \\
\end{array}$ & $\begin{array}{l}25 \\
66 \\
\end{array}$ & $\begin{array}{r}0.0 \% \\
-5.0 \% \\
\end{array}$ & $\begin{array}{r}0.0 \% \\
-4.8 \% \\
\end{array}$ \\
\hline $\begin{array}{l}\text { Net } 5.8 \mathrm{~m} / \mathrm{s} \text { at } 10 \mathrm{~m} \text { ANNUAL ENERGY PRODUCTION MWh (AEP) } \\
\text { Net } 8.4 \mathrm{~m} / \mathrm{s} \text { at } 50 \mathrm{~m} \text { ANNUAL ENERGY PRODUCTION MWh (AEP) }\end{array}$ & $\begin{array}{l}7,838 \\
9,620\end{array}$ & $\begin{array}{l}7,838 \\
9,620\end{array}$ & $\begin{array}{l}0.0 \% \\
0.0 \%\end{array}$ & $\begin{array}{l}0.0 \% \\
0.0 \%\end{array}$ \\
\hline Fixed Charge Rate & $11.85 \%$ & & & \\
\hline COE at $5.8 \mathrm{~m} / \mathrm{s} \$ / \mathrm{kWh}$ & 0.0511 & 0.0500 & $2.2 \%$ & \\
\hline $\mathrm{COE}$ at $8.4 \mathrm{~m} / \mathrm{s} \$ / \mathrm{kWh}$ & 0.0416 & 0.0407 & $2.2 \%$ & \\
\hline
\end{tabular}


Appendix C: MATLAB Script Example 


\section{The following script is an example to provide insight into the basic strategy used for controller design.}

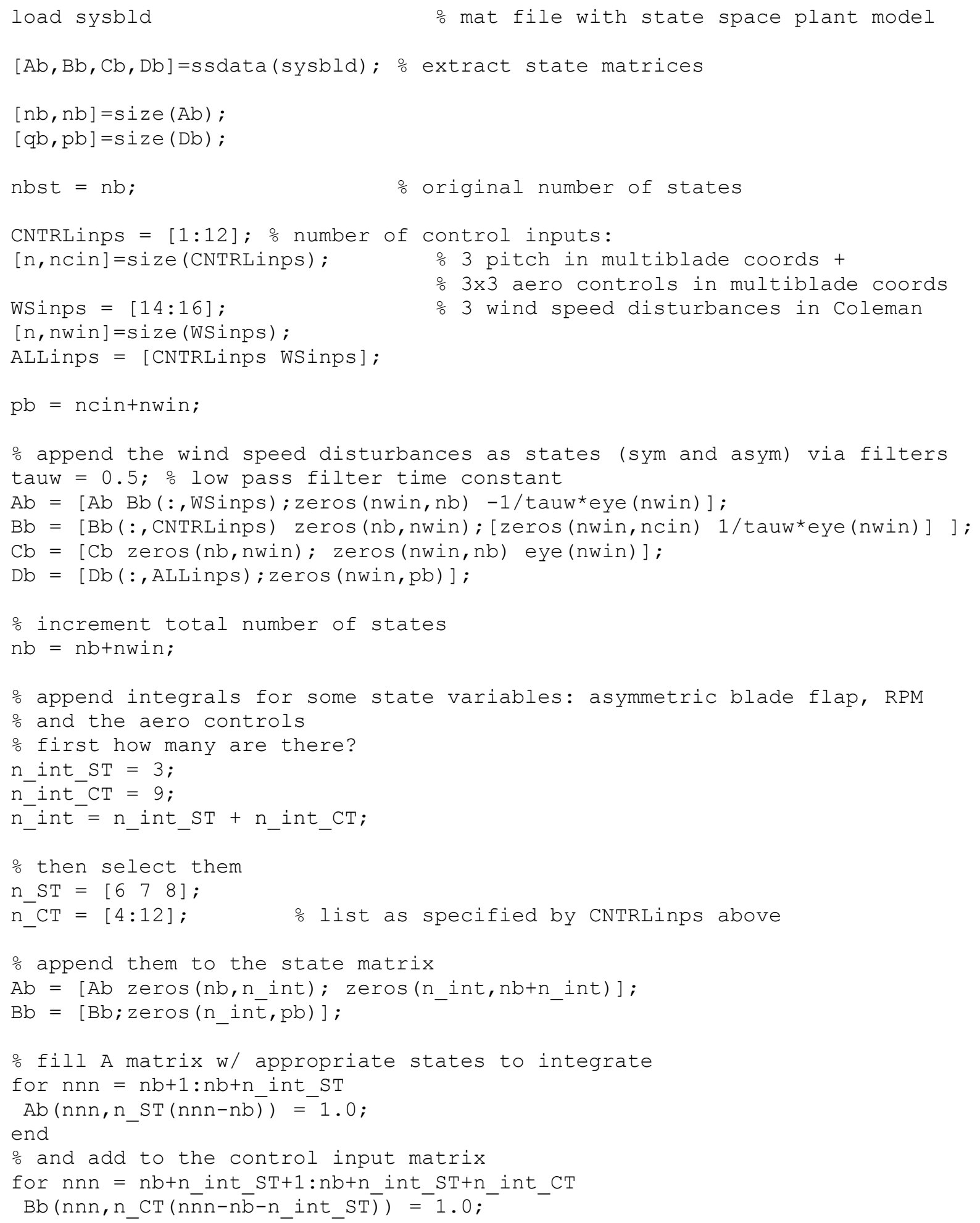


end

o and the output matrix

$\mathrm{Cb}=\left[\mathrm{Cb} \operatorname{zeros}\left(\mathrm{nb}, \mathrm{n} \_\right.\right.$int $) ;\left[\operatorname{zeros}\left(\mathrm{n}_{-}\right.\right.$int, $\left.\mathrm{nb}\right)$ eye $\left(\mathrm{n}_{-}\right.$int $\left.\left.)\right]\right]$;

$\mathrm{Db}=\left[\mathrm{Db} ; \operatorname{zeros}\left(\mathrm{n}_{-} \mathrm{in} \mathrm{t}, \mathrm{pb}\right)\right]$;

\% increment the total number of states

$\mathrm{nb}=\mathrm{nb}+\mathrm{n}$-int;

\% build continuous and discrete state models

sysb $=\mathrm{ss}(\mathrm{Ab}, \mathrm{Bb}, \mathrm{Cb}, \mathrm{Db})$;

sysd $=$ c2d (sysb,.05,' zoh');

CNTRLS $=[1: 1:$ ncin $]$

\% assign weighting factors for the LQR

o based on outputs, not states as this is more obvious

$\mathrm{Q}=\operatorname{zeros}(\mathrm{nb})$;

$Q(1,1)=0 ; \quad$ o pitch sym pos

$\mathrm{Q}(2,2)=0 ; \quad$ \% pitch asym horiz pos

$\mathrm{Q}(3,3)=0 ; \quad \frac{0}{0} \quad$ pitch asym vert pos

$Q(4,4)=1 . ; \quad \%$ twr pos

$Q(5,5)=0.005 ; \%$ blade sym pos

$\mathrm{Q}(6,6)=0.005 ;$ blade asym horiz pos

$\mathrm{Q}(7,7)=0.005 ; \%$ blade asym vert pos

$\mathrm{Q}(8,8)=1.0 ; \quad \% \mathrm{RPM}$

$Q(9,9)=31.6 ; \quad \%$ twr vel

$\mathrm{Q}(10,10)=0.1 ; \quad \frac{\circ}{0}$ blade sym vel

$\mathrm{Q}(11,11)=0.2 ; \quad \circ$ blade asym horiz vel

$\mathrm{Q}(12,12)=0.2 ; \quad \frac{\circ}{0}$ blade asym vert vel

$\mathrm{Q}(13,13)=0.1 ; \quad \frac{\circ}{\mathrm{b}} \mathrm{blade}$ edgewise "rotation"

$Q(14,14)=2.0 ; \quad \frac{\circ}{0}$ blade edgewise "rotation" rate

$Q(15,15)=0 ; \quad \frac{\circ}{0}$ WS sym Uncontrollable

$Q(16,16)=0 ; \quad \therefore$ WS asym Uncontrollable

$\mathrm{Q}(17,17)=0 ; \quad$ \% WS asym Uncontrollable

$Q(18,18)=4.0 ; \quad \%$ blade asym horiz error

$Q(19,19)=4.0 ; \quad \%$ blade asym vert error

$\mathrm{Q}(20,20)=0.6 ; \quad$ 을 $\mathrm{RPM}$ error

$\mathrm{Q}(21: 29,21: 29)=1.0 *$ eye $(9) ; \%$ Aero control errors

$\mathrm{R}=\operatorname{zeros}(\operatorname{ncin}) ;$

$\begin{array}{ll}\mathrm{R}(1,1)=1.0 ; & \text { \% pitch sym } \\ \mathrm{R}(2,2)=20.0 ; & \text { \% pitch asym horiz } \\ \mathrm{R}(3,3)=20.0 ; & \text { \% pitch asym vert }\end{array}$

$\mathrm{R}(4: 12,4: 12)=2.0 *$ eye $(9) ;$ 응 aero all

o calculate gains for continuous and discrete

$[\mathrm{Kb}, \mathrm{S}, \mathrm{E}]=\operatorname{lqry}(\mathrm{sysb}(:, \operatorname{CNTRLS}), \mathrm{Q}, \mathrm{R})$;

$[\mathrm{Kd}, \mathrm{S}, \mathrm{E}]=\operatorname{lqry}(\operatorname{sysd}(:, \operatorname{CNTRLS}), \mathrm{Q}, \mathrm{R})$;

Build closed loop models with direct (not filtered) WS inputs $\mathrm{Acl}=[\mathrm{Ab}(1:$ nbst, $1:$ nbst $)$ zeros (nbst, nwin)

Ab ( 1 :nbst, nbst+nwin+1:nb) ; Ab (nbst+1:nb, : ) ] ;

$\mathrm{Bcl}=[\mathrm{Bb}(1: \mathrm{nbst}, 1: \mathrm{ncin}) \mathrm{Ab}(1: \mathrm{nbst}, \mathrm{nbst}+1: n b s t+n w i n) ; B b(n b s t+1: n b,:)]$;

$\mathrm{CCl}=\mathrm{Cb}$;

$\mathrm{DCl}=\mathrm{Db}$; 


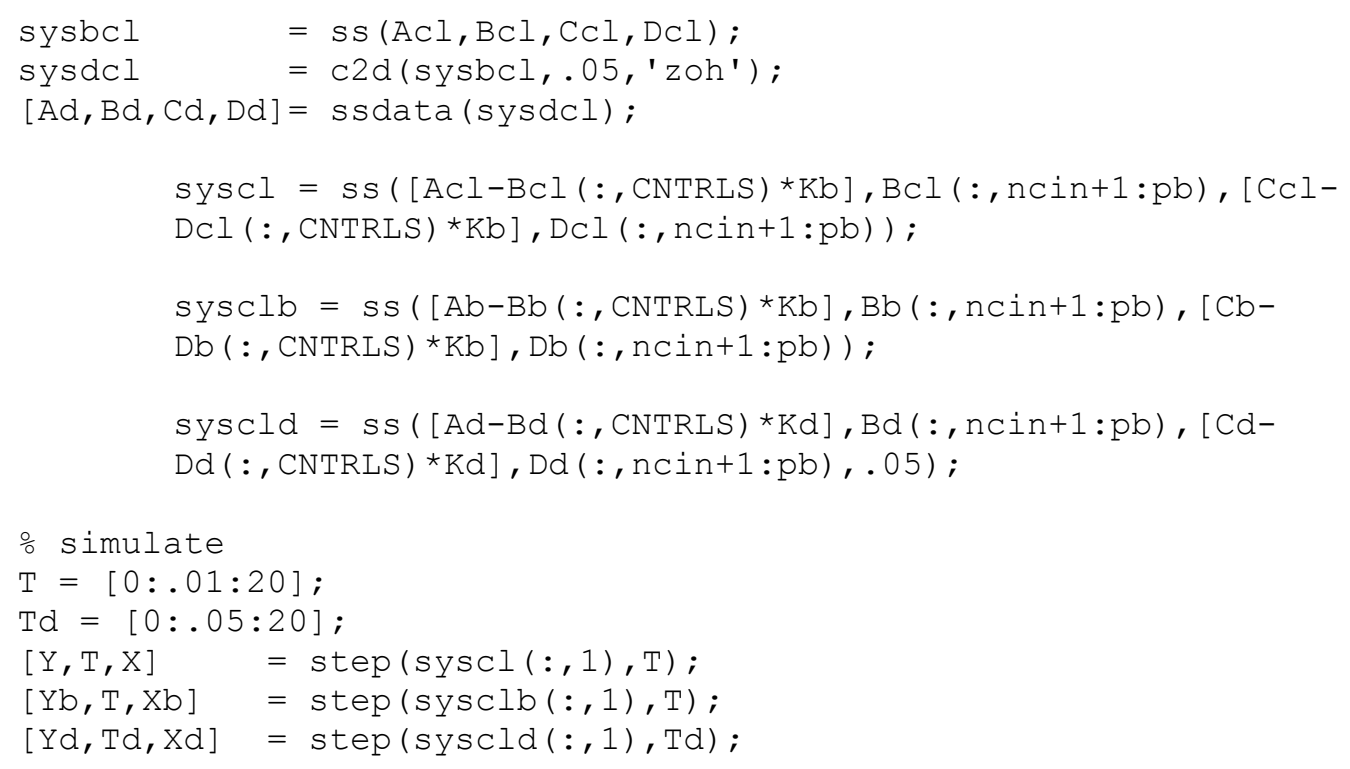


Appendix D: Abbreviations and Coordinates for Load Cases and Loads 


\section{Load Cases}

ECG: Extreme coherent gust

ECD: Extreme coherent gust with direction change

EOG: Extreme operating gust

EWS: Extreme wind shear

EWM: Extreme wind model (1-year and 50-year return)

\section{Loads}

B1RtMx: Blade 1 root bending (Mx is an edgewise load in chordal coordinates)

B1RtMy: Blade 1 root bending (My is a flapwise load in chordal coordinates)

B125Mx: Blade 1 bending at 25\% span ( $\mathrm{Mx}$ is an edgewise load in chordal coordinates)

B125My: Blade 1 bending at 25\% span (My is a flapwise load in chordal coordinates)

B150Mx: Blade 1 bending at 50\% span ( $\mathrm{Mx}$ is an edgewise load in chordal coordinates)

B150My: Blade 1 bending at 50\% span (My is a flapwise load in chordal coordinates)

B175Mx: Blade 1 bending at $75 \%$ span ( $\mathrm{Mx}$ is an edgewise load in chordal coordinates)

B175My: Blade 1 bending at $75 \%$ span (My is a flapwise load in chordal coordinates)

B195Mx: Blade 1 bending at $95 \%$ span (Mx is an edgewise load in chordal coordinates)

B195My: Blade 1 bending at 95\% span (My is a flapwise load in chordal coordinates)

LSShubMx: Low-speed shaft bending at the hub connection ( $\mathrm{Mx}$ is a torque)

LSShubMy: Low-speed shaft bending at the hub connection (My is a lateral moment)

LSShubMz: Low-speed shaft bending at the hub connection (Mz is a lateral moment)

YawbrgMy: Overturning moment at the yaw bearing (My is the fore-aft moment)

YawbrgMz: Yaw moment at the yaw bearing (Mz is a vertical moment)

TwrBaseMx: Bending at the tower base (Mx is a the side-side bending)

TwrBaseMy: Bending at the tower base (My is a the fore-aft bending) 


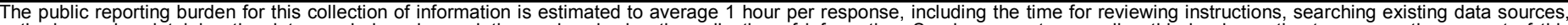

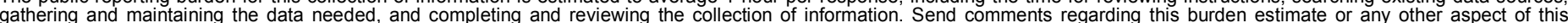

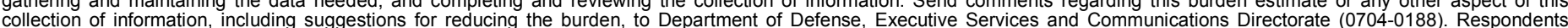

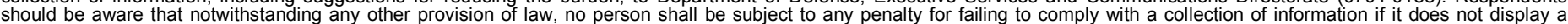

should be aware that notwithstanding

PLEASE DO NOT RETURN YOUR FORM TO THE ABOVE ORGANIZATION.

\begin{tabular}{l|ll} 
1. & REPORT DATE $(D D-M M-Y Y Y Y)$ \\
December 2008 & 2. & REPORT TYPE \\
& Subcontract Report
\end{tabular}

4. TITLE AND SUBTITLE

COE Reductions through Active Aerodynamic Control of Rotor Aerodynamics and Geometry
3. DATES COVERED (From - To)

10 August 2004 - 31 May 2007

5a. CONTRACT NUMBER

DE-AC36-08-GO28308

5b. GRANT NUMBER

5c. PROGRAM ELEMENT NUMBER

5d. PROJECT NUMBER

NREL/SR-500-43391

5e. TASK NUMBER

WER7.0101

5f. WORK UNIT NUMBER
7. PERFORMING ORGANIZATION NAME(S) AND ADDRESS(ES)

Global Energy Concepts

1809 7th Avenue, Suite 900, Seattle, Washington 98101

Phone: (206) 387-4200 Fax: (206) 387-4201

www.globalenergyconcepts.com

9. SPONSORING/MONITORING AGENCY NAME(S) AND ADDRESS(ES)

National Renewable Energy Laboratory

1617 Cole Blvd.

Golden, CO 80401-3393
8. PERFORMING ORGANIZATION REPORT NUMBER

YAM-4-33200-08

10. SPONSOR/MONITOR'S ACRONYM(S) NREL

11. SPONSORING/MONITORING AGENCY REPORT NUMBER NREL/SR-500-43391

\section{DISTRIBUTION AVAILABILITY STATEMENT}

National Technical Information Service

U.S. Department of Commerce

5285 Port Royal Road

Springfield, VA 22161

13. SUPPLEMENTARY NOTES

NREL Technical Monitor: Scott Schrek

14. ABSTRACT (Maximum 200 Words)

This study investigates potential cost of energy reductions that might be achieved by designing active systems to mitigate loads throughout the wind turbine system.

\section{SUBJECT TERMS}

wind turbine rotor design; wind energy system design; wind energy cost reductions; wnd turbine aerodynamics; WindPACT

16. SECURITY CLASSIFICATION OF:
\begin{tabular}{|l|l|l|}
\hline $\begin{array}{c}\text { a. REPORT } \\
\text { Unclassified }\end{array}$ & $\begin{array}{c}\text { b. ABSTRACT } \\
\text { Unclassified }\end{array}$ & $\begin{array}{l}\text { c. THIS PAGE } \\
\text { Unclassified }\end{array}$ \\
\hline
\end{tabular}

\begin{tabular}{l|l|} 
17. & LIMITATION \\
OF ABSTRACT & $\begin{array}{l}\text { 18. } \\
\text { NUMBER } \\
\text { OF PAGES }\end{array}$ \\
UL & \\
\end{tabular}

19a. NAME OF RESPONSIBLE PERSON

19b. TELEPHONE NUMBER (Include area code) 